\title{
Pattern of food intake, diet composition and human energy metabolism : an experimental approach
}

Citation for published version (APA):

van Verboeket, W. P. H. G. (1993). Pattern of food intake, diet composition and human energy metabolism : an experimental approach. [Doctoral Thesis, Maastricht University]. Rijksuniversiteit Limburg. https://doi.org/10.26481/dis.19930121wv

Document status and date:

Published: 01/01/1993

DOI:

10.26481/dis.19930121wv

Document Version:

Publisher's PDF, also known as Version of record

\section{Please check the document version of this publication:}

- A submitted manuscript is the version of the article upon submission and before peer-review. There can be important differences between the submitted version and the official published version of record. People interested in the research are advised to contact the author for the final version of the publication, or visit the DOI to the publisher's website.

- The final author version and the galley proof are versions of the publication after peer review.

- The final published version features the final layout of the paper including the volume, issue and page numbers.

Link to publication

\footnotetext{
General rights rights.

- You may freely distribute the URL identifying the publication in the public portal. please follow below link for the End User Agreement:

www.umlib.nl/taverne-license

Take down policy

If you believe that this document breaches copyright please contact us at:

repository@maastrichtuniversity.nl

providing details and we will investigate your claim.
}

Copyright and moral rights for the publications made accessible in the public portal are retained by the authors and/or other copyright owners and it is a condition of accessing publications that users recognise and abide by the legal requirements associated with these

- Users may download and print one copy of any publication from the public portal for the purpose of private study or research.

- You may not further distribute the material or use it for any profit-making activity or commercial gain

If the publication is distributed under the terms of Article $25 \mathrm{fa}$ of the Dutch Copyright Act, indicated by the "Taverne" license above, 


\section{PATTERN OF FOOD INTAKE, DIET COMPOSITION AND HUMAN ENERGY METABOLISM}

An experimental approach 


\title{
PATTERN OF FOOD INTAKE, DIET COMPOSITION AND HUMAN ENERGY METABOLISM
}

\author{
An experimental approach
}

\section{PROEFSCHRIFT}

ter verkrijging van de graad van doctor aan de Rijksuniversiteit Limburg te Maastricht, op gezag van de Rector Magnificus, Prof. mr. M.J. Cohen, volgens het besluit van het College van Dekanen, in het openbaar te verdedigen op donderdag, 21 januari 1993 om 16.00 uur

door

Wilhelmina Paulina Henrica Gerarda
Verboeket-van de Venne

geboren te Roermond 
Promotor:

Prof. dr. F. ten Hoor

Co-promotor:

Beoordelingscommissie:

Dr. K.R. Westerterp
Prof. dr. M.J. Drop (voorzitter)

Prof. dr. J.E. Blundell

Prof. dr. R.W. Stockbrïgger

Prof. dr. ir. A.J.H. van Es

Prof. dr. ir. R.J.J. Hermus

\section{CIP-GEGEVENS KONINKLIJKE BIBLIOTHEEK, DEN HAAG}

Verboeket-van de Venne, Wilhelmina Paulina Henrica Gerarda

Pattem of food intake, diet composition and human cnergy metabolism: an experimental approach / Wilhelmina

Paulina Henrica Gerarda Verboeket-van de Venne. - [S.I.:

s.n.] (Maastricht: Datawyse). - III.

Proefschrift Maastricht. - Met lit. opg. - Met

samenvatting in het Nederlands.

ISBN 90-9005680-7

NUGI 755

Trefw:: voedingsteer.

Vormgeving: $\quad$ Wilhelmine Verboeket-van de Venne

Omslagillustratie: Antoinette van Ool-van de Venne

Omslagrealisatie: Datawyse Maastricht

Druk: Datawyse Maastricht / Krips Repro Meppel

Het verschijnen van dit proefsehnft werd mede mogelijk gemaakt door steun van de Nederlandse Hartstichting en de Stichting Dr. Ir. J.H.J. van de Laar 


\section{Contents}

$\begin{array}{lll}\text { Chapter } 1 & \text { Introduction } & 7\end{array}$

Chapter 2 Influence of the feeding frequency on nutrient utilization in man: Consequences for energy metabolism

Chapter 3 Effect of the pattern of food intake on human energy metabolism

Chapter 4 Frequency of feeding, weight reduction and energy metabolism

Chapter 5 Habitual pattern of food intake in patients with liver disease

Chapter 6 Energy expenditure and substrate metabolism in patients with cirrhosis of the liver: Effects of the pattern of food intake

Chapter 7 Substrate utilization in man: Effects of dietary fat and carbohydrate

Chapter 8 Effects of dietary fat and carbohydrate exchange on human energy metabolism

Chapter 9 General discussion

Summary

Samenvatting

Abbreviations

Nawoord

Curriculum vitae

Publications 



\section{Chapter 1}

\section{Introduction}

The energy balance is determined by energy intake and energy expenditure. When energy intake exceeds energy expenditure, energy balance is positive and excess energy is stored. Reducing energy intake below energy expenditure results in a negative energy balance and loss of body weight. For practical purposes adult subjects are considered to be in energy balance when the average difference between energy intake and energy expenditure is less than $5 \%$ or $600 \mathrm{~kJ} / \mathrm{d}(1)$, making allowance for measurement error. However, a positive energy balance of $600 \mathrm{~kJ} / \mathrm{d}$ for a period of 5 years will lead to an increase of almost $30 \mathrm{~kg}$ fat. There are several factors that influence energy expenditure and hence energy balance. The nutritional factors include the total level of energy intake, the pattern of energy intake and the macronutrient composition of the diet.

\section{Total level of energy intake}

Dauncey (2) studied the short-term effects on energy balance by altering energy intake in adult subjects over one $24 \mathrm{~h}$ interval and measuring simultaneously energy expenditure. Energy intake was medium (usual energy intake), high (165 $\%$ of the usual energy intake) or low (45\% of the usual energy intake) and was divided in three meals daily of identical macronutrient composition. Mean $24 \mathrm{~h}$ energy expenditure on the high energy intake was significantly greater by $10 \%$ than that on the medium energy intake, whereas that on the low energy intake was significantly less by $6 \%$ compared to the medium intake. The effects of overeating on energy expenditure were greatesi at night, in contrast to the effects of under-eating on energy expenditure which were more pronounced during daytime. It is concluded that there are short-term effects on energy expenditure but not on energy balance.

Long-term effects of over-eating were investigated in the classic studies conducted by Neumann (3) and Gulick (4). They reported that body weight was sustained, despite a wide variety in energy intake for periods of several months to more than a year. In the Vermont Study of experimental obesity in humans, there was a marked variation in the ability of normal volunteers to gain weight when eating a large excess of energy (5). In a more recent study on deliberate overfeeding during 3 weeks in adult subjects, Forbes et al. (6) reported that individual variations in the 


\section{Chapter I}

rate of weight gain could not be explained on the basis of sex, initial body weight or fat content, duration of overfeeding, type of food eaten or daily food consumption. Several studies investigating the effect of over-eating on energy metabolism, showed that the increase in energy expenditure was modest and less than $15 \%$ of the original energy expenditure of the subjects (7-8) and could not compensate the increase in energy intake.

Long-term restriction of energy intake (half of the usual energy intake) in normal weight subjects results in a similar decrease of total energy expenditure, consisting of a decrease of each of the components of energy metabolism: basal metabolic rate $(35 \%)$, diet induced thermogenesis, representing the energy costs of processing food $(11 \%)$ and energy expended for physical activity (54\%) (9). Studies on the effect of energy restriction on energy expenditure in obese subjects are not consistent. After a period of 11-16 weeks on a hypocaloric diet, $24 \mathrm{~h}$ energy expenditure ( $24 \mathrm{~h} \mathrm{EE}$ ) was found to be decreased by $16 \%$ (10) or $22 \%$ (11). When $24 \mathrm{~h}$ EE was expressed per $\mathrm{kg}$ fat-free mass, $24 \mathrm{~h}$ EE decreased by $12 \%$ (10) or $20 \%$ (11). The resting metabolic rate (RMR) was significantly decreased when expressed in absolute values, but there was no change in RMR when expressed per $\mathrm{kg}$ fat-free mass (10). However, Van Dale et al, reported a significant decrease in the sleeping metabolic rate (SMR) both expressed in absolute values (11) and expressed per $\mathrm{kg}$ fat-free mass (12).

\section{Pattern of energy intake}

Animals including man are discontinuous caters and continuous metabolizers. Le Magnen and co-workers conducted numerous studies on the regulation of energy balance in rats (13-17). They reported that in the dark period, rats have a $50 \%$ higher energy intake than expenditure, while intake was $40 \%$ less than expenditure in the light period. During daytime energy intake is used almost immediately to cover actual energy requirements. During the night, however, part of the energy intake is oxidized and part of it is stored. Throughout the subsequent day, these stores are oxidized again, especially during the preprandial hours. Concerning the diurnal variation in the respiratory quotient (RQ), reflecting the nature of substrate being oxidized, a high RQ was observed during the night, indicative of fat synthesis (lipogenesis), and a drop in RQ during daytime, suggesting mobilization of body fat stores (lipolysis).

Cohn et al. (18) conducted experiments on tube-fed rats. Rats in one group were allowed to eat ad libitum and rats in a second group were fed an identical quantity of the same food by stomach tube twice a day. At the end of the experiment the animals which received their food by stomach tube had nearly twice as much body fat as did the rats allowed to eat ad libitum. Other studies investigated the influence 
of the pattern of food intake on body fat content and lipogenesis by training rats, which are typically 'nibbling' animals, to consume their food in a short period daily ('meal-eating' or 'gorging' pattem) (19-20). It was observed that during the absorptive period in meal-fed rats part of the ingested energy is utilized $(30 \%)$ and the remaining energy is stored as glycogen ( $22 \%$ of ingested energy) and fat (47 $\%$ of ingested energy). The lipogenic activity of the adipose tissue of meal-fed rats was greater than observed for nibbling rats, but this effect was most pronounced in rats on a low-fat diet. On a high-fat (low-carbohydrate) diet the need for fat synthesis is obviated and lipogenesis is inhibited. Reverting meal-fed rats to ad: libitum feeding resulted in a slow decrease of the lipogenic activity, whereas it increased rapidly when ad libitum fed rats were switched to meal-feeding.

In human subjects, studies on the influence of the pattern of energy intake can be divided into epidemiological studies investigating the relation in nomal living conditions of the subjects over a longer period of time, and experimental studies with a shorter observation interval and controlled food intake. Fábry and coworkers studied the effect of the pattern of energy intake in a large group of subjects ( $>2000$ ) including schoolchildren (21-22), healthy men aged 30-50 years (23) and elderly men aged 60-64 years (24). It was revealed that a pattern of energy intake containing 2-3 meals daily was associated with a tendency towards overweight, compared with a pattern of 5 or more meals daily. Metzner et al. (25) reported that subjects who consumed their daily intake in more frequent meals were less adipose than those who ate less frequently. Other metabolic effects of a gorging pattern of energy intake include enhanced lipogenesis (24,26-27), increased level of blood serum cholesterol (28-35) and impaired glucose tolerance $(24,28-29,33)$. Because overweight, hypercholesterolaemia and impaired glucose tolerance are regarded as risk factors for coronary heart disease, it is suggested that an infrequent pattern of energy intake can be considered as a possible factor in human pathology (36-37). Fábry et al. (38) studying the spontaneous pattern of energy intake in elderly men aged 60-64 years, observed a higher occurrence of ischaemic heart disease, in the subgroup with an infrequent meal pattern $(30.4 \%$ of the subjects) compared to the subgroup taking 5 or more meals per day (19.9\% of the subjects).

Considering the effect of the pattem of energy intake in hypocaloric conditions, loss of body weight was greater when a slimming diet was taken in more meals daily $(31,39)$, or was not affected by meal frequency $(40-42)$. On the other hand, in hypercaloric conditions when subjects were overfed for some time, weight gain was greater with a gorging pattem of energy intake (43-44), or was not different from that on a nibbling pattern of energy intake (45). 
Studies on the influence of the pattern of energy intake on energy metabolism and its components are scarce. There was no significant effect of meal frequency on 24 $\mathrm{h}$ EE in adult male subjects studied for two weeks on each dietary regimen (46), or female subjects who consumed their daily energy intake in 2,3 or 9 meals for six days each (47). Wolfram et al. (48) studying the effect of a slightly hypocaloric diet consumed as 1 or 5 meal(s) daily for two weeks, reported no influence of meal frequency on energy balance either. On a gorging pattern of energy intake overnight energy expenditure $(23.00 \mathrm{~h}-8.00 \mathrm{~h})$ was found to be higher, whereas energy expenditure during the waking hours $(9.00 \mathrm{~h}-23.00 \mathrm{~h})$ was decreased compared to a nibbling pattern (46). The basal metabolic rate (BMR) was not influenced by meal frequency (46). Garrow et al. (49) studying the effect of meal frequency in obese subjects on a reducing diet for 3 weeks, observed a decrease in BMR over time but this was unrelated to the pattern of energy intake. Some studies reported an increased diet induced thermogenesis (DIT) with a gorging pattern of energy intake (50-51), while others found no relationship between meal frequency and DIT (52-53).

Jenkins et al. (54) recently studied the effect of increasing meal frequency in patients with non-insulin-dependent diabetes. They concluded that spreading the nutrient load over a longer period of time may play an important role in the management of diabetes, by allowing adequate insulinization of tissues at relatively low insulin concentrations. In patients with cirrhosis of the liver, glycogen stores in the liver are small and inadequate. Therefore, already during short-term food deprivation like an overnight fast, gluconeogenesis from amino acids will take place, resulting in extra amino acid loss (55). A nibbling pattern of energy intake, including a late evening meal, seemed to improve the efficiency of nitrogen metabolism in patients with liver cirrhosis, probably by reducing the nocturnal amino acid breakdown (56).

\section{Macronutrient composition of the diet}

Weight maintenance requires not only energy balance but also balance between intake and oxidation of the three energy substrates: protein, fat and carbohydrate (57-58). In situations of energy or substrate imbalances, changes occur in the body stores and hence body weight or body composition. A high dietary fat intake is often associated with an increasing prevalence of obesity (59-61). Possible mechanisms for this association are based on a positive energy balance or the failure to adjust substrate oxidation to substrate intake.

Several studies reported an increased energy intake with a high-fat diet and a decreased energy intake with a low-fat diet, resulting in body weight gain on a high-fat diet and loss of body weight on a low-fat diet (61-63). On the other hand, 
Leibel et al. (64) recently showed that even with extreme changes in the fat and carbohydrate content of the food, there was no significant variation in the energy need to maintain body weight.

Considering the influence of diet composition on energy metabolism and its components, results are not consistent. Studies on the effect of isoenergetic exchange of fat and carbohydrate reported no change in $24 \mathrm{~h} \mathrm{EE}$ due to the composition of the diet (65-66), or a decreased $24 \mathrm{~h} \mathrm{EE}$ on a high-fat diet in postobese subjects (67). The sleeping metabolic rate (SMR) was found to be lower on a high-fat diet compared with a mixed diet (65), or was not affected by diet composition (66-67). There was no effect of diet composition on the basal metabolic rate (65-68) or energy expenditure for physical activity (66). The contribution of the diet induced thermogenesis to energy metabolism was reported to be lower on a high-fat diet compared with a low-fat diet $(67,69)$ or not affected (66).

Flatt et al. (70) reported that the presence or absence of fat in a breakfast providing fixed amounts of carbohydrate and protein had no effect on the nature of substrates oxidized during the postprandial hours. It was concluded that the body fails to adjust fat oxidation in response to excess fat intake (56-57). Others demonstrated that carbohydrate and protein stores are closely regulated by adjusting oxidation to intake, and that fat is exclusively used or stored in response to day-to-day fluctuations in energy balance (71).

Finally, the between-subject variation in response to dietary fat has to be considered. Recently, Thomas et al. (72) reported that lean subjects have a greater ability to increase fat oxidation in response to a high-fat diet than obese subjects.

\section{Outline of the thesis}

While reviewing the literature it appears that energy balance and hence body weight can be influenced by a number of nutritional factors. However, more experimentally controlled studies are needed to elucidate the following issues.

In man, energy intake is usually restricted to the waking hours. Since only a part of the ingested energy is utilized immediately, excess energy has to be stored during daytime to meet energy requirements during the night. The pattern of energy intake probably affects the level of energy storage, which could have implications for regulation of the body weight. Chapter 2 describes whether there is a diumal rhythm of lipogenesis and lipolysis in man, as was found in experimental animals, and if so, how this is affected by the pattern of energy intake to explain possible consequences of meal frequency for body weight regulation. 


\section{Chapter I}

Studies on the effect of the pattern of energy intake on human energy metabolism are usually conducted in a laboratory setting. To further elucidate the findings of epidemiological surveys, including an enhanced lipogenesis and a higher occurrence of overweight with a gorging pattern of energy intake, experiments in free living conditions may give additional information. Chapter 3 reports on the influence of the pattern of energy intake on $24 \mathrm{~h}$ energy metabolism (in both free living and experimentally controlled conditions) and on its components basal metabolic rate, diet induced thermogenesis and energy expenditure due to physical activity.

The effects of the pattern of food intake in hypocaloric conditions are described in Chapter 4 . Measured parameters included rate and composition of weight loss, 24 h energy expenditure, sleeping metabolic rate and diet induced thermogenesis.

Chapter 5 describes the results of a study on the habitual pattern of energy intake in subjects with a reduced capacity to store a short-term energy excess, i.e. patients with liver disease. Chapter 6 reports on the effect of the pattem of energy intake on energy metabolism and substrate oxidation in patients with cirrhosis of the liver. Because of their limited ability to store glycogen in the liver, an infrequent pattern of energy intake could evoke an earlier catabolic response than in healthy control subjects.

Chapters 7 and 8 describe the results of a study on the short term (3 day) effects of dietary fat and carbohydrate exchange on substrate oxidation and energy metabolism. A primary purpose was to investigate whether subjects adjust their substrate oxidation in response to a low-fat (high-carbohydrate) and high-fat (lowcarbohydrate) diet. Furthermore, we investigated whether the association between a high-fat diet and obesity could be explained on basis of a change in 24 h energy expenditure. To elucidate the metabolic responses to dietary fat and carbohydrate of subjects being more or less susceptible to become obese, the subject characteristics of a restrained or unrestrained attitude towards eating (73) were taken into account.

\section{References}

1 Garrow JS (1974): Energy balance and obesity in man. Amsterdam: North Holland Publishing Company. 1974

2 Dauncey MJ (1980): Metabolic effects of altering the 24, henergy intake in man using direct and indirect calorimetry. Br I Nutr 43: 257-269

3 Neumann RA (1902): Experimental contributions to the study of daily human nutritional requirements with particular reference to essential protein levels. Arch Hyg 45: 81-87 (in German) 
Gulick A (1922): A study of weight regulation in the adult human body during overnutrition. Am J Physiol 60: 371-395

Sims EAH (1976): Experimental obesity, dietary induced thermogenesis and their clinical implications. Clin Endocrinol Metab 5: 377-395

Forbes GB, Brown MR, Welle SL and Lipinsky LB (1986): Deliberate overfeeding in women and men: Energy cost and composition of the weight gain. Br J Nutr 56: 1-9

Webb P and Annis JF (1983): Adaptation to overeating in lean and overweight men and women. Hum Nutr: Clin Nutr 37C: 117-131

Dallosso HM and James. WPT (1984): Whole body calorimetry studies in adult men. 1. The effect of fat overfeeding on $24 \mathrm{~h}$ energy expenditure. Br J Nutr 52: 49-64

9 Keys A, Brozek J, Henschel A, Mickelsen D and Taylor HI. (1950): Biology of human starvation. Minneapolis: University of Minnesota. Press

10 Ravussin E, Burnand B, Schutz $Y$ and Jéquier E (1985): Energy expenditure before and after energy restriction on obese patients. Am J Clin Nutr 4: 753-759

11 Van Dale D, Schoffelen PFM, Ten Hoor F and Saris WHM (1989): Effects of adding exercise to energy restriction on 24-hour energy expenditure, resting metabolic rate and daily physical activity. Eur I Clin Nutr 43: 441-451

12 Van Dale D, Saris WHM, Schoffelen PFM and Ten Hoor F (1987): Does exercise give an additional effect in weight reduction regimens? Int J Obes 11: 367-375

13 Le Magnen J and. Devos M (1970): Metabolic correlates of the meal onset in the free food intake of rats. Physiol Behav 5: 805-814

14 Le Magnen J, Devos M, Gaudilliere JP, Louis-Sylvestre J and Tallon S (1973): Role of a lipostatic mechanisn in regulation by feeding of energy balance in rats. J Comp Physiol Psychol 84: 1-24

15 Le Magnen J (1976): Interactions of glucostatic and lipostatic mechanism in the regulatory control of feeding. In: Hunger: Basic mechanisms and clinical implications, eds D Novin, Wyrwicka and G Bray, pp. 89-101. New York: Raven Press.

16 Le Magnen J (1981): The metabolic basis of dual periodicity of f́eeding in rats. Behavi Brain Sci 4: 561-567

17 Le Magnen J and Devos M (1982): Daily body energy balance in rats. Physiol Behav 29: $807-811$

18 Cohn C, Joseph D, Bell L and Allweiss MD (1965): Studies on the effects of feeding frequency and dietary composition on fat deposition. Ann NY Acad Sci 131: 507-518

19 Leveille GA (1970): Adipose tissue metabolism: Influence of periodicity of eating and diet composition. Fedl Proc 29: 1294-130 J

20 De Bont AJ, Romsos DR, Tsai AC, Waterman RA and Leveille GA (1975): Influence of alterations in meal frequency on lipogenesis and body fat content in the rat. Proc Soc Exp Biol Med 149: 849-854

21 Fábry P, Hejda S, Cerny K, Osancova K and Pechar J (1966): Effect of meal frequency in schoolchildren. Changes in the weight-height proportion and skinfold thickness. Am J Clin Nutr 18: $358-361$ 
22 Hejda S, Fábry P and Osancová K (1967): Influence of the frequency of food intake on some somatometric indicators in chidren. In: Proc VIIth Intemat Congress of Nutrition 1966, ed NY Elmsford, pp. 259. Hamburg: Pergamon Press

23 Hejda S and Fábry P (1964): Frequency of food intake in relation to some parameters of the nutritional status. Nutritio et Dieta 6: 216

24 Fábry P, Fodor J, Hejl Z, Braun T and Zvolánková K (1964): The frequency of meals: Its relationship to overweight, hypercholesterolaemia, and decreased glucose tolerance. Lancet 2: 614-615

25 Metzner HL, Lamphiear DE, Wheeler NC and Larkin FA (1977): The relationship between frequency of eating and adiposity in adult men and women in the Tecumseh Community Health Study. Am J Clin Nutr 30: 712-715

26 Bortz WM, llowat P and Holmes WL (1969): The effect of feeding frequency in diurnal plasma free fatty acids and glucose levels. Metabolism 18: 120-123

27 Terpstra J, Hessei LW, Seepers J and Van Gent CM (1978): The influence of meal frequency on diumal lipid, glucose and cortisol levels in normal subjects. Eur J Clin Invest 8: 61-66

28 Gwinup G, Byron RC, Roush WH, Kruger FA. and Hamwi GJ (1963): Effect of nibbling versus gorging on serum lipids in man. Am J Clin Nutr 13: 209-213

29 Gwinup G, Byron RC, Roush WH, Kruger FA and Hamwi GJ (1963): Effect of nibbling versus gorging on glucose tolerance. Lancet 2: 165-167

30 Jagannathan SN, Connell WF and Beveridge JMR (1964): Effects of gourmandizing and semicontinuous eating of equicaloric amounts of formula-type high fat diets on plasma cholesterol and triglyceride levels in human volunteer subjects. Am J Clin Nutr 15: 90-94

31 Kudlicka V. Fábry P. Dobersky P and Kudlicková V (1967): Nibbling and meal eating in the treatment of human obesity. In: Proc. VIlth Internat Congress of Nutrition 1966, ed NY EImsford, pp. 264-266. Hamburg: Pergamon Press

32 Irwin MI and Feeley RM (1967): Frequency and size of meals and serum lipids, nitrogen and mineral retention, fat digestibility, and urinary thiamine and riboflavin in young women. Am J Clin Nutr 20:816-824

33 Young CM, Hutter LF, Scanlan SS, Rand CE, Lutwak L and Simko V (1972): Metabolic effects of meal frequency on normal young men. J Am Diet Ass 61: 391-398

34 Jenkins DJA, Wolever TMS, Vuksan V, Brighenti F, Cunnane SC, Rao AV, Jenkins AL, Buckley G. Patten R, Singer W, Corey P and Josse RG (1989): Nibbling versus gorging: Metabolic advantages of increased meal frequency. New Engl J Med 321: 929-934

Edelstein SL, Barrett-Connor EL, Wingard DL and Cohn BA (1992): Increased meal frequency associated with decreased cholesterol concentrations; Rancho Bernardo, CA, 1984-1987. Am J Clin Nutr 55: 664-669

36 Fábry P and Tepperman J (1970): Meal frequency - a possible factor in human pathology. Am J Clin Nutr 23: 1059-1068

37 Adams CE and Morgan JK (1981): Periodicity of eating: Implications for human food consumption. Nutr Res 1: $525-550$

38 Fábry P, Fodor Z, Hejl Z, Geizerová H and Balcarová O (1968): Meal frequency and ischacmic heart disease. Lancet 2: 190 
39 Debry G, Rohr R, Azouaou R, Vassilitch I and Mottaz G (1973): Ponderal losses in obese subjects submitted to restricted diets differing by nibbling and by lipid and carbohydrate. In: Energy balance in man, ed M Apfelbaum, pp. 305-310. Paris: Masson

40 Bortz. WM, Wroldsen A, Issekutz B and Rodahl K (1966): Weight loss and frequency of feeding. New Engl J Med 274: 376-379

41 Finkelstein B and Fryer BA (1971): Meal frequency and weight reduction of young women. Am J Clin Nutr 24: 465-468

42 Young CM, Scanlan SS, Topping CM, Simko V and Lutwak L. (1971): Frequency of feeding, weight reduction, and body composition. J Am Diet Assoc 59: 466-472

43 Mahler R (1972): The relationship between eating and obesity. Acta Diabet Lat 9: 449-465

44 Miller DS and Mumford P (1973): Luxuskonsumption. In Regulation of energy balance in man, ed M. Apfelbaum, pp. 195-207. Paris: Masson

45 Nunes WT and Canham JE (1963): The effect of varied periodicity of eating on serum lipids and carbohydrate tolerance in man (abstr.). Am J Clin Nutr 12: 334

46 Dallosso HM, Murgatroyd PR and James WPT (1982): Feeding frequency and energy balance in adult males. Hum Nutr: Clin Nutr 36C: $25-39$

47 Swindells YE, Holmes SA and Robinson MF (1968): The metabolic response of young women to changes in the frequency of meals. Br J Nutr 22; 667-680

48 Wolfram G, Kirchgeßner M, Müller HL and Hollomey S (1987): Thermogenese des Menschen bei unterschiedlicher Mahlzeitenhaüfigkeít. Ann Nutr Metab 31: 88-97

49 Garrow JS, Durant M, Blaza S, Wilkins D, Royston P and Sunkin S (1981): The effect of meal frequency and protein concentration on the composition of the weight lost by obese subjects. Br J Nutr 45: 5-15

50 Tai MM, Castillo P and Pi-Sunyer FX (1991): Meal size and frequency: Effect on the thermic effect of food. Am J Clin Nutr 54: 783-787

51 Molnár D (1990): The effect of meal frequency on postprandial thermogenesis in obese children (abstr). Int J Obesity 14 (Suppl. 2): 95.

52 Kinabo JLD and Durnin JVGA (1990): Effect of meal frequency on the thermic effect of food in women. Eur J Clin Nutr 44: 389-395

53 Belko AZ and Barbieri TF (1987): Effect of meal size and frequency on the thermic effect of food. Nutr Res 7: 237-242.

54 Jenkins DJA, Ocana A, Jenkins AL, Wolever TMS, Vuksan V, Katzman L, Hollands M, Greenberg $\mathrm{G}_{\text {" }}$ Corey P', Patten R, Wong G and Josse RG (1992): Metabolic advantages of spreading the nutrient load: Effects of increased meal frequency in non-insulin-dependent. diabetes. Am I. Clin Nutr 55: 461-467

55 Swart GR, Van den Berg JWO, Wattimena JLD, Rietveld T, Van Vuure JK and Frenkel M (1988): Elevated protein requirements in cirrhosis of the liver investigated by whole body protein turnover studies. Clin Sci 75: 101-107

56 Swart GR, Zillikens MC, Van Vuure JK and Van den Berg JWO (1989): Effect of a late evening meal on nitrogen balance in patients with cirrhosis of the liver. Br Med J 299: 1202-1203

57 Flatt JP (1987): The difference in the storage capacities for carbohydrate and for fat, and its implications in the regulation of body weight. Ann NY Acad Sci 499: 104-123 
58 Flatt JP (1988): Importance of nutrient balance in body weight regulation. Diabetes Metab Rev 6: $571-581$

59 Dreon DM, Frey-Hewitt B, Ellsworth N, Williams PT, Terry RB and Wood PD (1988): Dietary fat : carbohydrate ratio and obesity in middle-aged men. Am J Clin Nutr 47: 995 1000

60 Romieu I, Wille॥ WC, Stampfer MJ, Colditz GA, Sampson L, Rosner B, Hennekens CH and Speizer FE (1988): Energy intake and other determinants of relative weight. Am J Clin Nutr 47: 406-412

61 Tremblay A, Plourde G, Despres JP and Bouchard C (1989): Impact of dietary fat content and fat oxidation on energy intake in humans. Am J Clin Nutu 49: 799-805

62 Duncan KH, Bacon JA and Weinsier RL (1983): The effects of high and low energy density diets on satiety, energy intake and eating time of obese and nonobese subjects. Am J Clin Nutr 37: 763-767

63 Lissner L, Levitsky DA, Strupp BJ, Kalkwarf HJ and Roe DA (1987): Dietary fat and the regulation of energy intake in human subjects. Am J Clin Nutr 46: 886-892

64 Leibell RI., Hirsch J. Appel BE and Checani GC (1992): Energy intake required to maintain body weight is not affected by wide variation in diet composition. Am J Clin Nutr 55: 350-355

65 Ilumi M, Bumand B, Pittet P and Jéquier E (1982): Metabolic effects of a mixed and a high-carbohydrate low-fat diet in man, measured over $24 \mathrm{~h}$ in a respiration chamber. $\mathrm{Br} J$ Nutr 47: $33-43$

66 Abbott WGH, Howard BV, Ruotolo G and Ravussin E (1990): Energy expenditure in humans: Effects of dietary fat and carbohydrate. An J Physiol 258: E347-E351

67 Lean MEJ and James WPT (1988): Metabolic effects of isoenergetic nutrient exchange over 24 hours in relation to obesity in women. Int J Obes 12: 15-27

68 McNeill G, Bruce AC, Ralph A and James WPT (1988): Inter-individual differences in fasting nutrient oxidation and the infuence of diet composition. Int J Obes 12: 455-463

69 Schwartz. RS, Ravussin E, Massari M, O'Connell M and Robbins DC (1985): The thermic effect of carbohydrate versus fat feeding in man. Metabolism 34: 285-293

70 Flat JP, Ravussin E, Acheson KJ and Jequier E (1985): Effects of dietary fat on postprandial substrate oxidation and on carbohydrate and fat balances. J Clin Invest 76: 1019-1024

71 Abbott WGH, Howard BV, Christin L, Freymond D, Lillioja S, Boyce VL, Anderson TE; Bogardus C and Ravussin E (1988): Short-term energy balance: relationship with protein, carbohydrate, and fat balances. Am J Physiol 255: E332-E337

72 Thomas CD, Peters JC, Reed GW, Abumrad NN, Sun M and Hill JO (1992): Nutrient balance and energy expenditure duning ad libitum feeding of high-fat and high-carbohydrate diets in humans. Am J Clin Nutr 55: 934-942:

73 Westerterp-Plantenga MS. Wouters L and Ten Hoor F (1991): Restrained eating, obesity and cumulative food intake curves during four-course meals. Appetite 16: 149-158 


\title{
Chapter 2
}

\section{Influence of the feeding frequency on nutrient utilization in man: Consequences for energy metabolism}

\author{
W.P.H.G. Verboeket-van de Venne and K.R. Westerterp
}

Department of Human Biology, University of Limburg, P.O. Box 616, 6200 MD Maastricht, The Netherlands

European Journal of Clinical Nutrition 45: 161-169, 1991

\begin{abstract}
A study was conducted to investigate whether there is a diurnal pattern of nutrient utilization in man and how this is affected by meal frequency to explain possible consequences of meal frequency for body weight regulation. When the daily energy intake is consumed in a small number of large meals, there is an increased chance to develop overweight, possibly by an elevated lipogenesis (fat synthesis and accumulation) or storage of energy after the meal. Thirteen subjects, two males and eleven females, were fed to energy balance in two meals per day (gorging pattem) and seven meals per day (nibbling pattern) over 2-day intervals. On the second day on each feeding regimen, the diurnal pattern of nutrient utilization was calculated from simultaneous measurements of oxygen consumption, carbon dioxide production and urinary nitrogen excretion over 3 h intervals in a respiration chamber.

A gorging pattern of energy intake resulted in a stronger diumal periodicity of nutrient utilization, compared to a nibbling pattern. However, there were no consequences for the tota! $24 \mathrm{~h}$ energy expenditure ( $24 \mathrm{~h} \mathrm{EE}$ ) of the two feeding patterns $(5.57 \pm 0.16 \mathrm{~kJ} / \mathrm{min}$ for the gorging pattern; $5.44 \pm 0.18 \mathrm{~kJ} / \mathrm{min}$ for the nibbling pattern).

Conceming the periodicity of nutrient utilization, protein oxidation during the day did not change between the two feeding patterns. In the gorging pattern, carbohydrate oxidation was significantly elevated during the interval following the first meal (i.e. from $12.00 \mathrm{~h}$ to $15.00 \mathrm{~h}, \mathrm{p}<0.01$ ) and the second meal (i.e. from
\end{abstract}


$18.00 \mathrm{~h}$ to $21.00 \mathrm{~h}, \mathrm{p}<0.05$ ). The decreased rate of carbohydrate oxidation observed during the fasting period (from rising in the morning until the first meal at $12.00 \mathrm{~h}$ ), was compensated by an increased fat oxidation from $9.00 \mathrm{~h} \mathrm{to} 12.00 \mathrm{~h}$ to cover energy needs. In the nibbling pattern carbohydrate and fat oxidation remained relatively constant during the active hours of the day.

The increased lipogenic activity on a gorging pattern resulting in an elevated energy expenditure during the postprandial hours, indicated a greater contribution of the diet induced thermogenesis (DIT) to $24 \mathrm{~h} \mathrm{EE}$. Because $24 \mathrm{~h} \mathrm{EE}$ was not affected by the feeding frequency this might mean that the energy expenditure during the rest of the day was decreased, possibly by a decrease of the physical activity on the gorging pattem. There were no significant effects of meal frequency on either $24 \mathrm{~h}$ nutrient utilization or $24 \mathrm{~h} \mathrm{EE}$. A gorging pattern of energy intake resulted in a stronger diurnal periodicity of lipogenesis and lipolysis, compared to a nibbling pattern.

\section{Introduction}

The control of energy balance through energy intake is not only a function of the level of energy intake but also of the time pattern of energy intake, i.e. the feeding frequency. In man, energy intake is usually restricted to the period between getting up in the morning and going to bed at night while energy expenditure continues during the sleeping period. During the active part of the day there is a positive energy balance to anticipate for the overnight deficit. The excess of daily energy intake has to be temporarily stored. This has possibly consequences for the regulation of the body weight.

When the daily energy intake is consumed in a small number of large meals relatively more energy has to be stored compared to a feeding pattern with a large number of small meals. Hejda and Fábry (1) reported a higher energy intake in subjecis consuming their food in a greater number of meals. However, the body weight was highest in the group with the smallest number of meals and the lowest energy intake. In a study in elderly men. Fabry et al. (2) also found that the proportion of overweight subjects was markedly higher with a declining meal frequency. Metzner et al. (3) studying the relationship between frequency of eating. and adiposity in subjects with the same food intake, showed that those who ate more frequently during a 24 hour period were less adipose than those who ate less. frequently.

Besides the effects of meal frequency under isocaloric conditions, it is interesting to examine if similar effects occur in hypo-- or hypercaloric feeding patterns. Debry et al. (4) observed that for the same subjects receiving the same hypocaloric diet, weight reduction was greater when the diet was taken in more meals per day. Others did not report such an effect of meal frequency (5-7) Miller and Mumford (8) reported an increased rate of weight gain in overfeeding when 
the food intake was in two meals per day, compared with 14 small meals per day. A similar effect was described by Mahler (9) who overfed young men with a liquid supplement for 5 weeks: weight gain was significantly greater when the supplement was taken as one large meal in the evening. Nunes and Canham (10) failed to find such an effect.

Two studies investigated the effect of meal frequency on energy expenditure. Swindells et al. (11) reported no differences in resting oxygen consumption between women given a fixed amount of food in nine meals per day and two meals per day. Dallosso et al. (12), studying the effect of feeding frequency in adult males, also did not observe an effect on $24 \mathrm{~h}$ energy expenditure.

The effect of feeding frequency on body weight regulation is probably a function of the proportion of intake which has to be stored before use. In man, it is not yet known which part of the energy intake is stored as glycogen or fat and how this changes with the pattern of intake. Le Magnen (13-14) studied the diumal pattern of energy intake and energy expenditure in rats. During the active phase of a 24 hours" period the energy balance defined by energy intake minus energy expenditure is positive and lipogenesis (fat synthesis and accumulation) takes place. During the inactive phase there is a negative energy balance and lipolysis (fat oxidation) occurs to maintain the basal body functions. The relative hyperphagia observed in the active phase has to be compensated by relative hypophagia, if body weight regulation is to be achieved. Thus, in rats there is a diurnal rhythm of lipogenesis and lipolysis.

The present study was conducted to investigate whether there is a diurnal rhythm of lipogenesis and lipolysis in man and if so, how this is affected by meal frequency to explain possible consequences of meal frequency for body weight regulation. The diurnal pattern of nutrient utilization was calculated from simultaneous measurements of oxygen consumption, carbon dioxide production and urinary nitrogen excretion.

\section{Subjects and methods}

\section{Subjects}

Subjects were thirteen student volunteers whose age, height, weight and body mass index (BMI) are presented in Table 2.1. They were all non-smokers. 
Table 2.J Physical characteristics of the subjects.

\begin{tabular}{cccccc}
\hline Subject & Sex & $\begin{array}{c}\text { Age } \\
\text { (years) }\end{array}$ & $\begin{array}{c}\text { Height } \\
(\mathrm{m})\end{array}$ & $\begin{array}{c}\text { Weight } \\
(\mathrm{kg})\end{array}$ & $\begin{array}{c}\text { BMI } \\
\left(\mathrm{kg} / \mathrm{m}^{2}\right)\end{array}$ \\
\hline 1 & M & 23 & 1.84 & 66.3 & 19.6 \\
2 & M & 22 & 1.81 & 72.5 & 22.1 \\
3 & F & 18 & 1.77 & 61.0 & 19.5 \\
4 & F & 19 & 1.60 & 59.0 & 23.0 \\
5 & F & 19 & 1.71 & 62.2 & 21.3 \\
6 & F & 20 & 1.78 & 65.3 & 20.6 \\
7 & F & 19 & 1.70 & 64.8 & 22.4 \\
8 & F & 20 & 1.75 & 59.6 & 19.5 \\
5 & F & 19 & 1.65 & 50.0 & 18.4 \\
10 & F & 22 & 1.59 & 66.0 & 26.1 \\
11 & F & 20 & 1.70 & 67.0 & 23.2 \\
12 & F & 18 & 1.68 & 57.4 & 20.3 \\
13 & F & 23 & 1.65 & 50.2 & 18.4 \\
\hline
\end{tabular}

\section{Experimental design}

The experiment consisted of two periods of two consecutive days during one of which total daily intake was consumed in two meals (gorging pattem) and during the other in seven meals (nibbling pattem). Seven subjects started with the gorging pattern followed by the nibbling pattern, the other six subjects did the experiment in the altemate order. The interval between the two experimental periods was at least 7 days. The first day of each period consisted of a day of adaptation, during which the provided food was consumed at home according to the prescribed eating. pattern (gorging or nibbling), followed by the second day in a respiration chamber. The main measurements made in this chamber were oxygen consumption, carbon dioxide production and urinary nitrogen excretion (see below).

Before the subjects participated in the study, the sleeping metabolic rate (SMR) was measured during an overnight stay in the respiration chamber. This SMR was used to estimate the total energy need of a subject over 24 hours; assuming $24 \mathrm{~h}$ energy expenditure $(24 \mathrm{~h}$ EE) to be $1.4 \mathrm{x}$ SMR.. Subjects were fed to energy balance over the two periods of two days using this value. Fig. 2.1 is a schematic representation of the experimental design. 
Physical activity

Body weight

Meal pattern:

gorging

nibbling

Urine sample intervals

Time (h)

Experimental days

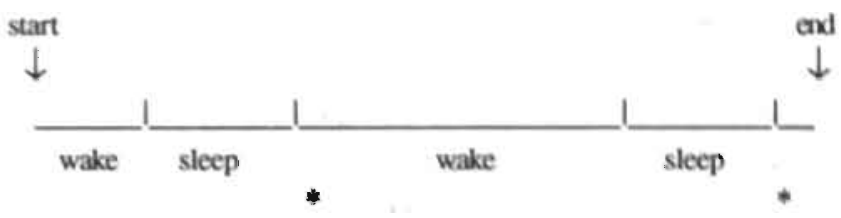

$\Delta \quad \Delta$

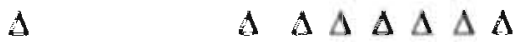

Fig. 2.1 Experimental design of the stay in the respiration chamber,

\section{Eating patterns}

The two eating patterns were characterized by a minimal or maximal spreading of the energy intake throughout the day. The gorging pattern consisted of two large meals: at $12.00 \mathrm{~h}$ a lunch containing 60 per cent of the total energy intake and at $18.00 \mathrm{~h}$ a meal with bread, fruit and orange juice containing the remaining 40 per cent. The nibbling pattern consisted of seven small meals: at $7.30 \mathrm{~h}, 10.00 \mathrm{~h}$ and $20.30 \mathrm{~h}$ a meal with bread $(15,10$ and 10 per cent of the energy intake), at $12.00 \mathrm{~h}$ and $18.00 \mathrm{~h}$ a meal ( 25 per cent each), at $14.00 \mathrm{~h}$ a dessert ( 10 per cent) and at $16.00 \mathrm{~h}$ a piece of fruit ( 5 per cent) was served.

The total energy intake, was the same for the two feeding patterns with the same menu and macro-nutrient composition. The food provided 16 per cent of the total energy content from protein, 38 per cent from fat and 46 per cent from carbohydrate. The value of the food quotient (FQ) as defined by Flatt (15) was 0.84 .

\section{Respiration chamber}

Oxygen consumption and carbon dioxide production were measured in a respiration chamber (16). This chamber measures $14 \mathrm{~m}^{3}$ and is furnished with a bed, chair, table, TV, radio, telephone, wash-bowl and toilet facilities. The chamber is ventilated with fresh air at $50 \mathrm{l} / \mathrm{min}$. The ventilation rate was measured with a dry gasmeter (Schlumberger, type G6). The concentration of oxygen and carbon dioxide was measured using a paramagnetic $\mathrm{O}_{2}$ analyser (Servomex, type 
OA 184) and an infrared $\mathrm{CO}_{2}$ analyser (Hartman \& Braun, type URAS 3G). Ingoing air was analysed once every $15 \mathrm{~min}$ and outgoing air once every $5 \mathrm{~min}$. The gas sample to be measured was selected by a computer which also stored and processed the data. The respiratory quotient (RQ) and energy expenditure (EE) (17) were calculated from $\mathrm{O}_{2}$ consumption and $\mathrm{CO}_{2}$ production. In daytime subjects were allowed to move freely, to sit, lie down, study, telephone, listen to the radio and watch television, only sleeping and strenuous exercise were not allowed.

\section{Body weight}

The subjects weighed theirselves (without clothing) in the morning upon rising, after voiding and before any food/drink consumption, on a digital balance (Seca delta, model 707) accurate to $0.1 \mathrm{~kg}$. Thus we got body mass values at the start and end of both $24 \mathrm{~h}$ observation periods in the respiration chamber.

\section{Urine collections}

Urine was collected in 4 portions: from $22.30 \mathrm{~h}$ day 1 to $7.30 \mathrm{~h}$ day 2 , from $7.30 \mathrm{~h}$ day 2 to $15.00 \mathrm{~h}$ day 2 , from $15.00 \mathrm{~h}$ day 2 to $22.30 \mathrm{~h}$ day 2 and from $22.30 \mathrm{~h}$ day 2 to $7.30 \mathrm{~h}$ day 3 . The subjects were instructed to void at the end of these intervals. Samples were collected in containers with $2 \mathrm{ml} \mathrm{H}_{2} \mathrm{SO}_{4}$ to prevent nitrogen loss through evaporation; volume and nitrogen concentration were measured subsequently, the latter using a Heracus analyser.

\section{Analysis of data}

Oxygen consumption, carbon dioxide production (and hence RQ and EE) were calculated over $3 \mathrm{~h}$ intervals during the observation period. Urinary nitrogen excretion was determined for the same intervals, taking into account the different collecting periods. The diurnal pattern of nutrient utilization was studied by comparing the $\mathrm{RQ}$, which reflected the composition of the fuel mixture oxidized, with the food quotient (FQ) of the diet. According to Flatt (15) body weight stability is achieved when the mean $24 \mathrm{~h} \mathrm{RQ}$ is equal to the FQ of the diet. When the RQ is above the FQ the energy balance is positive; a RQ below the FQ is accompanied by a negative energy balance. Le Magnen (13-14) studying the diumal pattern of energy balance in rats, reported lipogenic activity with a positive energy balance and lipolysis when the energy balance is negative. Concerning the $R Q / F Q$ ratio, we defined periods of lipogenesis $(R Q>F Q)$ and lipolysis $(R Q<$ FQ). Protein, carbohydrate, and fat oxidation were calculated according to Jéquier et al. (18). Data were analysed by repeated measures analysis of variance and Scheffé F-tests. In the text, tables and figures data are presented as the mean \pm standard error of the mean. 


\section{Results}

\section{Energy balance}

To interpret the effect of a change in meal frequency correctly, it is important that the subjects are in energy balance during the observation period. Garrow (19) stated that an adult is in energy balance when the difference between energy intake (EI) and energy expenditure (EE) is less than $600 \mathrm{~kJ}$ per day. The energy balance was determined by subtracting EE (measured from $7.00 \mathrm{~h}$ to $7.00 \mathrm{~h}$ ) from El. For the gorging pattern EI - EE was $+348 \pm 162 \mathrm{~kJ} / \mathrm{day}$, for the nibbling pattern +429 $\pm 217 \mathrm{~kJ} /$ day. At an individual level differences were higher, but this difference was highly reproducible between the two meal frequency regimens thus allowing further comparison.

\section{Energy expenditure}

Fig. 2.2 illustrates the $\mathrm{EE}$ (in $\mathrm{kJ} / \mathrm{min}$ ) over $3 \mathrm{~h}$ intervals from the night preceding the second experimental day to the early morning of the third day. There was no statistical difference in $24 \mathrm{~h}$ EE between the gorging and nibbling pattern (5.57 \pm $0.16 \mathrm{~kJ} / \mathrm{min}$ for the gorging pattern vs $5.44 \pm 0.18 \mathrm{~kJ} / \mathrm{min}$ for the nibbling pattern). However, when EI was consumed in two meals per day. EE was significantly elevated during the postprandial interval (EE12.00h-15.00h $>$ EE9.00h. $12.00 \mathrm{~h}, \mathrm{p}<0.001$ and EE18.00h-21.00h $>$ EE15.00h-18.00h, p $<0.05$ ). From $15.00 \mathrm{~h}$ to $18.00 \mathrm{~h} E \mathrm{E}$ had decreased significantly, compared to the previous interval $(p<0.01)$. When EI was spread throughout the day, EE did not show significant changes from $12.00 \mathrm{~h}$ to $21.00 \mathrm{~h}$.

Summarizing the results, no statistically significant difference in $24 \mathrm{~h}$ EE was observed between the gorging and nibbling pattern. Throughout the day, EE was significantly higher from $12.00 \mathrm{~h}$ to $15.00 \mathrm{~h}$ and from $18.00 \mathrm{~h}$ to $21.00 \mathrm{~h}$ when EI was consumed in two meals per day $(p<0.01$ and $p<0.05)$.

\section{Diumal pattem of nutrient utilization}

Fig. 2.3 illustrates the course of the RQ from the night preceding the second experimental day to the early morning of the third day for both gorging and nibbling pattern. There was no statistical difference in the mean $24 \mathrm{~h} \mathrm{RQ}$ between the two feeding patterns $(0.83 \pm 0.01$ for the gorging pattern; $0.85 \pm 0.01$ for the nibbling pattern). These values for the mean $24 \mathrm{~h} \mathrm{RQ}$ matched well with the FQ of the diet $(=0.84)$. 


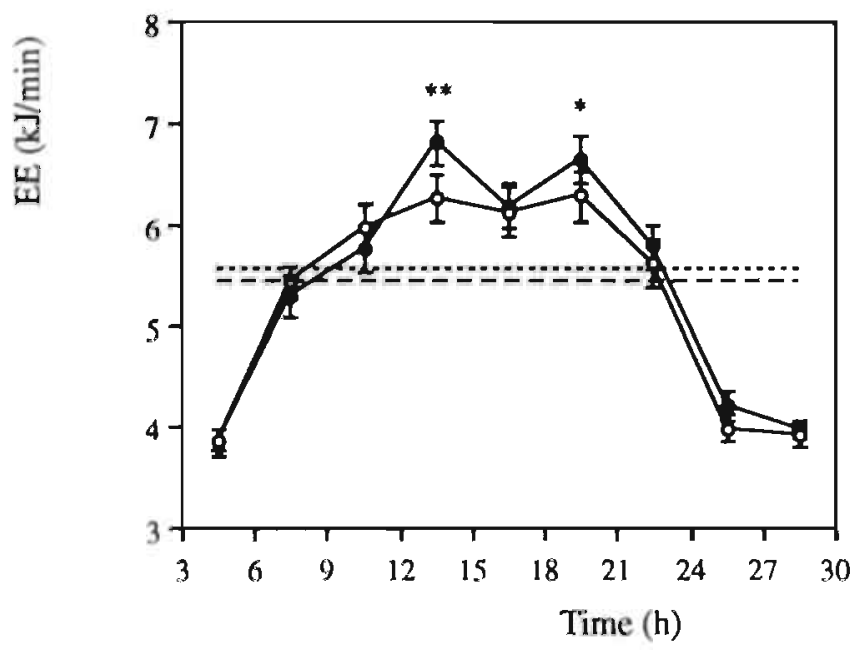

Fig. 2.2 Energy expenditure (EE) over $3 \mathrm{~h}$ intervals from $3.00 \mathrm{~h}-6.00 \mathrm{~h}$ on day 2 (3-6) to $3.00 \mathrm{~h}-6.00 \mathrm{~h}$ on day 3 (27-30), for both gorging (closed circles) and nibbling (open circles) pattern. The $24 \mathrm{~h}$ means for gorging (...) and nibbling (-- ) pattern are also shown. Statistical significance: * p<0.05,** p<0.01.

Although there were no effects of the feeding frequency on the mean $24 \mathrm{~h} \mathrm{RQ}$. significant changes did occur regarding the diurnal pattern of $R Q$. When the EI was consumed in two large meals per day, a strong diumal fluctuation in RQ was observed. From rising in the morning until the first meal at $12.00 \mathrm{~h}$, the RQ was below the FQ indicating lipolysis. Between $12.00 \mathrm{~h}$ and $24.00 \mathrm{~h}$ the RQ exceeded the FQ (lipogenesis) and after $24.00 \mathrm{~h}$ the $\mathrm{RQ}$ dropped quickly to a night level of 0.80 . When Ell was spread throughout the day (nibbling pattern) the fluctuation of $\mathrm{RQ}$ was considerably smaller. During the active period of the day the RQ had a constant level and was indicative of lipogenesis. Comparing the results, the overal! effect was a significantly lower $R Q(p<0.001)$ during the preprandial interval from $9.00 \mathrm{~h}$ to $12.00 \mathrm{~h}$ when the food was consumed in two meals per day. 


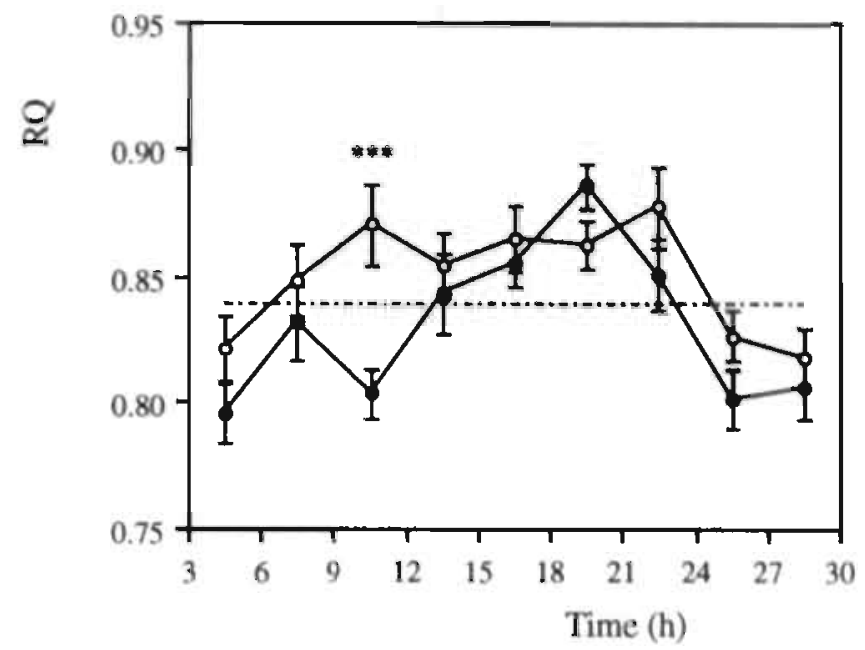

Fig. 2.3 RQ fluctuation over $3 \mathrm{~h}$ intervals from $3.00 \mathrm{~h}-6.00 \mathrm{~h}$ on day $2(3-6)$ to $3.00 \mathrm{~h}-6.00 \mathrm{~h}$ on day 3 (27-30), for both gorging (closed circles) and nibbling (open circles) pattern. The food

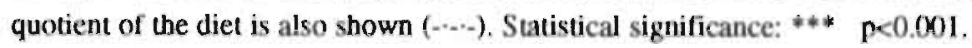

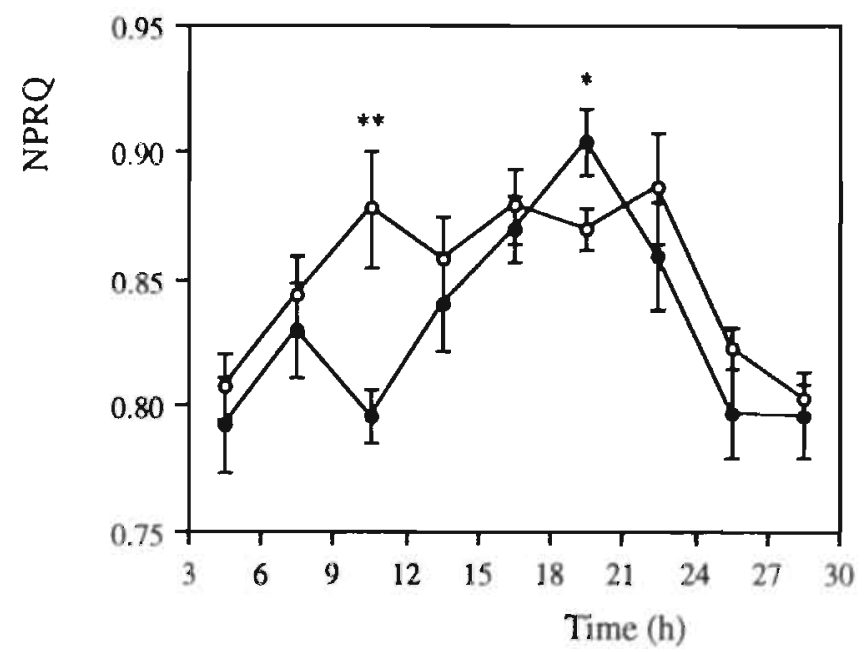

Fig. 2.4 NPRQ fluctuation over $3 \mathrm{~h}$ intervals from $3.00 \mathrm{~h}-6.00 \mathrm{~h}$ on day $2(3-6)$ to $3.00 \mathrm{~h}$ $6.00 \mathrm{~h}$ on day 3 (27-30), for both gorging (closed circles) and nibbling (open circles) pattern. Statistical significance: * $p<0.05, * \quad p<0.01$. 


\section{Chapter 2}

As mentioned above, by measuring oxygen consumption, carbon dioxide production and urinary nitrogen excretion, it is possible to calculate overall nutrient utilization. Analysis of the non-protein RQ (NPRQ $=R Q$ corrected for protein oxidation) was used to determine the proportion of oxygen consumption used for fat and carbohydrate oxidation. A NPRQ of 0.7 is indicative of pure fat oxidation, a NPRQ of 1.0 represents pure carbohydrate oxidation. The effect of meal frequency now became even more clear: from $9.00 \mathrm{~h}$ to $12.00 \mathrm{~h}$ the NPRQ was significantly lower $(p<0.01)$ for the gorging pattern, whereas its value was significantly higher $(p<0.05)$ from $18.00 \mathrm{~h}$ to $21.00 \mathrm{~h}$ (Fig. 2.4). Another striking result was the quick fall in NPRQ after the second meal of the gorging pattern. During the night NPRQ was lower in the gorging pattern.

Table 2.2 Nutrient oxidation (in g) over $3 \mathrm{~h}$ intervals from $3.00 \mathrm{~h}$ on day 2 to $6.00 \mathrm{~h}$ on day 3 for the gorging and nibbling pattern (mean $\pm S E M$ ).

\begin{tabular}{lrrrrrr}
\hline & \multicolumn{3}{c}{ GORGING PATTERN } & \multicolumn{3}{c}{ NIBBLING PATTERN } \\
Time (h) & Protein & \multicolumn{1}{c}{ Fat } & Carbohydrate & \multicolumn{1}{c}{ Protein } & Fat & Carbohydrate \\
& & & & & & \\
\hline $3-6$ & $9.6 \pm 1.8$ & $9.7 \pm 1.2$ & $8.7 \pm 1.6$ & $10.2 \pm 1.6$ & $8.4 \pm 0.6$ & $10.9 \pm 1.6$ \\
$6-9$ & $8.7 \pm 1.1$ & $11.9 \pm 1.5$ & $19.7 \pm 2.6$ & $9.2 \pm 0.6$ & $11.0 \pm 1.3$ & $22.8 \pm 2.2$ \\
$9-12$ & $7.7 \pm 1.0$ & $15.9 \pm 1.0^{*}$ & $17.4 \pm 2.6^{* * *}$ & $8.2 \pm 0.7$ & $10.2 \pm 2.2$ & $31.0 \pm 3.0$ \\
$12-15$ & $7.7 \pm 1.0$ & $15.0 \pm 2.1$ & $30.0 \pm 4.4$ & $8.2 \pm 0.7$ & $12.6 \pm 1.9$ & $29.4 \pm 1.9$ \\
$15-18$ & $13.3 \pm 2.3$ & $9.6 \pm 1.1$ & $30.0 \pm 3.3$ & $10.2 \pm 1.1$ & $9.8 \pm 1.4$ & $32.0 \pm 2.5$ \\
$18-21$ & $13.3 \pm 2.3$ & $8.0 \pm 1.2$ & $38.6 \pm 2.9^{* *}$ & $10.2 \pm 1.1$ & $10.8 \pm 0.9$ & $32.3 \pm 1.8$ \\
$21-24$ & $11.5 \pm 1.0$ & $10.3 \pm 1.8$ & $25.5 \pm 3.3$ & $9.4 \pm 0.8$ & $8.5 \pm 1.6$ & $30.6 \pm 3.4$ \\
$24-3$ & $9.8 \pm 1.8$ & $9.6 \pm 0.9$ & $11.7 \pm 2.0$ & $8.6 \pm 0.8$ & $8.6 \pm 0.6$ & $13.6 \pm 0.9$ \\
$3-6$ & $9.8 \pm 1.8$ & $9.3 \pm 1.0$ & $10.3 \pm 2.1$ & $8.6 \pm 0.8$ & $9.5 \pm 0.5$ & $11.1 \pm 0.7$ \\
& & & & & &
\end{tabular}

Statistical significance gorging, vs. nibbling pattern: * $p<0.05, * * p<0.01,{ }^{* * *} p<0.001$.

To express mumerically the effects of feeding frequency on nutrient utilization, we calculated the oxidation of protein, carbohydrate and fat over $3 \mathrm{~h}$ intervals from $3.00 \mathrm{~h}$ on day 2 to $6 .($ M h on day 3 (Table 2.2). There were no statistically significant changes in protein oxidation during the day between the two feeding patterns. In the gorging pattern an elevated protein oxidation was observed. especially from $15.00 \mathrm{~h}$ to $21.00 \mathrm{~h}$, but this effect was not significant. Concerning carbohydrate and fat oxidation, statistically significant changes between the two feeding patterns were observed. In the nibbling pattern carbohydrate and fat oxidation remained relatively constant during the active hours of the day. A feeding pattern of rwo meals per day resulted in a significant lower rate of carbohydrate oxidation during the time interval from $9.00 \mathrm{~h}$ to $12.00 \mathrm{~h}$, compared to 
the nibbling pattern $(p<0.001)$. Subsequently, carbohydrate oxidation increased significantly from $12.00 \mathrm{~h}$ to $15.00 \mathrm{~h}$ and from $18.00 \mathrm{~h}$ to $21.00 \mathrm{~h}$, compared to the preceding hours $(\mathrm{p}<0.01$ and $\mathrm{p}<0.05)$. In agreement with these results, fat oxidation was significantly elevated from $9.00 \mathrm{~h}$ to $12.00 \mathrm{~h}(15.9 \pm 1.0 \mathrm{~g}$ for the gorging pattern vs $10.2 \pm 2.2 \mathrm{~g}$ for the nibbling pattern; $\mathrm{p}<0.05)$. The fasting period of the gorging pattern (from rising in the morning until the first meal at $12.00 \mathrm{~h}$ ) resulting in a diminished rate of carbohydrate oxidation, thus seemed to be compensated by an increased fat oxidation.

\section{Discussion}

The results of the present study showed no significant effect of a changing feeding frequency on the mean $24 \mathrm{~h} \mathrm{RQ}$, although the diurnal pattern of RQ was markedly different between the two feeding regimens. With an EI of two meals per day the $\mathrm{RQ} / \mathrm{FQ}$ ratio indicated lipogenesis over 4 intervals (i.e. from $12.00 \mathrm{~h}$ to $24.00 \mathrm{~h}$ ) and lipolysis from $24.00 \mathrm{~h}$ to $12.00 \mathrm{~h}$. In the nibbling pattern lipogenesis lasted longer (i.e. from $6.00 \mathrm{~h}$ to $24.00 \mathrm{~h}$ ); lipolysis occurred from $24.00 \mathrm{~h}$ to $6.00 \mathrm{~h}$. Although the duration of lipogenic activity was prolonged in the nibbling pattern, its intensity was increased in the gorging pattern, reflected in a $20 \%$ higher rate of carbohydrate oxidation between $18.00 \mathrm{~h}$ and $21.00 \mathrm{~h}(\mathrm{p}<0.01)$.

These results of an increased lipogenic activity with a gorging pattern of food intake matched well with other studies. When animals were force-fed in one or two large meal(s), the adipose tissue became more sensitive to the lipogenic effects of insulin than in animals eating their food continuously through the day (20). Bray (21) studied the effects of gorging and nibbling on lipogenesis in human adipose tissue. A pattern of one large meal per day was accompanied by a more rapid formation of fat, as measured by the carbon incorporation of glucose into fatty acids in the adipose tissue. If a gorging pattern is accompanied by an increased chance to develop overweight, as suggested by several authors (1-3), this might be explained by an increased lipogenic activity during the postprandial hours, as observed in the present study.

The effect of feeding frequency on the diurnal pattern of nutrient utilization was more pronounced when the RQ was corrected for protein oxidation. The relative contributions to the fuel mixture oxidized made by carbohydrate and fat were assessed by determining the NPRQ. Flatt et al. (22) and Acheson et al. (23) described an increase of the NPRQ after carbohydrate ingestion, revealing that carbohydrate intake increased carbohydrate oxidation. The same effect also occurred when fat was consumed with a carbohydrate meal, showing a 'sparing effect' of fat from oxidation (22). Schutz et al. (24) studied the effect of a fat supplement on the substrate oxidation. They reported no changes in the oxidation of carbohydrate, fat and protein, indicating that dietary fat intake does not promote fat oxidation during the postprandial hours. 
In our experiment, the initial increase of the NPRQ observed at rising in the morning is not an uncommon result: a similar phenomenon was reported before by Lean and James (25). A possible explanation could be increase in carbohydrate utilization due to muscle glycogen oxidation during the arousal process. The decreased rate of carbohydrate oxidation afterwards, during the fasting period of the gorging pattern (i.e. from rising in the moming until the first meal at $12.00 \mathrm{~h}$ ) was compensated by an increased fat oxidation to cover energy needs, reflected in al lower NPRQ between $9.00 \mathrm{~h}$ and $12.00 \mathrm{~h}(\mathrm{p}<0.01)$.

Concerning the effect of feeding frequency on EE, results are contradictory. Irwin and Feeley (26) reported no changes in EE with an increase of the meal frequency from three to six meals per day in women on a uniform diet. According to Swindells et al. (11) there was no difference in oxygen consumption when daily El was consumed in nine meals rather than two meals per day. However, several studies showed a higher rate of fattening when daily EI was consumed in a small number of large meals (1-3). Since the storage of fat means that energy expenditure has been less than energy intake, this might mean that a gorging pattern of EI reduces energy expenditure or alternatively it might increase energy intake. Our data indicated no significant effects of the feeding frequency on the 24 $\mathrm{h}$ EE, possibly due to an inadequate duration of adaptation to the prescribed feeding pattern. However, meal frequency did influence the diurnal pattern of $\mathrm{EE}$. In the gorging pattern EE was significantly increased during the time interval following the first meal (i.e. from $12.00 \mathrm{~h}$ to $15.00 \mathrm{~h}, \mathrm{p}<0.01$ ) and the second meal (i.e. from $18.00 \mathrm{~h}$ to $21.00 \mathrm{~h}, \mathrm{p}<0.05$ ), compared to the nibbling pattern. Dallosso et al. (12) who did a similar experiment found no marked differences in EE with a changing feeding frequency. Their study showed an alteration of the profile of EE over the day with a changing frequency of meals, but the differences balanced themselves out. Zahorska-Markiewicz (27) and Miller and Wise (28) stated that a possible effect of meal frequency on $24 \mathrm{~h} \mathrm{EE}$ could be regulated through an interaction of the physical activity of the subjects and the diet induced thermogenesis (DIT). Molnár (29) investigated the effect of meal frequency on DIT in obese children. DIT was significantly higher after the consumption of one large than after three small meals.

Concerning our data, the increased EE observed during the postprandial intervals of the gorging pattern (i.e. from $12.00 \mathrm{~h}$ to $15.00 \mathrm{~h}$ and from $18.00 \mathrm{~h}$ to $21.00 \mathrm{~h})$, indicated a greater contribution of DIT to $24 \mathrm{~h}$ EE. Because $24 \mathrm{~h} \mathrm{EE}$ was not affected by the feeding frequency, this might mean that EE during the rest of the day was decreased. Possibly, the physical activity of the subject on a gorging pattern was decreased, resulting in a lower EE. Under the experimental conditions chosen for this study, physical activity was not measured. Further experimental work will be necessary to complete the effect of feeding frequency on both total 24 $\mathrm{h}$ EE and components of the $24 \mathrm{~h} \mathrm{EE}$. 
Summarizing the effects of feeding frequency on nutrient utilization and consequently EE, there were no significant effects on either $24 \mathrm{~h}$ nutrient utilization or $24 \mathrm{~h} \mathrm{EE}$, although diurnal fluctuations were markedly different between the two feeding patterns. A gorging pattern of EI resulted in a stronger diumal periodicity of lipogenesis and lipolysis, compared to a nibbling patterm.

\section{References}

1 Hejda S and Fábry P (1964): Frequency of food intake in relation to some parameters of the nutritional status. Nutritio et Dieta 6:216

2 Fábry P, Fodor J, Hejl Z, Braun T and Zvolánková K (1964): The frequency of meals: Its relationship to overweight, hypercholesterolaemia, and decreased glucose tolerance. Lancet 2: 614-615

3 Metzner HL, Lamphiear DE, Wheeler NC and Larkin FA (1977): The relationship between frequency of eating and adiposity in adult men and women in the Tecumseh Community Health Study. Am J Clin Nutr 30: 712-715

4 Debry G, Rohr R, Azouaou R, Vassilitch I and Mottaz G (1973): Ponderal losses in obese subjects submitted to restricted diets differing by nibbling and by lipid and carbohydrate. In: Energy balance in man, ed M Apfelbaum, pp. 305-310. Paris: Masson

5 Bortz WM, Wroldsen A, Issekutz B and Rodahl K (1966): Weight loss and frequency of feeding. New Engl J Med 274: 376-379

6 Finkelstein B and Fryer BA (1971): Meal frequency and weight reduction of young women. Am J Clin Nutr 24: 465-468

7 Young CM. Frankel DL, Scanlan SS, Simko V and Lutwak L (1971): Frequency of feeding, weight reduction, and nutrient utilization. J Am Diet Ass 59: 473-480

8 Miller DS and Mumford P (1973): Luxuskonsumption. In Regulation of energy balance in man, ed M. Apfelbaum. pp. 195-207. Paris: Masson

9 Mahler R (1972): The relationship between eating and obesity. Acta Diabet Lat 9: 449-465

10 Nunes WT and Canham. JE (1963): The effect of varied periodicity of eating on serum lipids and carbohydrate tolerance in man (abstr.). Am J Clin Nutr 12: 334

11 Swindells YE, Holmes SA and Robinson MF (1968): The metabolic response of young women to changes in the frequency of meals. Br J Nutr 22: 667-680

12 Dallosso HM, Murgatroyd PR and. James WPT (1982): Feeding frequency and energy balance in adult males. Hum Nutr: Clin Nutr 36C: $25-39$

13 Le Magnen J (1985): Hunger, Cambridge: Cambridge University Press

14 Le Magnen J, Devos M, Gaudillière JP, Louis-Sylvestre J and Tallon S (1973): Role of a. lipostatic mechanism in regulation by feeding of energy balance in rats. J Comp Physiol Psychol 84: 1-23

15 Flatt JP (1987): Dietary fat, carbohydrate balance, and weight maintenance: Effects of exercise. Am J Clin Nutr 45: 296-306 


\section{Chapter 2}

16 Schoffelen PFM, Saris WHM, Westerterp KR and Ten Hoor F (1984): Evaluation of an automatic indirect calorimeter for measurement of energy balance in man. In: Human energy metabolism: Physical activity and energy expenditure measurements in epiderniological research based upon direct and indirect calorimetry, Euro Nut Report 5, ed AJH Van Es, pp. 51-54. Wageningen: The Netherlands Nutrition Foundation

17 Weir JB de V (1949): New methods for calculating metabolic rate with special reference to protein metabolism. J Physiol (London) 109: 1-9

18 Jequier E, Acheson K and Schutz. Y (1987): Assessment of energy expenditure and fuel utilization in man. Ann Rev Nutr 7: 187-208

19 Garrow IS (1974): Energy Balance and Obesity in Man, 1st edn. Amsterdam: North Holland Publishing Company

20 Leveille GA (1970): Adipose tissue metabolism: Influence, of periodicity of eating and diet composition. Fed Proc 29: 1294-1301

21 Bray GA (1972): Lipogenesis in human adipose tissue: Some effects of nibbling and gorging. J Clin Invest 51 : 537-548

22 Flatt JP, Ravussin E, Acheson KJ and Jéquier E (1985): Effects of dietary fat on postprandial substrate oxidation and on carbohydrate and fat balances. J Clin Invest 76: 10191024

23 Acheson KJ, Schutz. Y, Bessard T, Ravussin E, Jéquier E and Flatt JP (1984): Nutritional influences on lipogenesis and thermogenesis after a carbohydrate meal. Am J Physiol 246: E62-70

24 Schutz Y, Flat JP and Jéquier E (1989): Failure of dietary fat intake to promote fat oxidation: A factor favoring the development of obesity. Am J Clin Nutr 50: 307-314

25 Lean MEJ and James WPT (1988): Metabolic effects, of isoenergetic nutrient exchange over 24 hours in relation to obesity in women. Int J Obesity 12: 15-27

26 Irwin MI and Feeley RM (1967): Frequency and size of meals and senum lipids, nitrogen and mineral retention, fat digestibility, and urinary thiamine and riboflavin in young women. Am J Clin Nutr 20: 816-824

27. Zathorska-Markiewicz is (1980): Thennic effect of food and exercise in obesity. Eur J Appl Physiol 44: 231-235

28 Miller DS and Wise A (1975): Exercise and dietary-induced thermogenesis. Lancet 1:1290

29 Molnar D (1990): The efiect of meal frequency on posınrandial thermogenesis in obese children (abstr). In J Obesity 14 (Suppl. 2): 95 


\title{
Chapter 3
}

\section{Effect of the pattern of food intake on human energy metabolism}

\author{
W.P.H.G. Verboeket-van de Venne, K.R. Westerterp and A.D.M. Kester
}

Departments of Human Biology and Medical Informatics and Statistics, University of Limburg, P.O. Box 616, 6200 MD Maastricht, The Netherlands

British Journal of Nutrition in press

\begin{abstract}
The pattern of food intake can affect the regulation of body weight and lipogenesis. We studied the effect of meal frequency on human energy expenditure and its components. During one week ten male adults (age 25-61 уг, BMI 20.7$30.4 \mathrm{~kg} / \mathrm{m}^{2}$ ) were fed to energy balance at two meals per day (gorging pattern) and during another week at seven meals per day (nibbling pattern). For the first six days of each week the food was provided at home, followed by a $36 \mathrm{~h}$ stay in a respiration chamber. Oxygen consumption and carbon dioxide production (and hence energy expenditure. EE) were calculated over $24 \mathrm{~h}$. Energy expenditure in free living conditions was measured over the two weeks with doubly labeled water (average daily metabolic rate, ADMR).

The three major components of ADMR are basal metabolic rate (BMR), diet induced thermogenesis (DIT) and energy expenditure for physical activity (ACT). There was no significant effect of meal frequency on $24 \mathrm{~h}$ EE or ADMR. BMR and ACT did not differ between the two patterns either. DIT was significantly elevated in the gorging pattern, but this effect was neutralized by correction for the relevant time interval. With the method used for determination of DIT, no significant effect of meal frequency on the contribution of DIT to ADMR could be demonstrated.
\end{abstract}




\section{Introduction}

The pattem of food intake, i.e. the feeding frequency, has a considerable effect on the body composition of experimental animals. If rats which normally eat six to eight meals a day (nibbling pattern) are trained to eat only once or twice a day (gorging pattern), their body fat mass will increase (1-4). Cohn et al. (1) conducted some studies on tube-fed rats. Rats in one group were allowed to eat ad libitum and rats in a second group were fed an identical quantity of food by stomach tube twice a day. At the end of the experiment the animals which received their food by stomach tube had nearly twice as much body fat as did the rats allowed to eat ad libitum.

In man, meal frequency is often cited as one of the variables that can influence energy balance. It has been observed that obese individuals often skip breakfast (5) and tend to eat most of their food in one meal, usually in the late afternoon or evening (6). Using epidemiological methods, Fábry and co-workers studied the relationship between meal frequency and obesity. They reported a higher energy intake in subjects consuming their food in a greater number of meals. However, body weight was highest in the group who ate the fewest meals and' the iowest energy intake ( $T$ ). In a survey of elderiy men, Fábry et al. (8) found that subjects who ate one or two meals a day tended to be more overweight than those who ate three or more meals a day. Fábry confirmed this finding in a study of school children (9). Metzner et al. (10) studying the relationship between meal frequency and adiposity in subjects with the same total daily food intake, showed that those who ate more frequently during a $24 \mathrm{~h}$ period were less adipose than those who ate less frequently. Furthermore, a gorging pattern of food intake has been shown to enhance lipogenesis $(8,11)$, to increase body weight $(12)$, to increase blood serum cholesterol level (13-17) and to reduce glucose tolerance (17-20),

Siudies of the effect of meal frequency on $24 \mathrm{~h}$ energy expenditure and its components basal metabolic rate (BMR), diet induced thermogenesis (DIT) and energy expenditure due to physical activity (ACT) have been inconsistent. In a previous study, in which we investigated the short term (2 d) effect of meal frequency on energy metabolism, we observed an increased energy expenditure during the posiprandial hours on a gorging pattern indicating a greater contribution of DIT to $24 \mathrm{~h}$ energy expenditure (21). In view of the fact that $24 \mathrm{~h}$ energy expenditure was not affected by the meal frequency, this would suggest that energy expenditure due to physical activity was decreased on a gorging pattern.

The present study was conducted to investigate whether there is an effect of the pattern of food intake on $24 \mathrm{~h}$ energy metabolism (in both free living and experimentally controlled conditions) and, more specifically, on the components of energy expenditure: basal metabolic rate (BMR), diet induced thermogenesis (DIT) and energy expenditure due to physical activity (ACT). 


\section{Subjects and methods}

\section{Subjects}

Ten healthy male adults volunteered for this investigation. Their physical characteristics are presented in Table 3.1. They were all non smokers. The procedures to be used in the studly were carefully explained to each subject before he gave his consent to participate. The protocol was reviewed and approved by the University of Limburg Ethical Committee.

Table 3.1 Physical characteristics of the subjects and order of treatment (G: gorging pattern; $\mathrm{N}$ : nibbling pattern).

\begin{tabular}{cccccc}
\hline Subject & $\begin{array}{c}\text { Age } \\
(\mathrm{yr})\end{array}$ & $\begin{array}{c}\text { Height } \\
(\mathrm{m})\end{array}$ & $\begin{array}{c}\text { Weight } \\
(\mathrm{kg})\end{array}$ & $\begin{array}{c}\text { BMI } \\
\left(\mathrm{kg} / \mathrm{m}^{2}\right)\end{array}$ & $\begin{array}{c}\text { Order of } \\
\text { treatment }\end{array}$ \\
\hline 1 & 46 & 1.79 & 97.3 & 30.4 & G-N \\
2 & 53 & 1.79 & 80.7 & 25.2 & G-N \\
3 & 43 & 1.65 & 57.5 & 21.1 & N-G \\
4 & 31 & 1.89 & 76.3 & 21.4 & N-G \\
5 & 61 & 1.76 & 89.4 & 28.9 & G-N \\
6 & 33 & 1.76 & 74.5 & 24.1 & G-N \\
7 & 38 & 1.73 & 67.0 & 22.4 & N-G \\
8 & 25 & 1.75 & 63.5 & 20.7 & N-G \\
9 & 60 & 1.60 & 75.3 & 29.4 & G-N \\
10 & 36 & 1.80 & 86.4 & 26.7 & G-N \\
\hline
\end{tabular}

\section{Experimental design}

The experiment was conducted over two consecutive weeks during one of which daily intake was consumed at two meals (gorging pattern) and during the other at seven (nibbling pattern). The order of administration of gorging and nibbling pattern was randomized, with six subjects receiving the gorging pattern first and four the nibbling pattem. For the first six days of each week food was provided at home for consumption according to the prescribed eating pattern (gorging or nibbling). On the last day of each week the subjects stayed in a respiration chamber in which oxygen consumption, carbon dioxide production and physical activity were measured (see below). Subjects were fed to energy balance basing the average daily energy requirement on a 7-day food record, filled out 1 to 15 week(s) before the experimental period. During these seven consecutive days, subjects recorded their food intake in a diary that was divided into seven periods a day (three meals, four inter-meal periods). Over the two-week experimental 


\section{Chapter 3}

period, data were collected on energy intake, energy expenditure, and changes in body mass and body composition. Fig. 3.1 illustrates the experimental design schematically.

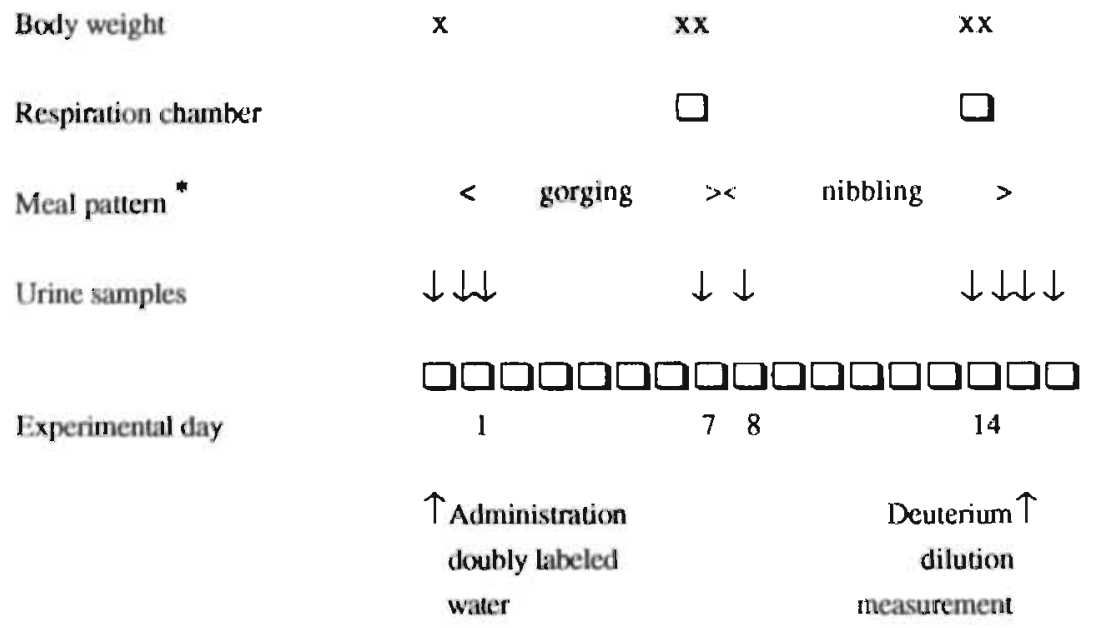

Fig. 3.1 Experimental design of the study.

* Reverse order for four subjects.

\section{Eating patterns}

The two cating patterns were characterized by a minimal or maximal spreading of the energy intake throughout the day. The gorging pattern consisted of two large meals: at $12.00 \mathrm{~h}$ a lunch with bread, fruit and orange juice containing 40 per cent of the daily energy intake and at $18.00 \mathrm{~h}$ a dinner plus dessert containing the remaining 60 per cent. The nibbling pattern consisted of seven small meals: at $7.30 \mathrm{~h}$ a breakfast ( 15 per cent of daily energy intake), at $10.00 \mathrm{~h}$ a morning snack ( 10 per cent of energy ), at $12.00 \mathrm{~h}$ a lunch ( 25 per cent of energy), at $14.00 \mathrm{~h}$ a dessert ( 10 per cent of energy), at $16.00 \mathrm{~h}$ a piece of fruit ( 5 per cent of energy), at $18.00 \mathrm{~h}$ a small dinner ( 25 per cent of energy) and at $20.30 \mathrm{~h}$ an evening snack ( 10 per cent of energy) was consumed. Subjects were instructed to consume all food items and returned any left overs.

The total daily energy intake was the same for the two eating patterns with the same menu and macronutrient composition. The food provided 16 per cent of energy as protein, 38 per cent as fat and 46 per cent as carbohydrate. The value of the food quotient $(\mathrm{FQ})$ as defined by Flatt (22) was 0.85 . 


\section{Measurement of energy expenditure}

Energy expenditure (EE) was measured over the two consecutive weeks of the experimental period with doubly labeled water (ADMR, average daily metabolic rate) and on the last day of each week in a respiration chamber ( $24 \mathrm{~h} \mathrm{EE}$ ). Thus, ADMR was measured under free living conditions. The $24 \mathrm{~h}$ EE measurement allowed separate assessment of the basal metabolic rate (BMR) and diet induced thermogenesis (DIT) (see below), permitting calculation of the energy expenditure due to physical activity (ACT) as ADMR minus (BMR+DIT). In this study we measured the sleeping metabolic rate (SMR), and have assumed this to be $5 \%$ less than BMR which is higher on account of the energy cost of arousal (23).

\section{Determination of $A D M R$}

ADMR was measured throughout the $14 \mathrm{~d}$ of the study using the doubly labeled water technique (24). Before going to bed at night on day 0 the subjects ingested a ${ }^{2} \mathrm{H}_{2}{ }^{18} \mathrm{O}$ drink after emptying the bladder (baseline urine sample). The dosage was based on body mass in order to create a ${ }^{2} \mathrm{H}$ excess of $150 \mathrm{ppm}$ and an ${ }^{18} \mathrm{O}$ excess of $300 \mathrm{ppm}$. Further urine samples were collected by the subjects at home on day 1 in the morning after the first voiding, on day 1 before going to bed at night, and during the stay in the respiration chamber on days $7,8,14$ and 15 in the moming after the first voiding. Isotope abundances in the urine samples were measured with an isotope ratio mass spectrometer (VG Isogas, Aqua Sira). $\mathrm{CO}_{2}$ production was calculated as the difference between the disappearance rates of ${ }^{18} \mathrm{O}$ and ${ }^{2} \mathrm{H}$, correcting for isotope fractionation and isotope incorporation in other compartments than $\mathrm{H}_{2} \mathrm{O}$ (25). Assessment of ADMR was based on this $\mathrm{CO}_{2}$ production using an energy equivalent of $531 \mathrm{~kJ} / \mathrm{mol}(\mathrm{RQ}=0.85)$, according to the average $\mathrm{FQ}$ calculated from the macronutrient composition of the diet.

\section{Determination of $24 h E E, B M R, D I T$ and $A C T$}

EE was calculated according to Weir (26) from $\mathrm{O}_{2}$ consumption and $\mathrm{CO}_{2}$ production as measured in a respiration chamber (27). This chamber measures 14 $\mathrm{m}^{3}$ and is furnished with a bed, chair, table, TV, radio, telephone, wash-bowl and toilet facilities. The chamber is ventilated with fresh air at $50 \mathrm{l} / \mathrm{min}$. The ventilation rate was measured with a dry gasmeter (Schlumberger, type G6). The concentration of oxygen and carbon dioxide was measured using a paramagnetic $\mathrm{O}_{2}$ analyser (Servomex, type OA 184) and an infrared $\mathrm{CO}_{2}$ analyser (Hartman \& Braun, type URAS $3 \mathrm{G}$ ). Ingoing air was analysed once every $15 \mathrm{~min}$. and outgoing air once every $5 \mathrm{~min}$. The gas sample to be measured was selected by a computer which also stored and processed the data. The system was checked monthly with ethanol combustion. Differences between calculated and measured $\mathrm{O}_{2}$ consumption and $\mathrm{CO}_{2}$ production were 0.5 (SD 1.2) per cent and -2.5 (SD 1.6) per cent respectively. 


\section{Chapter 3}

$24 \mathrm{~h} \mathrm{EE}$ was calculated from $7.00 \mathrm{~h}$ to $7.00 \mathrm{~h}$. To describe the effect of meal frequency on energy expenditure throughout the day, EE was also calculated over $3 \mathrm{~h}$ intervals. The physical activity of the subjects was monitored by means of a radar system, based on the Doppler principle. In daytime subjects were allowed to move freely, to sit, lie down, study, telephone, listen to the radio and wateh television. Only sleeping and strenuous exercise were not allowed. SMR was measured from $3.00 \mathrm{~h}$ to $6.00 \mathrm{~h}$, when subjects were asleep. Furthermore, SMR was divided by 0.95 to assess BMR. The method used for determination of DIT was previously described by Schutz et al. (28) and is based on simultaneous measurements of both physical activity and energy expenditure. The relationship between physical activity and energy expenditure for each individual, both averaged over $30 \mathrm{~min}$. periods, was plotted. Only the intervals after the first meal until bedtime were used, i.e. from $12.00 \mathrm{~h}$ to $23.00 \mathrm{~h}$ for the gorging pattern $(=11$ postprandial hours) and from $7.30 \mathrm{~h}$ to $23.00 \mathrm{~h}$ for the nibbling pattern $(=15.5$ postprandial hours). The intercept of the regression line at zero activity represents the energy expenditure in the inactive state $\left(\mathrm{EE}_{0}\right.$ activity $)$ consisting of two components: BMR and DIT. By subtracting BMR from $\mathrm{EE}_{0 \text { activity }}$ we obtained DIT, and corrected it for the relevant time interval (see below). ACT was calculated as ADMR - BMR - DIT (corrected for time). Thus, the separate components of ADMR are obtained by the following equations:

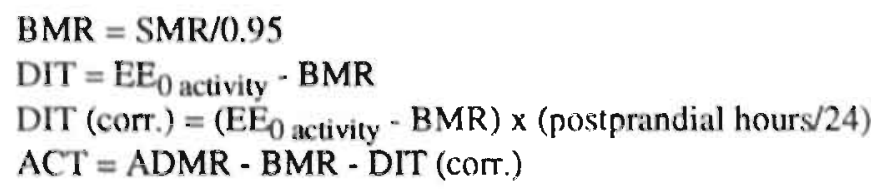

\section{Body weight and body composition}

Subjects weighed themselves (without clothing) on the mornings of days $0,7,8$, 14 and 15 , after voiding and before consuming any food/drink. A digital balance (Seca delta, model 707) accurate to $0.1 \mathrm{~kg}$ was used.

Body composition was ascertained by deuterium dilution at the start and end of the two-week experimental period. At the start body composition was assessed by analysing the urine samples collected on the evening of day 0 (baseline urine sample) and on the morning of day 1 after the first voiding. At the end of the experimental period, i.e. before going to bed at night on day 15 , a ${ }^{2} \mathrm{H}_{2} \mathrm{O}$ dilution was drunk at home after emptying the bladder (baseline urine sample). The dosage was based on body mass in order to create a ${ }^{2} \mathrm{H}$ excess of $100 \mathrm{ppm}$. A second urine sample was collected by the subjects at home on day 16 in the moming after the first voiding. Total body water (TBW) was calculated as the deuterium dilution space divided by 1.04 , correcting for exchange of the deuterium label with nonaqueous hydrogen of body solids (29). Fat-free mass (FFM) was calculated from TBW assuming a hydration coefficient of 0.73 ; fat mass (FM) was calculated as body weight minus FFM. 


\section{Analysis of data}

Data on energy intake, energy expenditure and body composition were analysed by paired t-tests within eating patterns. Differences between patterns were tested using the modified paired t-test for the cross-over design as described by Armitage and Berry (30). The diurnal variation in EE was analysed by using the method of summary measures (31). Changes in body weight were statistically tested using repeated measures analysis of variance and Scheffé F-tests. Correlation between physical activity and energy expenditure was qquantified using the Pearson correlation coefficient. Data are presented as the mean and standard error of the mean (SE) in the text, tables and figures.

\section{Results}

\section{Energy intake, $A D M R$ and $24 \mathrm{~h} E E$}

Energy intake (EI), ADMR and $24 \mathrm{~h} \mathrm{EE}$ of individual subjects are presented in Table 3.2. ADMR was not significantly different between the two patterns (gorging pattern: 11.8 (SD 1.0) $\mathrm{MJ} / \mathrm{d}$; nibbling pattern: 12.3 (SD 1.6) $\mathrm{MJ} / \mathrm{d}$; $\mathrm{p}=0.400$ ). Analysis of $24 \mathrm{~h}$ EE shows that there was no significant effect of meal frequency. Mean $24 \mathrm{~h} \mathrm{EE}$ was 9.4 (SE 0.2) $\mathrm{MJ} / \mathrm{d}$ for both gorging and nibbling pattern ( $p=0.819$ ). In both eating patterns $24 \mathrm{~h} \mathrm{EE}$ was significantly lower than ADMR (gorging pattern: $p=0.0003$; nibbling pattern: $p=0.0001$ ), probably because of the restricted physical activity of the subjects while staying in the respiration chamber. Table 3.3 presents the dilution spaces and fractional elimination rates for ${ }^{18} \mathrm{O}$ and ${ }^{2} \mathrm{H}$.

Mean EI was significantly lower than ADMR, resulting in a negative energy balance in free living conditions for both gorging (EI-ADMR = -1.8 (SE 0.3) $\mathrm{MJ} / \mathrm{d}$ ) and nibbling pattern (EI-ADMR $=-2.1(\mathrm{SE} 0.6) \mathrm{MJ} / \mathrm{d}$ ). EI was not significantly different from $24 \mathrm{~h}$ EE on the gorging pattern ( $p=0.153$ ), and significantly higher than $24 \mathrm{~h} \mathrm{EE}$ on the nibbling pattern ( $p=0.034$ ). Therefore, subjects were in a slightly positive energy balance while they were staying in the respiration chamber (gorging pattern: $\mathrm{El}-24 \mathrm{~h} \mathrm{EE}=+0.7(\mathrm{SE} 0.4) \mathrm{MJ} / \mathrm{d}$; nibbling pattern: EI-24 h EE $=+0.8($ SE 0.3) $\mathrm{MJ} / \mathrm{d})$. 
Table 3.2 Energy intake (EI, in $\mathrm{MJ} / \mathrm{d}$ ) and energy expenditure (in $\mathrm{MJ} / \mathrm{d}$ ) of individual subjects measured in free living conditions (ADMR) and sedentary conditions in a respiration chamber (24 h EE).

\begin{tabular}{crrrrrr}
\hline & \multicolumn{3}{c}{ GORGING PATTERN } & \multicolumn{3}{c}{ NBBLDNG PATTERN } \\
Subject & \multicolumn{1}{c}{ EI } & ADMR & 24 h EE & EI & ADMR & $24 \mathrm{~h} \mathrm{EE}$ \\
& & & & & & \\
\hline 1 & 9.8 & 11.9 & 10.8 & 9.9 & 15.9 & 10.7 \\
2 & 10.8 & 11.6 & 9.4 & 10.8 & 11.9 & 9.4 \\
3 & 9.3 & 11.5 & 8.5 & 9.4 & 10.6 & 8.7 \\
4 & 11.4 & 12.5 & 9.2 & 11.5 & 12.8 & 9.7 \\
5 & 8.9 & 10.3 & 10.0 & 9.0 & 12.5 & 9.3 \\
6 & 8.3 & 11.2 & 9.7 & 9.3 & 11.5 & 9.2 \\
7 & 8.4 & 12.0 & 8.0 & 8.4 & 11.4 & 8.5 \\
8 & 11.3 & 13.4 & 9.2 & 11.3 & 10.6 & 9.6 \\
9 & 10.8 & 10.6 & 9.2 & 10.8 & 12.8 & 9.3 \\
10 & 11.4 & 12.9 & 9.5 & 11.4 & 13.2 & 9.4 \\
& & & & & & \\
Mean & 10.0 & 11.8 & $9.4 *$ & $10.2 \ddagger 8$ & $12.3 \ddagger$ & 9.4 \\
SE & 0.4 & 0.3 & 0.2 & 0.4 & 0.5 & 0.2 \\
& & & & & & \\
\hline
\end{tabular}

I El vs. ADMR in the gorging patiem, $p=0.0006$

\# EI vs. ADMR in the nibbling pattern, $p=0.004$

* EI vs. $24 \mathrm{~h} \mathrm{EE}$ in the gorging pattern, $p=0.153$ (NS)

$\$ \quad$ El vs. $24 \mathrm{~h} \mathrm{EE}$ in the nibbling pattern, $p=0.034$

\section{Diumal variation in EE}

Fig. 3.2 shows the individual data for EE on both eating patterns, expressed over $3 \mathrm{~h}$ intervals. The diurnal variation in EE was analysed by dividing the day into two periods of 12 hours: $7.00 \mathrm{~h}-19.00 \mathrm{~h}$ and $19.00 \mathrm{~h}-7.00 \mathrm{~h}$. These periods were chosen because subjects rise at $7.00 \mathrm{~h}$ in the morning and $24 \mathrm{~h} \mathrm{EE}$ measurements were made between $7.00 \mathrm{~h}$ and $7.00 \mathrm{~h}$. From $7.00 \mathrm{~h}-19.00 \mathrm{~h}$ EE was not significantly different between both pattems (Area Under Curve(gorging) $=7.00$ (SE $0.20) \mathrm{kJ} / \mathrm{min}$, AUC(nibbling) $=7.23$ (SE 0.14) $\mathrm{kJ} / \mathrm{mnin} ; \mathrm{p}=0.111$ ). In the period from $19.00 \mathrm{~h}-7.00 \mathrm{~h}$ EE was significantly elevated in the gorging pattern (AUC (gorging) $=6.00($ SE 0.16$) \mathrm{kJ} / \mathrm{min}, \mathrm{AUC}$ (nibbling) $=5.80($ SE 0.13$) \mathrm{kJ}$; $p=0.026$ ). 
Table 3.3 Dilution spaces (in 1) and fractional elimination rates (day ${ }^{-1}$ ) from body water of excess ${ }^{18} \mathrm{O}$ and ${ }^{2} \mathrm{H}$, during the two-week experimental period.

\begin{tabular}{ccccccc}
\hline & & & \multicolumn{2}{c}{ Day $1-7$} & \multicolumn{2}{c}{ Day $8-14$} \\
Subject & $\mathrm{D}_{\mathrm{O}}$ & $\mathrm{D} H$ & $\mathrm{k}_{18}$ & $\mathrm{k}_{2}$ & $\mathrm{k}_{18}$ & $\mathrm{k}_{2}$ \\
\hline 1 & 46.20 & 47.03 & 0.09273 & 0.07111 & 0.10347 & 0.07534 \\
2 & 42.53 & 42.54 & 0.09468 & 0.07179 & 0.09877 & 0.07521 \\
3 & 35.45 & 36.42 & 0.11180 & 0.08683 & 0.11014 & 0.08344 \\
4 & 40.53 & 41.63 & 0.10473 & 0.07871 & 0.10470 & 0.07924 \\
5 & 41.01 & 42.50 & 0.07834 & 0.05792 & 0.08960 & 0.06501 \\
6 & 38.74 & 40.14 & 0.08038 & 0.05698 & 0.09647 & 0.07184 \\
7 & 40.00 & 41.45 & 0.11062 & 0.08676 & 0.10954 & 0.08462 \\
8 & 36.59 & 37.93 & 0.11624 & 0.09184 & 0.12119 & 0.09104 \\
9 & 36.28 & 37.60 & 0.09723 & 0.07320 & 0.10849 & 0.07970 \\
10 & 41.17 & 42.66 & 0.13100 & 0.10445 & 0.09650 & 0.07030 \\
\hline
\end{tabular}

$\mathrm{D}_{\mathrm{O}} \quad$ dilution space for ${ }^{18} \mathrm{O}$

$\mathrm{D}_{\mathrm{H}}$ dilution space for ${ }^{2} \mathrm{H}$

$\mathrm{k}_{18}$ fractional elimination rate based on excess ${ }^{18} \mathrm{O}$

$\mathbf{k}_{2}$ fractional elimination rate based on excess ${ }^{2} \mathrm{H}$
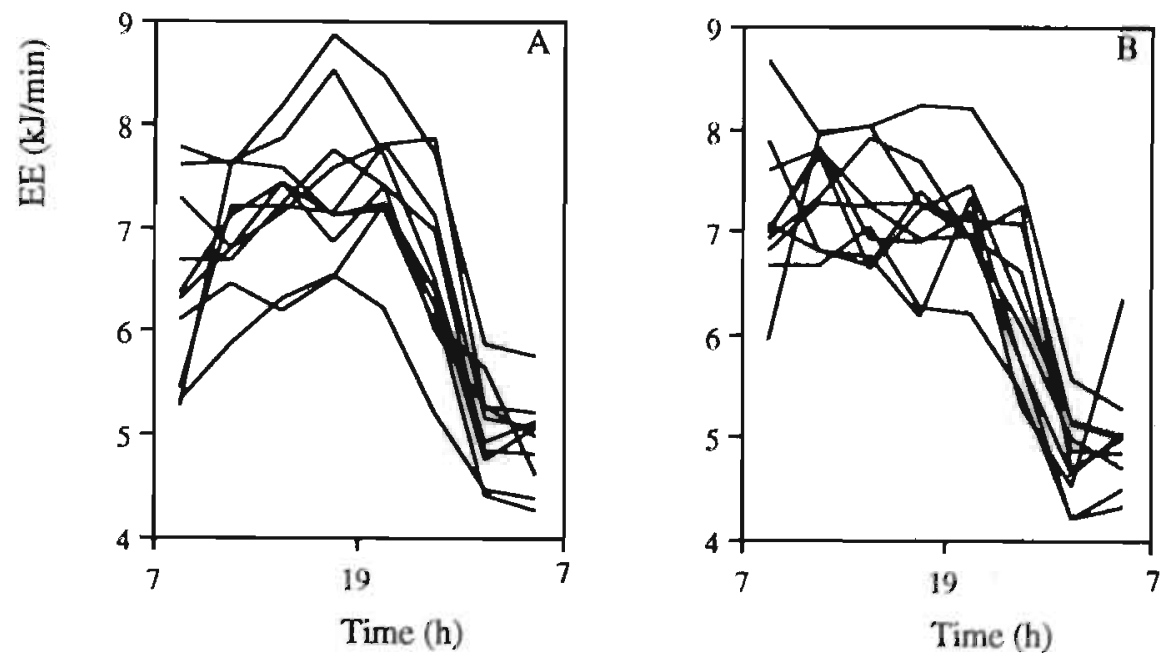

Fig. 3.2 Individual plots of diurnal energy expenditure (EE) as measured in the respiration chamber against time for all subjects on a gorging (A) and nibbling (B) pattern. 


\section{Chapter 3}

\section{Body weight and body composition}

Body weight, fat-free mass and fat mass over the two-week experimental period are presented in Table $3.4(\mathrm{n}=9$; data of subject 9 were not complete with respect to bodly composition measurements). Body weight changes (-0.6 (SE 0.3$) \mathrm{kg} / 14$ d) were not significantly different from zero. Weight loss was not associated with the pattern of food intake: 0.3 (SE 0.2 ) $\mathrm{kg}$ for both gorging and nibbling pattern $(p=0.801)$. Fat-free mass and fat mass did not change significantly during the study. There was a significant relationship (Pearson's $r=0.779, p=0.014$ ) between the discrepancy between energy intake and energy expenditure and the change in body weight over the experimental period, in that subjects with the highest energy deficit lost most weight.

Table 3.4 Mean body weight, fat-free mass and fat mass, all expressed in $\mathrm{kg}$, during the twoweek experimental period $(n=9)$.

\begin{tabular}{lcccccc}
\hline & \multicolumn{2}{c}{ Start } & \multicolumn{2}{c}{ After 1 week } & \multicolumn{2}{c}{ End } \\
& Mean & SE & Mean & SE & Mean & SE \\
& & & & & & \\
\hline Body weight & 77.09 & 4.3 & 76.8 & 4.3 & 76.4 I & 4.3 \\
Fat-free mass & $58.7 \ddagger$ & 1.4 & & & $58.7 \ddagger$ & 1.3 \\
Fat mass & $18.3^{\S}$ & 3.2 & & & $17.7 \S$ & 3.1 \\
\hline
\end{tabular}

\footnotetext{
I boxly weight repeated measures, $\mathrm{p}=0.085$ (NS)

$\neq$ fat-free mass start vs. end, $p=0.889$ (NS)

$\S$ fat mass start vs. end, $p=0.308$ (NS)
}

\section{$B M R, D I T$ and $A C T$}

Fig. 3.3A shows the diumal variation in energy expenditure and physical activity of one subject on the gorging pattern. Fig.3.3B presents the individual regression line of energy expenditure on physical activity of the same subject. Only the intervals after the first meal until bedtime were used for assessment of DIT (closed circles). The open circles in the graph indicate the interval from $7.30 \mathrm{~h}$ to $12.00 \mathrm{~h}$. Within individuals, energy expenditure and physical activity were related significantly, except for subject 3 on both gorging and nibbling pattern and subject 6 on the gorging pattem (Table 3.5 ). 


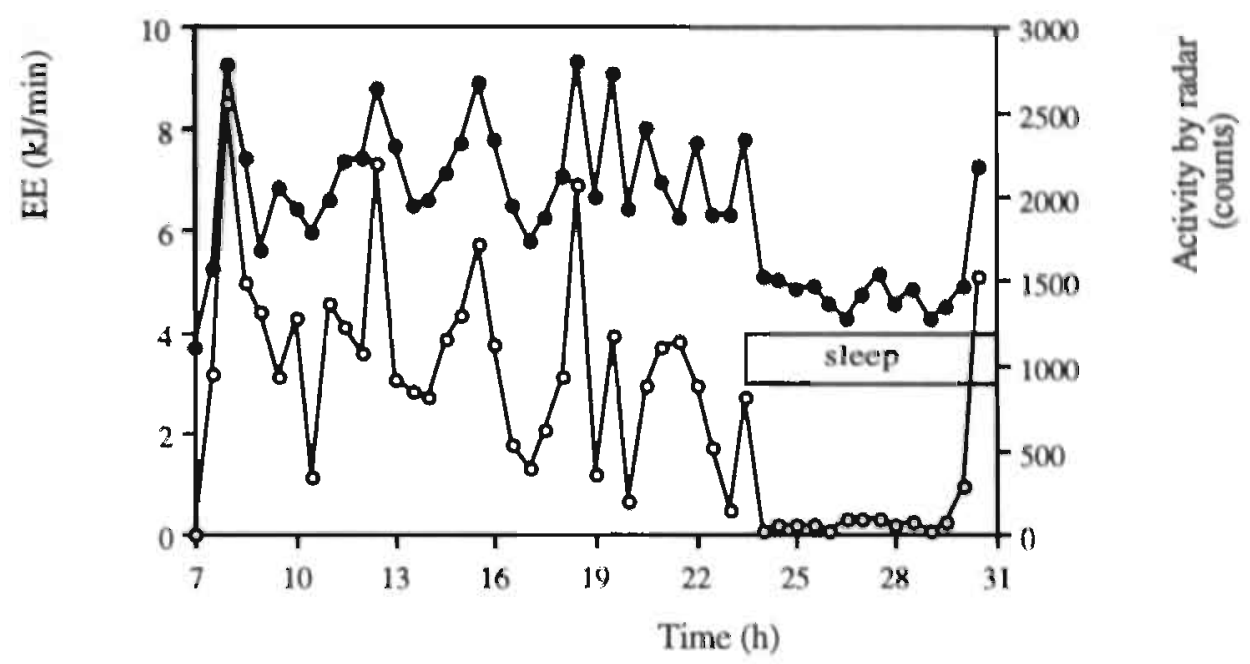

Fig. 3.3A Energy expenditure (closed circles) and activity (open circles) (averaged over $30 \mathrm{~min}$. periods) during the time course of the day in one subject (subject 9) on the gorging pattem.

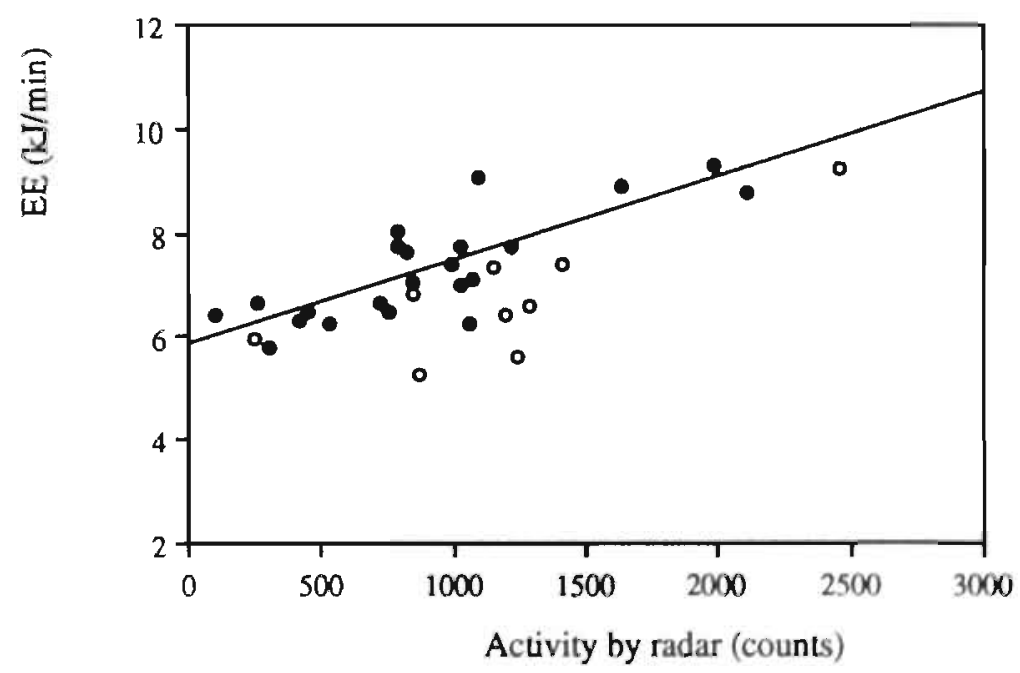

Fig. 3.3B Relationship between energy expenditure (EE) and activity in the same subject, each point representing a $30 \mathrm{~min}$. period from $12.00 \mathrm{~h}-23.00 \mathrm{~h}$ (closed circles). The open circles indicate the 30 min. periods from $7.30 \mathrm{~h}-12.00 \mathrm{~h}$.

Regression line: $\mathrm{EE}=5.84+\left(1.61 \times 10^{-3}\right)$ activity (Pearson's $r=0.807, \mathrm{p}=0.0001$ ). 
Table 3.5 Individual data of $\mathrm{EE}_{0}$ activity on both gorging and nibbling pattem. Data are expressed in $\mathrm{kJ} / \mathrm{min} .95 \%$ Confidence limits for $\mathrm{EE}_{0}$ activity are given between brackets.

\begin{tabular}{|c|c|c|c|c|c|c|}
\hline \multirow[b]{2}{*}{ Subject } & \multicolumn{3}{|c|}{$\begin{array}{l}\text { GORGING PATTERN } \\
\text { (df } 21 \text { ) }\end{array}$} & \multicolumn{3}{|c|}{$\begin{array}{l}\text { NIBBLING PATTERN } \\
\text { (df } 30 \text { ) }\end{array}$} \\
\hline & $\mathrm{EE}_{0}$ activity & $r$ & p & $\mathrm{EE}_{0}$ activity & $r$ & $p$ \\
\hline 1 & $6.66( \pm 0.62)$ & 0.826 & 0.0001 & $6.16( \pm 0.91)$ & 0.691 & 0.0001 \\
\hline 2 & $6.38( \pm 0.53)$ & 0.677 & 0.0005 & $6.18( \pm 0.80)$ & 0.551 & 0.0013 \\
\hline 3 & $6.64( \pm 0.91)$ & 0.045 & 0.8580 & $5.67( \pm 1.37)$ & 0.305 & 0.1084 \\
\hline 4 & $5.88( \pm 0.98)$ & 0.554 & 0.0075 & $5.62( \pm 0.98)$ & 0.585 & 0.0005 \\
\hline 5 & $6.07( \pm 0.81)$ & 0.783 & 0.0001 & $5.41( \pm 0.80)$ & 0.684 & 0.0001 \\
\hline 6 & $6.40( \pm 1.17)$ & 0.414 & 0.0558 & $5.49( \pm 0.47)$ & 0.835 & 0.0001 \\
\hline 7 & $5.43( \pm 0.78)$ & 0.507 & 0.0161 & $5.61( \pm 0.65)$ & 0.551 & 0.0013 \\
\hline 8 & $6.23( \pm 0.69)$ & 0.609 & 0.0026 & $5.89( \pm 0.67)$ & 0.709 & 0.0001 \\
\hline 9 & $5.84( \pm 0.57)$ & 0.807 & 0.0001 & $5.66( \pm 0.42)$ & 0.815 & 0.0001 \\
\hline 10 & $6.75( \pm 0.69)$ & 0.516 & 0.0140 & $6.11( \pm 0.40)$ & 0.799 & 0.0001 \\
\hline de & of freedorn & & & & & \\
\hline $\mathrm{Pe}$ & On correlation & icient t & non & vity and energ & enditu & \\
\hline
\end{tabular}

The effect of meal frequency on ADMR and its components BMR, DIT and ACT is presented in Table 3.6. ADMR was not significantly different between the two patterns. BMR did not differ between both patterns, while DIT was significantly elevated in the gorging pattern. Because DIT was measured over a period of 11 hours in the gorging pattern and 15.5 hours in the nibbling pattern, we have to correct DIT. When correcting for the relevant time interval, the effect of meal frequency on DIT was neutralized: DIT (gorging) $=\left(E_{0}\right.$ activity $\left.-B M R\right) \times 11 / 24$ (measured over $11 \mathrm{~h})=0.9(\mathrm{SE} 0.1) \mathrm{MJ} / \mathrm{d} ; \mathrm{DrT}$ (nibbling) $=\left(\mathrm{EE}_{0}\right.$ actuvity $\left.-\mathrm{BMR}\right) \mathrm{x}$ $15.5 / 24$ (measured over $15.5 \mathrm{~h})=0.9(\mathrm{SE} 0.1) \mathrm{MJ} / \mathrm{d}$. Thus, the contribution of DIT to ADMR was 7.6 (SE 0.8) \% for the gorging pattern and 7.3 (SE 0.8) \% for the nibbling pattern $(\mathrm{p}=0.653)$. ACT was not significantly different between the two patterns. 
Table 3.6 Mean ADMR, EE 0 activity SMR, BMR, DIT and ACT of all subjects on both eating patterns. Data are expressed in MJ/d.

\begin{tabular}{|c|c|c|c|c|}
\hline & \multicolumn{2}{|c|}{ GORGING PATTERN } & \multicolumn{2}{|c|}{ NIBBLING PATTERN } \\
\hline & Mean & SE & Mean & SE \\
\hline ADMR & $11.8^{\mathrm{a}}$ & 0.3 & $12.3^{a}$ & 0.5 \\
\hline $\mathrm{EE}_{0}$ activity & $9.0^{b}$ & 0.2 & $8.3^{b}$ & 0.1 \\
\hline SMR & 6.7 & 0.1 & 6.6 & 0.1 \\
\hline BMR & $7.0^{\mathrm{c}}$ & 0.2 & $7.0^{\mathrm{c}}$ & 0.1 \\
\hline DIT & $2.0^{d}$ & 0.2 & $1.3^{\mathrm{d}}$ & 0,1 \\
\hline DIT (corr.) $)^{\mathbf{T}}$ & $0.9^{\mathrm{e}}$ & 0.1 & $0.9^{\mathrm{e}}$ & 0.1 \\
\hline $\mathrm{ACT} \&$ & $3.9^{f}$ & 0.3 & $4.5^{f}$ & 0.4 \\
\hline
\end{tabular}

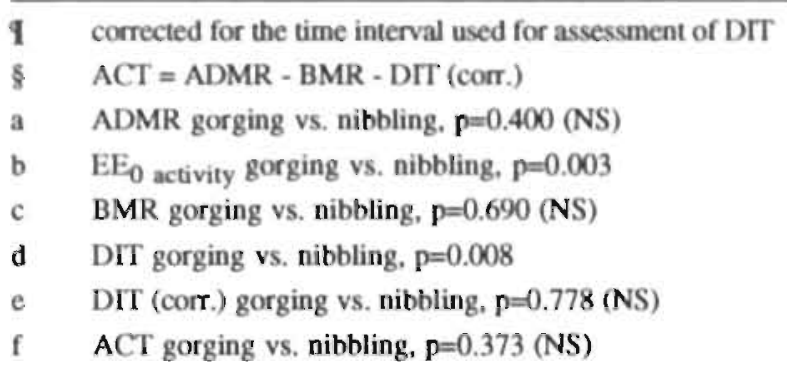

\section{Discussion}

According to Ravussin et al. (32) there is an inverse relationship between a reduced $24 \mathrm{~h}$ energy expenditure and the rate of subsequent weight gain. A reduced daily energy expenditure is therefore a possible risk factor in the development of obesity. Several studies have investigated the effects of meal frequency on $24 \mathrm{~h}$ energy expenditure. Dallosso et al. (12), studying the effect of meal frequency in adult males failed to observe an effect on $24 \mathrm{~h} \mathrm{EE}$. Their study showed an alteration of the profile of energy expenditure over the day with changing meal frequency, but the differences balanced themselves out. According to Wolfram et al. (33), there was no influence of meal frequency on energy balance in adolescents, studied under the condition of slight undernutrition. In the present study, there was no significant effect of meal frequency on ADMR or $24 \mathrm{~h}$ EE either. Therefore, the greater percentage of overweight and adiposity in gorging people, as observed in epidemiologic studies (7-10) cannot be explained by a decrease in daily energy expenditure (present study).

In the present study, there was a significant difference between $24 \mathrm{~h} \mathrm{EE}$ and ADMR for both gorging (20.1 (SE 3.2) \%) and nibbling pattern (23.2 (SE 2.1) $\%$ ) due to the restriction of spontaneous physical activity of the subjects while 
staying in the respiration chamber. Because EI was not adjusted for this difference in $\mathrm{EE}_{\text {, }}$ changes in energy balance between free-living and sedentary conditions are to be expected. There are two possible reasons for the deficit between diary estimated energy requirements and actual requirements. One is that subjects may have underreported their EI. Prentice et al. (34) described a mean difference of 33 per cent between reported EI and measured EE for obese subjects, while the corresponding difference for lean subjects was only 2 per cent. However, subjects in the present study were not expected to have any reasons for intentional underreporting. A second possibility might be a negative influence of keeping a dietary record on habitual EI. In fact, several of the subjects studied reported that having to record all they eat and drink for 7 days changed their feeding habits, i.e. by unintended restriction of their EI.

The study design employed a cross-over of dietary treatments, with the order of administration randomized. It is important in such cases to consider the possibility of a carry-over effect of the first treatment into the second half of the study. There are indications however, that people can adjust in a relatively short period of time to changes in energy intake. Hill et al. (35) conducted a study to determine whether substrate oxidation is influenced by changes in diet composition over a 7-day interval. The results showed that there were no significant changes in measured parameters on days 3 and 7, indicating a rapid adjustment (within 3 days) of the body to changes in energy intake, i.e. diet composition. Concerning the experimental design of this study, we hypothesized that our subjects also adjusted in a short period of time to the administered eating pattem and assume that the carry-over effect was unimportant in this study.

As we used a single dose of doubly labeled water to measure ADMR, it is important to consider the possibility that reduced isotopic enrichment affected precision of the measurements during the second 7-day period. According to Schoeller (36) the optimal metabolic period to measure energy expenditure in human adults is 5 to 28 days. Taking the biological half-life of ${ }^{18} \mathrm{O}$ to be about 7 days, a calculated ${ }^{18} \mathrm{O}$ excess of $300 \mathrm{ppm}$ would be produced in the first week of the study and one of $150 \mathrm{ppm}$ in the second week. This would mean that during the second week measurement of ADMR is less precise. Schoeller (36) estimated the precision of ADMR as $\pm 3 \%$ in the first week vs. $\pm 7 \%$ in the second week. However, randomization of the presentation of dietary patierns should balance the difference in precision across the study group.

Studies of the effect of meal frequency on the energy components BMR, DIT and ACT have been inconsistent. According to Swindells et al. (37) there was no difference in resting oxygen consumption of young women when daily EI was consumed in nine or two meals a day. Some studies reported an increasing DIT with a gorging pattern of food intake (38-39) while others described no relationship (40-4I). The time interval used for determination of DIT in these studies ranged from $5-10 \mathrm{~h}$, as well as the number of meals indicated as 'gorging' (one or two meals), or 'nibbling' (two to six meals). Zahorska-Markiewicz (42) 
and Miller and Wise (43) suggested that an interaction of the physical activity of the subjects and DIT could be of great importance in regulating energy expenditure.

Our data indicated no influence of meal frequency on $\mathrm{BMR} \mathrm{EE}_{0}$ activity was significantly elevated in the gorging pattern, due to an increased DIT. However, when correcting the data on DIT for the relevant time interval, the effect of meal frequency was neutralized. Fig. 3.3B shows the relationship between physical activity and EE in a subject on the gorging pattern. The data of the preprandial period (i.e. from $7.30 \mathrm{~h}$ to $12.00 \mathrm{~h}$ ), represented as open circles, are localized beneath the regression line, indicating that it is justified to exclude these points from regression analysis. Furthermore, we expect no contribution to DIT during the preprandial period of the gorging pattern. Considering the data on diurnal variation in EE (Fig. 3.2), we suggest that the contribution of DIT in the gorging pattern is continued till the early night, reflected by a greater area under the curve (AUC) from $19.00 \mathrm{~h}$ to $7.00 \mathrm{~h}$ which could not be explained by a change in physical activity. Thus, despite the fact that subjects following the nibbling pattern consume an evening snack at $20.30 \mathrm{~h}$, EE from $19.00 \mathrm{~h}$ to $7.00 \mathrm{~h}$ was still significantly higher at the gorging pattern. Fábry (20) suggested that if a gorging pattern of food intake leads to an inhibition of spontaneous physical activity ('laziness' after a rich meal), this inhibition can vary greatly, depending on a subject's baseline activity. In the present study, there was no effect of meal frequency on the contribution of ACT to ADMR but we have no information about the general level of activity of the subjects under free-living conditions. Measurements of physical activity in sedentary conditions in the respiration chamber, determined by means of a radar system, revealed that there was no difference in physical activity between gorging (701 (SE 48) counts/24 h) and nibbling pattern (749 (SE 34) counts/24 $\mathrm{h} ; \mathrm{p}=0.243$ ).

In conclusion, no significant effect of meal frequency on ADMR or $24 \mathrm{~h} \mathrm{EE}$ was observed. The contribution of DIT to ADMR was significantly increased in the gorging pattern. However, when the relevant time interval for DIT was taken into account, the effect of meal frequency was neutralized. BMR and ACT were not significantly different between the gorging and nibbling pattern. We can only speculate about the reasons for these findings. One could imagine that the effect of meal frequency is more obvious when subjects are accustomed to consume a gorging or nibbling pattern of food intake. If this is the case, further investigation is necessary. Considering the results of other studies on the effect of meal frequency on human energy metabolism $(12,21,33)$ and the results of the present study (also focussing on energy expenditure in free living conditions), a more likely conclusion may be that meal frequency has no effect at all on total daily energy expenditure. 


\section{References}

1 Cohn C, Joseph D, Bell L and Allweiss MD (1965): Studies on the effects of feeding frequency and dietary composition on fat deposition. Ann NY Acad Sci 131: 507-518

2 Leveille GA (1970): Adipose tissue metabolism: Influence of periodicity of eating and diet composition. Fed Proc 29: 1294-1301

3 Fáhry P and Tepperman J (1970): Meal frequency - a possible factor in human pathology. Am J Clin Nutr 23: 1059-1068

4 Tepperman J and Tepperman HM (1970): Gluconeogenesis, lipogenesis and the Sherringtoman metaphor. Fed Proc 29: 1284-1293

5 Hoenemann RL̃. Hampton MC, Shapiro LR and Behnke AR (1966): Adolescent food practices associated with obesity. Fed Proc 25: 4-10

6 Huenemann RL (1972): Food habits of obese and non-obese adolescents. Postgrad Med 51: 99-105

7 Hejda $S$ and Fabry $\mathrm{P}$ (1964): Frequency of food intake in relation to some parameters of the nutritional status. Nutritio et Dieta 6: 216

8 Fâhry P, Fodor J, Hejl Z, Braun T and Zvolánková K (1964): The frequency of meals: Its relationship to overweight, hypercholesterolaemia, and decreased glucose tolerance. Lancet 2: 614-615

9 Fabry P, Hejda S, Cerny K, Osancova K and Pechar J (1966): Effect of meal frequency in school children. Changes in the weight-height proportion and skinfold thickness. Am J Clin Nutr 18: 358-361

10) Metzner HI, Lamphicar DE, Wheeler NC and Larkin FA (1977): The relationship between frequency of eating and adiposity in adult men and women in the Tecumseh Community licalth Study. Am J Clin Nutr 30: 712-715

11 Terpstra J. Hessel I.W. Seepers J and Van Gent CM (1978): The influence of meal Irequency on diurnal lipid, glucose and cortisol levels in normal subjects. Eur J Clin Invest 8: 61.66

12. Dallosso HM. Murgatroyd PR and James WPT (1982): Feeding frequency and energy balance in adult males. Hum Nutr: Clin Nutr 36C: 25.39

13 Gwinup G, Byron RC. Roush WH, Kruger FA. and Hamwi GI (1963): Effect of nibbling versus gonging on serum lipids in man. Am J Clin Nutr 13: 209-213

14 Cohn $\mathrm{C}$ (1964): Feeding patterns and some aspects of cholesterol metabolism. Fed Proc 23: $76-81$

I5 Jagannathan SN, Comnell WF and Beveridge JMR (1964): Effects of gourmandizing and semicontimuous eating of equicaloric amounts of formula-type high fat diets on plasma. cholesterol and triglyceride levels in human volunteer subjects. Am J Clin Nutr 15: 90-94

10 Irwin MI and Feeley RM (1967): Frequency and size of meals and serum lipids, nitrogen and mineral retention, fat digestibility, and urinary thiamine and riboflavin in young women. Am J Clin Nutr 20: 816-824

17 Young CM, Hutter LF. Scanlan SS. Rand CE, Lutwak L and Simko V (1972): Metabolic effects of meal frequency on normal young men. J Am Diet Ass 61: 391-398 
Gwinup G, Byron RC. Roush WH, Kruger FA and Hamwi GJ (1963): Effect of nibbling versus gorging on glucose tolerance. Lancet 2: 165-167

19 Debry G, Rohr R, Azouaou R, Vassilitch I and Mottaz G (1973): Ponderal losses in obese subjects submitted to restricted diets differing by nibbling and by lipid and carbohydrate. In: Energy balance in man, ed M Apfelbaum, pp. 305-310. Paris: Masson

20 Fábry P (1973): Food intake pattern and energy balance. In: Energy balance in man, ed M Apfelbaum, pp. 297-303. Paris: Masson

21 Verboeket-van de Venne WPHG and Westerterp KR (1991): Influence of the feeding frequency on nutrient utilization in man: Consequences for energy metabolism. Eur 3 Clin Nutr 45: 161-169

22 Flatt JP (1987): Dietary fat, carbohydrate balance, and weight maintenance: Effects of exercise. Am J Clin Nutr 45: 296-306

23 Goldberg GR, Prentice AM, Davies HL and Murgatroyd PR (1988): Ovemight and basal metabolic rates in men and women. Eur J Clin Nutr 42: 137-144

24 Westerterp KR, Saris WHM, Van Es M and Ten Hoor F (1986): Use of the doubly labeled water technique in humans during heavy sustained exercise. J Appl Phys 61: 2162-2167

25 Westerterp KR and Saris WHM (1991): Limits of energy turnover in relation to physicai performance, achievement of energy balance on a daily basis. J Sports Sci 9: 1-15

26 Weir JB de V (1949): New methods for calculating metabolic rate with special reference to predict protein metabolism. J Phys 109: 1-9

27 Schoffelen PFM, Saris WHM, Westerterp KR and Ten Hoor F (1984): Evaluation of an automatic indirect calorimeter for measurement of energy balance in man. In: Human energy metabolism: Physical activity and energy expenditure measurements in epidemiological research based upon direct and indirect calorimetry, Euro Nut Report 5, ed AJH Van Es, pp. 51-54. Wageningen: The Netherlands Nutrition Foundation

28 Schutz Y, Bessard T and Jéquier E (1984): Diet-induced thermogenesis measured over a whole day in obese and nonobese women. Am J Clin Nutr 40: 542-552

29 Schoeller DA, Van Santen E, Peterson DW, Dielz W, Jaspan J and Klein PD (1980): Total body water measurement in humans with ${ }^{18} \mathrm{O}$ and ${ }^{2} \mathrm{H}$ labeled water. Am J Clin Nutr 33: 2686-2693

30 Armitage P and Berry G (1987): Statistical methods in medical research, pp. 224-225. Oxford: Blackwell Scientific

31. Matthews JNS, Altman DG, Campbell MJ and Royston P (1990): Analysis of serial measurements in medical research. Br Med J 300: 230-235

32 Ravussin E, Lillioja S, Knowler WC, Christin L, Freymond D. Abbott WGH, Boyce V, Howard BV and Bogardus C (1988): Reduced rate of energy expenditure as a risk factor for body-weight gain. New Engl J Med 318: 467-472

33 Wolfram G, KirchgeBner M, Müller HL and Hollomey S (1987): Thermogenese des Menschen bei unterschiedlicher Mahlzeitenhäufigkeit. Ann Nutr Metab 31: 88-97

34 Prentice AM, Black AE, Coward WA, Davies HL, Goldberg GR, Murgatroyd PR, Ashford J, Sawyer M and Whitehead RG (1986): High levels of energy expenditure in obese. women. Br Med J 292: 983-987 


\section{Chapter 3}

35 Hill JO, Peters JC, Reed GW, Schlundt DG, Sharp T and Greene III. (1991): Nutrient balance in humans: Effects of diet composition. Am J Clin Nur 54: 10-17

36 Schoeller DA (1983): Energy expenditure from doubly labeled water: Some fundamental considerations in humans. Am J Clin Nutr 38: 999-1005

37 Swindells YE, Holmes SA and Robinson MF (1968): The metabolic response of young women to changes in the frequency of meals. Br J Nutr 22: 667-680

38 Tai M, Castillo P and Pi-Sunyer FX (1990): Effect of nibbling versus gorging on the thermic effect of food (TEF) (abstr.). Am J Clin Nutr 51 (Suppl.: 30th Annual Meeting): 526

39 Molnár D (1990): The effect of meal frequency on postprandial thermogenesis in obese children (abstr.). Int J Obes 14 (Suppl. 2): 95

40 Belko AZ and Barbieri TF (1987): Effect of meal size and frequency on the thermic effect of food. Nutr Res 7: 237-242

41 Kinabo JLD and Durnin JGVA (1990): Effect of meal frequency on the thermic effect of food in women. Eur J Clin Nutr 44: 389-395

42 Zahorska-Markiewicz B (1980): Themic effect of food and exercise in obesity. Eur J Appl Phys 44: 231-235

43 Miller DS and Wise A (1975): Exercise and dietary-induced thermogenesis. Lancet 1: 1290 


\title{
Chapter 4
}

\section{Frequency of feeding, weight reduction and energy metabolism}

\author{
W.P.H.G. Verboeket-van de Venne and K.R. Westerterp \\ Department of Human Biology, University of Limburg, P.O. Box 616, $6200 \mathrm{MD}$ \\ Maastricht, The Netherlands
}

International Journal of Obesity, in press

\section{Abstract}

A study was conducted to investigate the effect of feeding frequency on the rate and composition of weight loss and $24 \mathrm{~h}$ energy metabolism in moderately obese women on a $4.18 \mathrm{MJ} / \mathrm{day}$ diet. During four consecutive weeks fourteen female adults (age 20-58 years, BMI $25.4-34.9 \mathrm{~kg} / \mathrm{m}^{2}$ ) restricted their food intake to 4.18 $\mathrm{MJ} /$ day. Seven subjects consumed the diet in two meals daily (gorging pattern), the others consumed the diet in three to five meals (nibbling pattern). Body mass and body composition, obtained by deuterium dilution, were measured at the start of the experiment and after two and four weeks of dieting. Sleeping metabolic rate (SMR) was measured at the same time intervals using a respiration chamber. At the end of the experiment $24 \mathrm{~h}$ energy expenditure ( $24 \mathrm{~h} \mathrm{EE}$ ) and diet. induced thermogenesis (DIT) were assessed by a $36 \mathrm{~h}$ stay in the respiration chamber.

There was no significant effect of the feeding frequency on the rate of weight loss, fat mass loss or fat-free mass loss. Furthermore, fat mass and fat-free mass contributed equally to weight loss in subjects on both gorging and nibbling diet. Feeding frequency had no significant effect on SMR after two or four weeks of dieting. The decrease in SMR after four weeks was significantly greater in subjects on the nibbling diet, $24 \mathrm{~h} \mathrm{EE}$ and DIT were not significantly different, between the two feeding regimens.

It is concluded that the pattern of food intake has no significant effect on the rate and composition of weight loss in obese women on a $4.18 \mathrm{MJ} /$ day diet for four weeks; and that $24 \mathrm{~h}$ energy metabolism and its compartments SMR and DIT are not significantly affected by the feeding frequency. 


\section{Introduction}

The development of obesity is a consequence of an energetic state of imbalance over a prolonged period of time, in which energy intake (EI) exceeds energy expenditure (EE). In man, frequency of feeding is often cited as one of the variables that can influence energy balance. Debry et al. (1) studied weight reduction in 119 obese subjects who where given a moderately hypocaloric diet (5.02-7.53 MJ/day) as three meals ('gorging' pattern) or seven meals ('nibbling' pattern). They observed that for the same subjects receiving the same food intake weight reduction was greater with seven meals than with three meals daily (mean weight loss with seven meals: $142 \mathrm{~g} /$ day; mean weight loss with three meals: 78 $\mathrm{g} /$ day). Others failed to show any significant relationship between frequency of feeding and weight loss (2-4).

Several studies investigated the effect of feeding frequency on $24 \mathrm{~h}$ energy expenditure ( $24 \mathrm{~h}$ EE) or its compartments in isocaloric conditions. Dallosso et al. (5) studying the effect of feeding frequency in adult men, did not observe a significant change in $24 \mathrm{~h}$ EE due to the pattern of food intake. According to Wolfram et al. (6) energy balance was not influenced by the feeding frequency, studied in subjects on a slightly hypocaloric diet. In a previous study in which we investigated the short term (two day) effect of feeding frequency (7), we observed no significant effect of feeding frequency on $24 \mathrm{~h}$ EE. However, on the gorging pattern energy expenditure was increased during the postprandial hours, indicating a greater contribution of diet induced thermogenesis (DIT) to $24 \mathrm{~h} \mathrm{EE}$. Similarly some studies described an increasing DIT with a gorging pattern of food intake (89), while others reported no relationship between the feeding frequency and DIT (10-11). Swindells et al. (12) studying the influence of feeding frequency in young women approximately in energy balance, reported no differences in resting oxygen consumption due to the pattern of food intake.

The present study was conducted to investigate the effect of feeding frequency on the rate and composition of weight loss in moderately obese women on a $4.18 \mathrm{MJ} /$ day diet. Furthermore $24 \mathrm{~h}$ energy metabolism was studied, including two of the compartments of energy expenditure: sleeping metabolic rate (SMR) and diet induced thermogenesis (DIT).

\section{Subjects and methods}

\section{Subjects}

Fourteen female adults, randomly allocated in two groups for experimental purposes, participated in this study. The selection criteria to enter the study included age (20-60 years) and body mass index $\left(25-35 \mathrm{~kg} / \mathrm{m}^{2}\right)$. Mean age was $46.1 \pm 3.3$ years (range $20-58$ ) and body mass index $30.2 \pm 0.8 \mathrm{~kg} / \mathrm{m}^{2}$ (range 25.4-34.9). The procedures to be used in the study were carefully explained to 
each subject before she gave her consent to participate. The protocol was reviewed and approved by the University of Limburg Ethical Committee.

\section{Experimental design}

The experiment consisted of four consecutive weeks during which daily intake was restricted to $4.18 \mathrm{MJ} /$ day. Seven subjects (subjects 1-7) consumed the diet in two meals daily according to a gorging pattern, the others (subjects 8-14) consumed the diet in three to five meals per day (nibbling pattern). In the four week dietary period, subjects were free in their choice of food as long as the energy content did not exceed $4.18 \mathrm{MJ}$ daily. Two research dieticians explained the purpose of the dietary regimens. Over the four week experimental period, data were collected on energy intake, energy expenditure ( $24 \mathrm{~h} \mathrm{EE}$, SMR and DIT), body mass and body composition.

\section{Eating patterns}

The two eating patterns prescribed to the women were characterized by the presence or absence of a breakfast. Subjects on the gorging diet had to consume two meals daily: a lunch at $12.00 \mathrm{~h}$ containing $40 \%$ of the daily energy intake $(1.67 \mathrm{MJ})$ and a dinner at $18.00 \mathrm{~h}$ containing the remaining $60 \%(2.51 \mathrm{MJ})$. Subjects on the nibbling diet were instructed to consume three to five meals: a breakfast at $7.30 \mathrm{~h}(30 \%$ energy), a lunch at $12.00 \mathrm{~h}$ (30\% energy) with the opportunity to eat $10 \%$ energy between $12.00 \mathrm{~h}$ and $15.00 \mathrm{~h}$, and a dinner at $18.00 \mathrm{~h}$ ( $40 \%$ energy) with the opportunity to eat $10 \%$ energy between $18.00 \mathrm{~h}$ and $21.00 \mathrm{~h}$. Between the meals no extra consumptions were allowed, except for coffee or tea (without sugar and milk) and mineral or tap water. During the experiment alcohol consumption was allowed, as long as it fitted into the energy content of the diet and the eating pattern. During the $36 \mathrm{~h}$ stay in the respiration chamber and on the day before, portion food (gorging diet: 2 meals, nibbling diet: 5 meals) was provided to the subjects to ensure accurate compliance to the diet content and frequency of feeding.

\section{Measurement of energy intake}

Before the experiment staried, a 7-day food record was filled out by the subjects to estimate their usual energy intake and frequency of feeding. During these seven consecutive days, subjects recorded their food intake in a diary that was divided into seven periods a day (three meals, four inter-meal periods). Brand names were asked for as well as cooking recipes that were used. In weeks 1 and 4 of the experimental period subjects again recorded their food intake and pattern of food intake. For the subjects this facilitated accurate fulfilment of the diet, and simultaneously we could check the energy intake and frequency of feeding during the experimental period. Energy and nutrient consumption was calculated using the computerized Dutch food composition table (13). 


\section{Measurement of energy expenditure}

Over the four week experimental period energy expenditure was measured at regular intervals. At the start of the experiment and after two weeks dieting the sleeping metabolic rate (SMR) was measured during an overnight stay in a respiration chamber. At the end of the experiment, after four weeks dieting, energy expenditure was measured during a $36 \mathrm{~h}$ stay in the respiration chamber to determine $24 \mathrm{~h}$ EE, SMR and DIT.

\section{Determination of $24 h E E, S M R$ and DIT}

Energy expenditure was calculated from $\mathrm{O}_{2}$ consumption and $\mathrm{CO}_{2}$ production (14) as measured in a respiration chamber (15). This chamber measured $14 \mathrm{~m}^{3}$ and is furnished with a bed, chair, table, TV, radio, telephone, wash-bowl and toilet facilities. The chamber is ventilated with fresh air at $50 \mathrm{l} / \mathrm{min}$. The ventilation rate was measured with a dry gasmeter (Schlumberger, type G6). The concentration of oxygen and carbon dioxide was measured using a paramagnetic $\mathrm{O}_{2}$ analyser (Servornex, type OA 184) and an infra-red $\mathrm{CO}_{2}$ analyser (Hartman \& Braun, type URAS 3G). Ingoing air was analysed once every $15 \mathrm{~min}$. and outgoing air once every $5 \mathrm{~min}$. The gas sample to be measured was selected by a computer which also stored and processed the data. The physical activity of the subjects in the chamber was monitored by means of a radar system, based on the Doppler principle. In the daytime subjects were allowed to move freely, to sit, lie down, study, telephone, listen to the radio and watch television; only sleeping and strenuous exercise were not allowed.

$24 \mathrm{~h}$ EE was calculated from 7.00h to 7.00h. SMR was measured from $3.00 \mathrm{~h} \mathrm{to} 6.00 \mathrm{~h}$, when subjects were asleep. The method used for determination of DIT was as previously described (16), and is based on simultaneous measurements of both physical activity and energy expenditure of the subjects. The individual relationship between the physical activity and energy expenditure both averaged over $30 \mathrm{~min}$. periods was plotted. Only the intervals after the first meal until bedtime were used, i.e. from $12.00 \mathrm{~h}$ to $23.00 \mathrm{~h}$ for subjects on the gorging pattern and from $7.30 \mathrm{~h}$ to $23.00 \mathrm{~h}$ for subjects on the nibbling pattem. The intercept of the regression line at zero activity represents the energy expenditure in the inactive state (EE $E_{0}$ activity) consisting of two components: SMR and DIT. By subtracting SMR from EE 0 activity we obtained DIT, thus including the energy cost of arousal (17).

\section{Body mass and body composition}

Body mass of the subjects was measured at the start of the experiment and after two and four weeks of dieting. Subjects were weighed (without clothing) in the morning upon rising, after voiding and before any food/drink consumption, on a digital balance (Seca delta, modiel 707) accurate to $0.1 \mathrm{~kg}$. Body composition was assessed at the same intervals using the deuterium dilution technique. Before going to bed at night during the stay in the respiration chamber a ${ }^{2} \mathrm{H}_{2} \mathrm{O}$ dilution was 
drunk after emptying the bladder (baseline urine sample). The dosage calculation was based on body mass in order to create a ${ }^{2} \mathrm{H}$ excess of $100 \mathrm{ppm}$. A second urine sample was collected by the subjects on the next day in the morning, from the second voiding between $8.00 \mathrm{~h}$ and $10.00 \mathrm{~h}$. Deuterium was measured in urine samples with an isotope ratio mass spectrometer (VG Aqua Sira). Total body water (TBW) was calculated as the measured deuterium dilution space divided by 1.04 (18). Fat-free mass was calculated as TBW/0.73; fat mass was calculated as body mass minus fat-free mass.

\section{Analysis of data}

Changes in energy intake, body mass, body composition and SMR were statistically tested using repeated measures analysis of variance (ANOVA) and Scheffé F tests. Data on 24 h EE, DIT and differences between the two groups were analysed by unpaired $t$ tests. Correlations between physical activity and energy expenditure were analysed using the Pearson correlation coefficient. In the text and tables data are presented as the mean and standard error of the mean (SE).

\section{Results}

\section{Energy intake}

Data on habitual energy intake, dietary intake in weeks 1 and 4 of the experimental period, and the number of meals per day eaten are presented in Table 4.1. Mean habitual energy intake was significantly higher than dietary intake in week 1 and 4 . for both gorging (habitual EI vs. EI week 1, p<0.001; habitual EI vs. EI week 4, $\mathrm{p}<0.01$ ) and nibbling pattern (habitual EI vs. EI week 1, p <0.001; habitual EI vs. EI week 4, $p<0.001$ ). Dietary intake was not significantly different between week 1 and week 4 of the experimental period, and also not significantly different from the prescribed dietary intake of $4.18 \mathrm{MJ} /$ day. The number of meals per day eaten by each group prior to the study was on average 6-7 meals. Subjects on the gorging diet consumed two meals daily as prescribed in the study design; subjects on the nibbling diet actually consumed four meals daily, indicating a high rate of compliance to the frequency of feeding during the first and fourth week of the diet. 


\section{Chapter 4}

Table 4.I Habitual energy intake (EI), energy intake in weeks 1 and 4 of the dietary period, and the number of meals per day eaten for subjects on a gorging or nibbling pattern. Data on energy intake are expressed in MJ/day; feeding frequency is expressed in meals per day.

\begin{tabular}{lcccc}
\hline & \multicolumn{2}{c}{$\begin{array}{c}\text { GORGING PATTERN } \\
\text { Mean }\end{array}$} & SE & \multicolumn{2}{c}{ NIBBLING PATTERN } \\
& & & Mean & SE \\
\hline Habitual EI & 8.20 & 0.70 & 7.98 & 0.39 \\
EI week 1 & 3.99 & 0.34 & 4.35 & 0.16 \\
EI week 4 & 4.56 & 0.75 & 4.26 & 0.16 \\
& & & & \\
Habitual feeding frequency & 6.4 & 0.3 & 6.7 & 0.7 \\
Feeding frequency weck 1 & 2.1 & 0.1 & 4.4 & 0.4 \\
Feeding frequency weck 4 & 2.1 & 0.1 & 4.3 & 0.3 \\
\hline
\end{tabular}

Table 4.2 presents the macronutrient composition of the habitual energy intake and dietary intake in week 1 and 4 for subjects on the gorging or nibbling pattern. There were no significant differences concerning intake of protein, fat, carbohydrate or alcohol between subjects on the gorging or nibbling pattern, neither before the experiment nor in week 1 or week 4. Protein intake was significantly increased during week 1 and week 4 of the experiment compared to the habitual protein intake, both for subjects on the gorging and on the nibbling pattern. Fat intake was unchanged in the dietary period for subjects on the gorging pattern, but significantly decreased for subjects on the nibbling pattern, possibly due to the relatively higher habitual fat intake. Intake of carbohydrate was only significantly increased in week 1 of the dietary period for subjects on the nibbling pattern. Alcohol consumption was not significantly different during the dietary period compared to habitual intake, although consumption seemed to be higher in the habitual situation.

\section{Body mass and body composition}

The analytical precision for ${ }^{2} \mathrm{H}$ was $0.2 \mathrm{ppm}$. Table 4.3 shows mean body mass, fat mass and fat-free mass of both groups during the four week experimental period. Comparing the two eating patterns, there was no significant difference at the start of the experiment in body mass. fat mass or fat-free mass between both groups. After two and four weeks of dieting, there was no significant effect of the feeding frequency on body mass, fat mass or fat-free mass. 
Table 4.2 Diet composition of the habitual energy intake and energy intake in weeks 1 and 4 of the experimental period for subjects on a gorging or nibbling pattern. Data are expressed as a percentage of the total energy intake.

\begin{tabular}{|c|c|c|c|c|}
\hline & \multicolumn{2}{|c|}{ GORGING PATTERN } & \multicolumn{2}{|c|}{ NIBBLING PATTERN } \\
\hline & Mean & SE & Mean & SE \\
\hline Habitual protein \% & 14.2 & 1.5 & 14.2 & 0.9 \\
\hline Protein $\%$ week 1 & $20.6^{* *}$ & 1.5 & $19.6^{* * *}$ & 0.9 \\
\hline Protein \% week 4 & $18.8^{\circ}$ & 1.4 & $18.6^{* *}$ & 0.8 \\
\hline Habitual fat $\%$ & 36.9 & 2.8 & 40.3 & 1.4 \\
\hline Fat \% week 1 & 33.4 & 3.2 & $29.4^{* * \bullet}$ & 1.1 \\
\hline Fat \% week 4 & 31.9 & 2.0 & $33.7^{* *}$ & 1.5 \\
\hline Habitual carbohydrate \% & 45.9 & 2.6 & 43.8 & 1.9 \\
\hline Carbohydrate \% week 1 & 44.5 & 3.0 & $50.8^{*}$ & 1.6 \\
\hline Carbohydrate \% week 4 & 47.6 & 2.4 & 46.9 & 1.1 \\
\hline Habitual alcohol \% & 3.0 & 1.2 & 1.6 & 0.7 \\
\hline A.lcohol $\%$ week 1 & 1.5 & 1.2 & 0.0 & 0.0 \\
\hline Alcohol \% week 4 & 1.7 & 1.0 & 0.7 & 0.4 \\
\hline
\end{tabular}

Statistical significance vs. habitual intake: * $\mathrm{p}<0.05, *$ p $<0.01, * * 0, p<0.001$.

Differences did oceur after dieting in the separate groups. Body mass significanily decreased during the study on both gorging (BM 0 vs. 2 weeks, $\mathrm{p}<0 .(0) 1 ; \mathrm{BM} 0$ vs. 4 weeks, $p<0.001 ; B M 2$ vs. 4 weeks, $p<0.05$ ) and nibbling pattern (BM 0 vs. 2 weeks, $p<0.001$; BM 0 vs. 4 weeks, $p<0.001$; BM 2 vs. 4 weeks, $\mathrm{p}<0.001)$. In subjects on the gorging pattern fat mass significantly decreased during the four week dietary period $(p<0.05)$; fat-free mass did not change significantly. In subjects on the nibbling pattern both fat mass and fat-free mass significantly decreased during the four weeks (FM: $p<0.001$; FFM: $p<0.01$ ).

There was no significant effect of the feeding frequency on josses of body mass, fat mass or fat-free mass. Losses of fat mass and fat-free mass contributed equally to loss of body mass. 
Table 4.3 Mean body mass, fat mass and fat-free mass of subjects on a gorging or nibbling pattern during the four week experimental period. Losses of body mass, fat mass and fat-free mass are calculated as data at 0 weeks (starting conditions) minus data at 4 weeks. All values are expressed in kg.

\begin{tabular}{|c|c|c|c|c|c|c|c|c|}
\hline & \multicolumn{8}{|c|}{ GORGING PATTERN } \\
\hline & \multicolumn{2}{|c|}{0 weeks } & \multicolumn{2}{|c|}{2 weeks } & \multicolumn{2}{|c|}{4 weeks } & \multicolumn{2}{|c|}{ Loss } \\
\hline & Mean & SE & Mean & SE & Mean & SE & Mean & SE \\
\hline Boxly mass & 82.2 & 4.6 & 79.5 & 4.5 & 78.1 & 4.3 & 4.] $\mathrm{ns}$ & 0.5 \\
\hline Fat mass & 33.6 & 2.9 & 31.9 & 2.4 & 31.3 & 2.6 & $2.3^{\mathrm{ns}}$ & 0.6 \\
\hline \multirow[t]{4}{*}{ Pat-free mass } & 48.6 & 3.0 & 47.6 & 3.1 & 46.8 & 2.8 & $1.8^{\mathrm{ns}}$ & 0.5 \\
\hline & \multicolumn{8}{|c|}{ NIBBL.ING PATTERN } \\
\hline & \multicolumn{2}{|c|}{0 weeks } & \multicolumn{2}{|c|}{2 weeks } & \multicolumn{2}{|c|}{4 weeks } & \multicolumn{2}{|c|}{ Lass } \\
\hline & Mean & SE & Mean & SE & Mean & SE & Mean & SE \\
\hline Body mass & 79.0 & 2.6 & 76.3 & 2.7 & 74.3 & 2.6 & 4.7 & 0.4 \\
\hline Fat mass & 31.7 & 2.2 & 30.1 & 2.2 & 29.0 & 2.2 & 2.7 & 0.5 \\
\hline Fat-free mass & 47.3 & 1.5 & 46.2 & 1.5 & 45.3 & 1.6 & 2.0 & 0.4 \\
\hline
\end{tabular}

ns no significant difference between gorging and nibbling pattem

\section{Sleeping metabolic rate}

Table 4.4 illustrates the data on SMR, SMR per $\mathrm{kg}$ body mass and SMR per $\mathrm{kg}$ fat-free mass for subjects on the gorging or nibbling pattern. In subjects on the gorging pattern SMR significantly decreased in the first two weeks of the experiment $(p<0.01)$, but was not significantly different from SMR after four weeks. Expressed per $\mathrm{kg}$ body mass. SMR significantly decreased in the first two weeks $(p<0.05)$ but then significantly increased in weeks 3 and $4(p<0.01)$, resulting in no net change of SMR. SMR per $\mathrm{kg}$ fat-free mass did not change significantly over the four week period. In the nibbling pattern SMR significantly decreased in weeks 1 and 2 ( $p<0.001$ ) and remained at that level during the rest of the study. SMR per $\mathrm{kg}$ body mass did not change significantly over the four week period. Expressed per $\mathrm{kg}$ fat-free mass, SMR decreased significantly from the start of the experiment to week 4 ( $p<0.05$ ).

There was no significant effect of the feeding frequency on SMR, SMR per $\mathrm{kg}$ body mass or SMR per $\mathrm{kg}$ fat-free mass, neither after two weeks nor after four weeks of dieting. Considering the effect of the feeding frequency on changes in SMR, subjects on a nibbling pattern had a sironger decrease in SMR $(-9.0 \pm 1.2$ $\%$ of starting conditions) compared to subjects on a gorging pattern $(-3.6 \pm 1.7$ \%). Expressed per $\mathrm{kg}$ body mass or fat-free mass, no statistically significant effect 
of the feeding frequency on SMR was obtained (SMR/BM: $p>0.05$; SMR/FFM: $p>0.1$ ), possibly due to the limited number of subjects and the high inter-person variability.

Table 4.4 Mean SMR (in kJ/min), SMR per $\mathrm{kg}$ body mass (in $\mathrm{kJ} / \mathrm{kg} . \mathrm{h}$ ) and SMR per $\mathrm{kg}$ fatfree mass (in $\mathrm{kJ} / \mathrm{kg} . \mathrm{h}$ ) during the four week experimental period. Changes in SMR, SMR/BM and SMR/FFM are expressed as a percentage of starting conditions.

\begin{tabular}{|c|c|c|c|c|c|c|c|c|}
\hline & \multicolumn{8}{|c|}{ GORGING PATTERN } \\
\hline & \multicolumn{2}{|c|}{ O weeks } & \multicolumn{2}{|c|}{2 weeks } & \multicolumn{2}{|c|}{4 weeks } & \multicolumn{2}{|c|}{ Changes } \\
\hline & Mean & SE & Mean & SE & Mean & SE & Mean & SE \\
\hline SMR & 4.17 & 0.19 & 3.86 & 0.19 & 4.02 & 0.19 & $.3 .6^{\circ}$ & 1.7 \\
\hline SMR/BM & 3.07 & 0.10 & 2.93 & 0.11 & 3.11 & 0.12 & $1.4^{\mathrm{ns}}$ & 1.6 \\
\hline \multirow[t]{4}{*}{ SMR/FFM } & 5.18 & 0.10 & 4.90 & 0.15 & 5.19 & 0.14 & $0.1^{\mathrm{ns}}$ & 2.2 \\
\hline & \multicolumn{8}{|c|}{ NIBBLING PATTERN } \\
\hline & \multicolumn{2}{|c|}{0 weeks } & \multicolumn{2}{|c|}{2 weeks } & \multicolumn{2}{|c|}{4 weeks } & \multicolumn{2}{|c|}{ Changes } \\
\hline & Mean & SE & Mean & SE & Mean & SE & Mean & SE \\
\hline SMR & 4.12 & 0.14 & 3.74 & 0.14 & 3.74 & 0.11 & -9.0 & 1.2 \\
\hline$S M R / B M$ & 3.13 & 0.08 & 2.95 & 0.08 & 3.03 & 0.06 & -3.2 & 1.6 \\
\hline SMR/FFM & 5.22 & 0.06 & 4.86 & 0.06 & 4.97 & 0.14 & -4.9 & 1.9 \\
\hline
\end{tabular}

- $\mathrm{p}<0.05$, gorging vs. nibbling pattem

ns no significant difference between gorging and nibbling pattern

\section{4 h Energy metabolism}

The effect of the feeding frequency on $24 \mathrm{~h}$ energy metabolism and its comparments is presented in Table 4.5. Two subjects (subjec 4 and 13) were excluded from the assessment of DIT, because there was no significant correlation between their physical activity and energy expenditure. 24t h EE was not significantly different between the gorging and nibbling pattern. SMR and DIT (in $\mathrm{kJ} / \mathrm{min}$ ) did not differ between the two groups. When correcting for the time interval used for determination of DIT, there was still no effect of the feeding frequency on DIT: DIT(gorging) $=\left(E_{0}\right.$ activity - SMR $) \times 11 \times 60$ (measured over $11 \mathrm{~h})=562(\mathrm{SE} 64) \mathrm{kJ} / \mathrm{d} ; \mathrm{DIT}$ (nibbling) $=\left(E_{0}\right.$ activity $\left.-\mathrm{SMR}\right) \times 15.5 \times 60$ (measured over $15.5 \mathrm{~h})=854(\mathrm{SE} 143) \mathrm{kJ} / \mathrm{d}$. When DIT was expressed as a percentage of $24 \mathrm{~h} \mathrm{EE}$ or $24 \mathrm{~h} \mathrm{EI}$, there were no significant differences between subjects on the gorging or nibbling diet. 
Table 4.5 Mean $24 \mathrm{~h}$ energy expenditure ( $24 \mathrm{~h}$ EE), sleeping metabolic rate (SMR), energy expenditure in the inactive state $\left(\mathrm{EE}_{0}\right.$ activity), diet induced thermogenesis (DIT), 24 h physical activity (obtained by radar) and $24 \mathrm{~b}$ respiratory quotient (RQ) of subjects on a gorging or nibbling pattern. Data on DIT are expressed in absolute values (in $\mathrm{kJ} / \mathrm{min}$ and $\mathrm{kJ} / \mathrm{day}$ ) and as a percentage of $24 \mathrm{~h} \mathrm{EE}$ and $24 \mathrm{~h} \mathrm{El}$.

\begin{tabular}{|c|c|c|c|c|}
\hline & \multicolumn{2}{|c|}{ GORGING PATTERN } & \multicolumn{2}{|c|}{ NLBBLING PATTERN } \\
\hline & Mean $^{a}$ & SE & Mean b & $S E$ \\
\hline 24 h EE (kJ/day) & 7838 & 416 & 7867 & 202 \\
\hline SMR (kJ/min) & 3.97 & 0.21 & 3.69 & 0.12 \\
\hline $\mathrm{EE}_{0}$ activity $(\mathrm{kJ} / \mathrm{min})$ & 4.82 & 0.24 & 4.61 & 0.21 \\
\hline $\mathrm{DIT}(\mathrm{kJ} / \mathrm{min})$ & 0.85 & 0.10 & 0.92 & 0.15 \\
\hline DIT (kJ/day) & 562 & 64 & 854 & 143 \\
\hline DIT (\% of EE) & 7.2 & 0.8 & 10.8 & 1.7 \\
\hline DIT (\% of EI) & 13.4 & 1.5 & 20.4 & 3.4 \\
\hline Physical activity (counts) & 665 & 56 & 885 & 125 \\
\hline $24 \mathrm{~h} \mathrm{RQ}$ & 0.80 & 0.01 & 0.78 & 0.01 \\
\hline
\end{tabular}

a all subjects except subject 4

b all subjects except subject 13

\section{Discussion}

In this study we investigated the effect of feeding frequency on the rate and composition of weight loss in moderately obese women on a $4.18 \mathrm{MJ} / \mathrm{day}$ diet. Results of similar studies have failed to indicate a consistent pattern. Some have reported that weight loss is greater on a nibbling diet $(1,19)$, whereas others report that there is no relationship between frequency of feeding and weight loss (2-4). Schlundt et al. (20) recently examined the impact of eating breakfast in a behavioral weight-control programme controlling for initial breakfast eating habits. Greater weight loss was achieved for baseline breakfast eaters on a no-breakfast treatment and for baseline breakfast skippers on a breakfast treatment. In the present study we found no effect of feeding frequency on the rate of weight loss (Table 4.3).

There was no significant effect of feeding frequency on the rate of fat mass (FM) loss or fat-free mass (FFM) loss (Table 4.3). In the gorging pattern FM loss accounted for $\pm 56 \%$ to weight loss and FFM loss for $\pm 44 \%$. In the nibbling pattern the contribution was $\pm 57 \%$ for FM and $\pm 43 \%$ for FFM. These results support the view of Garrow et al. (21) that feeding frequency has a minor role in the preservation of lean tissue. 
Using the deuterium dilution technique for assessment of body composition implicates the assumption that the body has two compartments, e.g. FM and FFM. FFM was calculated from TBW assuming that the average hydration of FFM (22) is $73 \%$, although this hydration ratio may rise with increasing fatness (23). However, for women with a mean body fat percentage of $40 \%$ as in the present study, the difference in \% water of FFM compared to lean women is lower than 2 \% (24). Furthermore, in the first week on a hypocaloric diet we might expect water diuresis that is not only related to FFM loss, but to excess extracellular water and sodium re-absorption kinetics as well. Thus, FFM as calculated from TBW might be slightly overestimated. On the other hand this applies equally to both groups, as physical characteristics at baseline were not significantly different between the two groups of subjects.

A second objective of this study was to investigate whether there is an effect of feeding frequency on $24 \mathrm{~h}$ EE, SMR and DIT in hypocaloric conditions. The results indicated no significant effect of feeding frequency on SMR, either expressed in absolute values or per $\mathrm{kg} \mathrm{BM}$ or FFM. From literature it is well known that the rate of weight loss decreases with time. The reason for this phenomenon is thought to be a decrease of RMR which occurs with caloric restriction (25-30). Furthermore, a lowering of RMR would imply lower energy requirements which induce resistance to further weight loss and facilitate weight gain when dieting is given up. In the present study, we observed a decrease of SMR in weeks 1 and 2 at the same extent for both feeding patterns. However, in weeks 3 and 4 SMR is rising in subjects on the gorging diet, resulting in no net change of SMR over the experimental period. After four weeks of dieting, the decrease in SMR (both in absolute values and expressed as a percentage of starting conditions) is greater for subjects on the nibbling diet. One explanation for this finding could be the relative higher energy intake in week 4 as observed in subjects on the gorging diet (Table 4.1), reflecting less compliance to the diet compared to week 1 . We suggest that skipping breakfast while on a hypocaloric diet is associated with more difficulty in adherence to the diet. Schlundt et al. (20) supported this view by reporting a greater reduction in unplanned, impulsive eating when subjects on a reducing diet include a breakfast.

Concerning the contribution of diet induced thermogenesis to $24 \mathrm{~h}$ EE, no significant effect of feeding frequency could be obtained, either expressed in $\mathrm{kJ} /$ day or as a percentage of $24 \mathrm{~h} \mathrm{EE}$ or $24 \mathrm{~h}$ EI. Physical activity of the subjects, only measured during the $36 \mathrm{~h}$ stay in the respiration chamber, was not affected by feeding frequency either. Furthermore, we have no indications that physical activity during the weeks of the study was different for the two groups of subjects.

Summarizing the results of the present study, there are no significant effects of the pattern of food intake on losses of body mass, fat mass or fat-free mass during a four week dietary period. $24 \mathrm{~h} \mathrm{EE,} \mathrm{SMR} \mathrm{and} \mathrm{DIT} \mathrm{are} \mathrm{not} \mathrm{significantly}$ influenced by the feeding frequency. 


\section{Chapter 4}

\section{References}

1 Debry G, Rohr R, Azouaou R, Vassilitch I and Moltaz G (1973): Ponderal losses in obese subjects submitted to restricted diets differing by nibbling and by lipid and carbohydrate. In: Energy balance in man, ed M Apfelbaum, pp. 305-310. Paris: Masson

2 Borz. WM, Wroldsen A, Issekutz B and Rodahl K (1966): Weight loss and frequency of feeding. New Engl J Med 274: 376-379

3 Finkelstein B and Fryer BA (1971): Meal frequency and weight reduction of young women. Am J Clin Nutr 24: 465-468

4 Young CM, Scanlan SS, Topping CM, Simko V and Lutwak L (1971): Frequency of feeding, weight reduction, and body composition. J Am Diet Assoc 59: 466-472

5 Dallosso HM, Murgatroyd PR and James WPT (1982): Feeding frequency and energy balance in adult males. Hum Nutr: Clin Nutr 36C: $25-39$

6 Wolfram G, Kirchgeßner M, Muller HL and Hollomey S (1987): Thermogenese des Menschen bei unterschiedlicher Mahlzeitenhaufigkeit. Ann Nutr Metab 31: 88-97

7 Verboeket-van de Venne WPIG and Westerterp KR (1991): Influence of the feeding frequency on nutrient utilization in man: Consequences for energy metabolism. Eur J Clin Nutr 45: 161-169

8 Tai MM, Castillo P and Pi-Sunyer FX (1991): Meal size and frequency: Effect on the thermic effect of food. Am J Clin Nutr 54: 783-787

9 Molnár D (1990): The effect of meal frequency on postprandial thermogenesis in obese children (absu.). Int J Obes 14 (Suppl. 2): 95

10 Belko AZ and Barbieri TF (1987): Effect of meal size and frequency on the thermic effect of food. Nutr Res 7: 237-242

11 Kinabo JLD and Durnin JVGA (1990): Effect of meal frequency on the thermic effect of forxl in women. Eur J Clin Nutr 44: 389-395

12 Swindells YE, Holmes SA and Robinson MF (1968): The metitbolic response of young women to changes in the frequency of meals. $\mathrm{Br} J$ Nutr 22: 667-680

13 Becel voedingsprogramma: Een professioneel programma voor de personal computer (versie NL03a) (1988). Rotterdan: Nederlandle Unilever Bedrijven B.V.

14 Weir JB de V (1949): New methods for calculating metabolic rate with special reference to predict protein metabolism. J Physiol 100: 1.9)

15 Schoffelen PFM, Saris WHM, Westernerp KR and Ten Hoor F (1984): Evaluation of an antomatic indirect calorimeter for measurement of energy balance in man. In: Human energy metabolism: Physical activity and energy expenditure measurements in epidemiological research based upen direct and indirect calorimetry, Euro Nut Report 5, ed AJH Van Es, pp. 51-54. Wageningen: The Netherlands Nutrition Foundation

16 Schutz Y, Bessard T and Jf́quier E (1984): Diet-induced thernnogenesis measured over a whole day in obese and nonobese women. Añ J Clin Nutr 40: 542-552

17 Goldberg GiR, Prentice AM, Davies HL and Murgatroyd PR. (1988): Overnight and basal metabolic rates in men and women. Eur J Clirr Nutr 42: 137-144 
18 Schoeller DA and Jones PJH (1987): Measurement of total body water by isotopic dilution: A unified approach to calibrations. In: In vivo body composition studies, eds $\mathrm{KJ}$ Ellis, S Yasumura and WD Morgan, pp. 131-136. London: Institute of Physical Sciences in Medicine

19 Kudlicka V, Fâbry P, Dobersky P and Kudlicková V (1966): Nibbling and meal eating in the treatment of human obesity. In: Proceedings of the VIIth International Congress of Nutrition, Vol II, ed J Kühnau, pp. 264-266. Hamburg: Pergamon Press

20 Schlundt DG, Hill JO, Sbrocco T, Pope-Cordle J and Sharp T (1992): The role of breakfast in the treatment of obesity: A randomized clinical trial. Am J Clin Nutr 55: 645651

21 Garrow JS, Durrant M, Blaza S, Wilkins D, Royston P and Sunkin S (1981): The effect of meal frequency and protein concentration on the composition of the weight lost by obese subjects. Br J Nutr 45: 5-15

22 Garrow JS (1974): Energy balance and obesity in man. 1st edn. Amsterdam: North Hílland Publishing Company

23 Albu S, Lichtman S, Heymsfield S, Wang J, Pierson RN and Pi-Sunyer FX (1989): Reassessment of body composition models in morbidly obese. FASEB I 3: A336

24 Deurenberg P, Leenen R, Van der Kooy K and Hautvast JGAJ (1989): In obese subjects the body fat percentage calculated with Siri's formula is an overestimation. Eur J Chin Nutr 43: 569-575

25 Bray GA (1969): Effect of caloric restriction on energy' expenditure in obese patients. Lancet 2: 397-399

26 Apfelbaum M, Bostsarron $J$ and Lacatis D (1971): Effect of caloric restriction and excessive caloric intake on energy expenditure. Am J Clin Nutr 24: 1405-1409

27 Garrow JS. Durrant ML, Manin S, Stalley SF and Warwick PM (1978): Factors deternining weight loss in obese patients in a metabolic ward. Int J Obes 2: 441-447

28 Garrow is (1981): Thennogenesis, and obesity in man. In: Recent advances in obesity research, Vol III, eds P Bjömtorp, M Cairella and AN Howard, pp. 208-213. London: Johin Libbey

29 Doré C, Hesp R, Wilkins D and Garrow JS (1982): Prediction of energy requirements of obese patients after massive weight loss. Hum Nutr: Clin Nutr 36C: $41-48$

30 Welle L, Amatruda JM, Forbes GB and Lockwood DH (1984): Resting metabolic rates of obese women after rapid weight loss. J Clin Endocrinol Metab 59: 41-44 



\title{
Chapter 5
}

\section{Habitual pattern of food intake in patients with liver disease}

W.P.H.G. Verboeket-van de Venne, K.R. Westerterp, B. van Hoek and G.R. Swart

Departments of Human Biology, University of Limburg, Maastricht, Gasiroenterology/Hepatology, University Hospital Maastricht and Internal Medicine II. University Hospital Rotterdam, The Netherlands

submitted for publication

\begin{abstract}
Patients with liver disease are frequently undernourished. We determined the habitual pattern of energy intake and intake of protein, fat, carbohydrate and alcohol in patients with liver disease. 20 Patients differing with respect to cause, duration and severity of liver disease reported their habitual food intake using a 7 day food record. Control subjects formed a representative sample of the Dutch population.

Results: In patients with liver disease, energy intake (EI) per kg body mass was significantly decreased compared to controls. Total fat intake was reduced in patients, whereas total carbohydrate intake was elevated. In the first four hours after rising, EI and protein intake were significantly increased in the patient group. During the late evening the contribution of carbohydrate to EI was higher in patients with liver disease than in control subjects. These findings are probably functional in order to minimize episodes of catabolism.
\end{abstract}

\section{Introduction}

Undernutrition and malnutrition are common among patients with liver disease (13). Undernutrition which can be defined as a state of inadequate energy intake is especially present in patients with end-stage cirrhosis of the liver, resulting in loss 


\section{Chapter 5}

of body weight. The lean body mass is one of the variables that indicates the severity of undernutrition: when carbohydrate and fat sources are inadequate in providing energy, muscle protein is used. Mills et al. (4) studying the nutritional status of patients with alcoholic liver disease of varying severity, reported a decreased lean body mass, although mean body weight was $108 \%$ of ideal body weight.

In malnutrition of patients with liver disease the accent lies on a deficient intake of protein. Swart et al. (5) reported that cirrhotic patients have elevated protein requirements, probably caused by small and inadequate liver glycogen stores, resulting in gluconeogenesis from amino acids and hence extra amino acid loss. On the other hand, protein-restricted diets are sometimes prescribed to cirrhotic patients to prevent or treat porto-systemic encephalopathy. By increasing the efficiency of nitrogen metabolism, it is not necessary to choose between protein requirement and protein tolerance. A study on the effect of the pattern of food intake on nitrogen balance in cirrhotic patients, revealed that a late evening meal improved the efficiency of nitrogen metabolism (6).

In the present study we investigated the habitual pattern of food intake in patients with liver disease. Our hypothesis was that energy intake might be increased during the early moming in patients with liver disease when compared to controls, to compensate a more catabolic state after an overnight fast in patients with liver disease, due to reduced liver glycogen stores. Furthermore, we studied the habitual intake of macronutrients, i.e. intake of protein, fat, carbohydrate and alcohol.

\section{Subjects and methods}

\section{Subjects}

Ten male and ten female patients with liver disease participated in the study. Their mean age was 51 (range 25-71) years. Mean body mass index was 25.4 (range $20.4-33.3) \mathrm{kg} / \mathrm{m}^{2}$. Further details are shown in Table 5.1. One patient (subject 10) was studied while staying in the hospital for treatment; the other subjects visited the out-patient clinic regularly and were studied at home. Subject 17 was on a sodium-restricted diet during the experiment; subject 20 on a protein-restricted diet $(60 \mathrm{~g}$ protein/day). The patients had not received any other dietary advice. Medication included azathioprine (subject 17), diuretics (subjects 9, 17 and 20), lactulose (subject 20), prednison (subjects 16, 17 and 18) and $\mathrm{Zn}$-acetate (subject 20). The research protocol was reviewed and approved by the local Ethical Committee. The procedures in the study were carefully explained to the patients before they gave their consent to participate. 
Table 5.1 Characteristics of the patients.

Abbreviations: AICAH, autoimmune chronic active hepatitis; Alc cirrh, alcoholic cirrhosis; Alc hep, alcoholic hepatitis; Alc SH, alcoholic steatohepatitis; BMI, body mass index; CAHB, chronic active hepatitis B; Crypt cirrh, cryptogenic cirnosis; HL, hyperlipidaemia; PBC, primary biliary cirmosis; PSC, primary sclerosing cholangitis; SH, steatohepatitis.

\begin{tabular}{ccccccc}
\hline Subject & Sex & $\begin{array}{c}\text { Age } \\
\text { (years) }\end{array}$ & $\begin{array}{c}\text { BMl } \\
\left(\mathrm{kg} / \mathrm{m}^{2}\right)\end{array}$ & Diagnosis & $\begin{array}{c}\text { Cirnosis } \\
\text { (yes/no) }\end{array}$ & $\begin{array}{c}\text { Chilt-Pugh } \\
\text { classification }\end{array}$ \\
\hline 1 & M & 50 & 26.6 & SH/HL & no & \\
2 & M & 40 & 33.3 & Aic SH & no & \\
3 & M & 49 & 27.8 & SH/HL & no & \\
4 & M & 56 & 27.8 & SH & no & \\
5 & M & 46 & 28.4 & Aic hep & no & \\
6 & M & 61 & 26.4 & CAHB & yes & A \\
7 & M & 38 & 23.1 & PSC & yes & A \\
8 & M & 49 & 26.9 & Alc cirm & yes & A \\
9 & M & 49 & 23.5 & PSC & yes & B \\
10 & M & 40 & 20.4 & Alc hep & yes & C \\
11 & F & 48 & 24.2 & PSC & no & \\
12 & F & 61 & 22.9 & AlCAH & yes & A \\
13 & F & 55 & 33.3 & Crypt cirsh & yes & A \\
14 & F & 47 & 22.3 & PBC & yes & A \\
15 & F & 55 & 22.4 & PBC & yes & A \\
16 & F & 70 & 21.1 & AICAH & yes & A \\
17 & F & 71 & 21.5 & AlCAH & yes & B \\
18 & F & 56 & 28.5 & PSC & yes & B \\
19 & F & 25 & 25.3 & AlCAH & yes & B \\
20 & F & 58 & 22.3 & Crypt cirrh & yes & B \\
\hline- & & & & & & \\
\hline
\end{tabular}

\section{Food record}

A 7-day food record was filled out by the subjects to determine their habitual dietary intake. During these seven consecutive days, subjects recorded their food intake in a diary that was divided in 7 periods a day (three meals, fotir inter-meal periods). Brand names were asked for as well as cooking recipes that were used. Energy and nutrient (protein, fat, carbohydrate and alcohol) consumption was calculated using the computerized Dutch food composition table (7).

\section{Analysis of data}

The results of the present study were compared with a dietary survey of a representative sample of the Dutch population within the age group of 22 till 74 


\section{Chapter 5}

years ( $\mathrm{n}=3961 ; 22-49$ years: $1296 \mathrm{M}, 1286 \mathrm{~F} ; 50-64$ years: $431 \mathrm{M}, 460 \mathrm{~F} ; 65-74$ years: $227 \mathrm{M}, 261 \mathrm{~F}$ ) (8). Mean body mass of the reference group was assumed to be $70 \mathrm{~kg}$ for men and $55 \mathrm{~kg}$ for women (9). Differences between patients with liver disease and control subjects were tested using unpaired t-tests with $p<0.05$ as level of significance. Diumal distribution of energy and macronutrient intake was studied by determining intake over 4 intervals, i.e. from 1 to 4 hours after rising in the morning (including breakfast and morning snack), from 5 to 8 hours after rising (including lunch and afternoon snack), from 9 to 12 hours after rising (dinner) and from 13 to 24 hours after rising (evening snack). In the text, tables and figures data are presented as the mean and standard error of the mean (SE).

\section{Results}

\section{Energy and macronutrient intake}

Table 5.2 presents mean energy and macronutrient intake for patients with liver disease and control subjects. Total EI (in kJ/d) was not significantly different between the two groups. However, when expressing EI per $\mathrm{kg}$ body mass, intake was significantly decreased in patients with liver disease (df 24, unpaired t-value: $2.74, \mathrm{p}<0.05$ ). The contribution of fat to EI was significantly decreased in patients compared to control subjects (df 24 , unpaired t-value: $2.70, \mathrm{p}<0.05$ ). Carbohydrate intake was significantly increased in the patient group (df 24 , unpaired tvalue: $2.77, \mathrm{p}<0.01)$.

Table 5.2 Habitual energy and macronutrient intake for patients with liver disease and control subjects. Intake of protein. fat, carbohydrate and alcohol is expressed as a percentage of total cnergy intake (mean $\pm \mathrm{SE}$ ).

Liver disease

$8047 \pm 597$
$70.9 \pm 2.8$
$113.7 \pm 7.8$

Energy intake per $\mathbf{k g}$ body mass $\left(\mathrm{kJ}^{\mathrm{kg}} \mathrm{kg}^{-1} \cdot \mathrm{d}^{-1}\right)$

protein intake (\%)

fat intake (\%)

carbohydrate intake (\%)

alcohol intake (\%)

$14.5 \pm 0.6$
$32.0 \pm 1.9$
$50.2 \pm 1.8$
$3.3 \pm 2.3$

$13.6 \pm 0.3$

$41.6 \pm 0.3$

$40.9 \pm 0.3$

$3.9 \pm 0.5$

Statistical significance vs, control subjects: ${ }^{*} \mathrm{p}<0.05,{ }^{* *} \mathrm{p}<0.01$. 


\section{Pattern of food intake}

Fig. 5.1 presents the diurnal distribution of El for patients and control subjects. Patients with liver disease showed an increased EI in the first four hours after rising, compared to control subjects (df 24, unpaired t-value: $2.49, \mathrm{p}<0.05$ ). During the following intervals, EI was lower in patients than in control subjects, but this result reached significance only when the three intervals were combined $(p<0.05)$. The contribution of protein, fat, carbohydrate and alcohol to total energy intake is shown in Fig. 5.2. During the first four hours after rising the contribution of protein to total energy intake was significantly increased in the patient group (df 24 , unpaired t-value: $2.58, \mathrm{p}<0.05)$. Fat intake was significantly decreased in patients with liver disease when compared to controls during the second interval (i.e. 5-8 hours after rising; df 24, unpaired t-value: $2.76, \mathrm{p}<0.05$ ) and third interval (i.e. 9-12 hours after rising; df 24 , unpaired $t$-value: $3.73, \mathrm{p}<0.001$ ). The contribution of carbohydrate to total energy intake was significantly increased in the patient group during the third interval ( $\mathrm{df} 24$, unpaired $t$-value: $3.64, \mathrm{p}<0.01$ ) and fourth interval (i.e. 13-24 hours after rising; df 22, unpaired t-value: 2.50 , $\mathrm{p}<0.05)$.

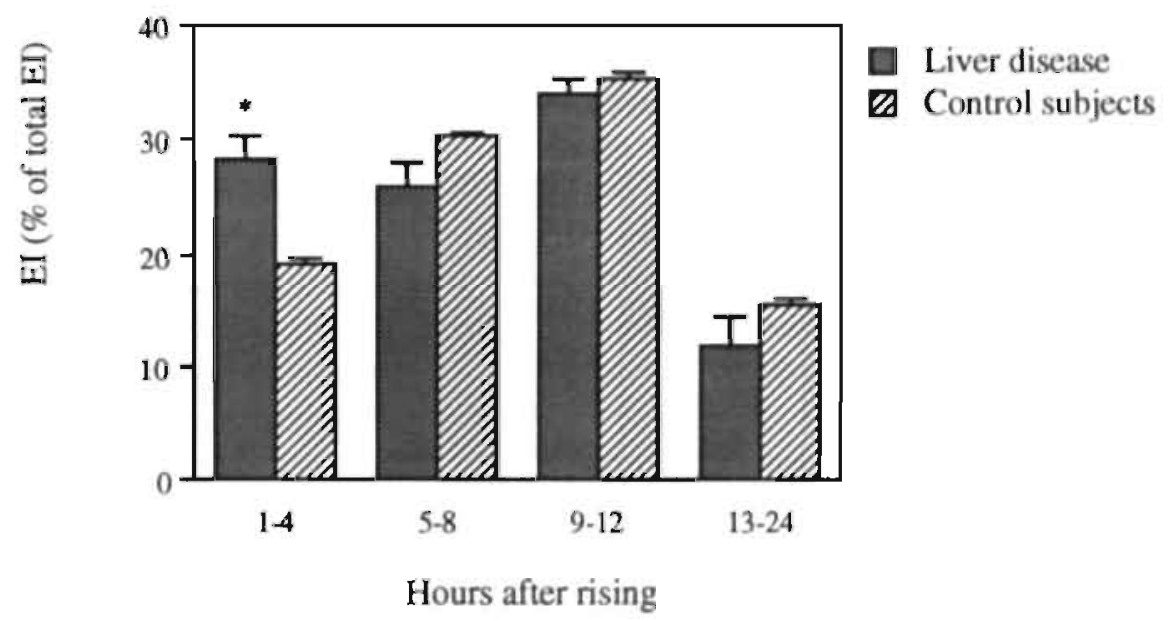

Fig. 5.1 Habitual pattern of energy intake (ED) for patients with liver disease and control subjects. Statistical significance vs. controls: " $\mathrm{p}<0.05$. 
Liver disease

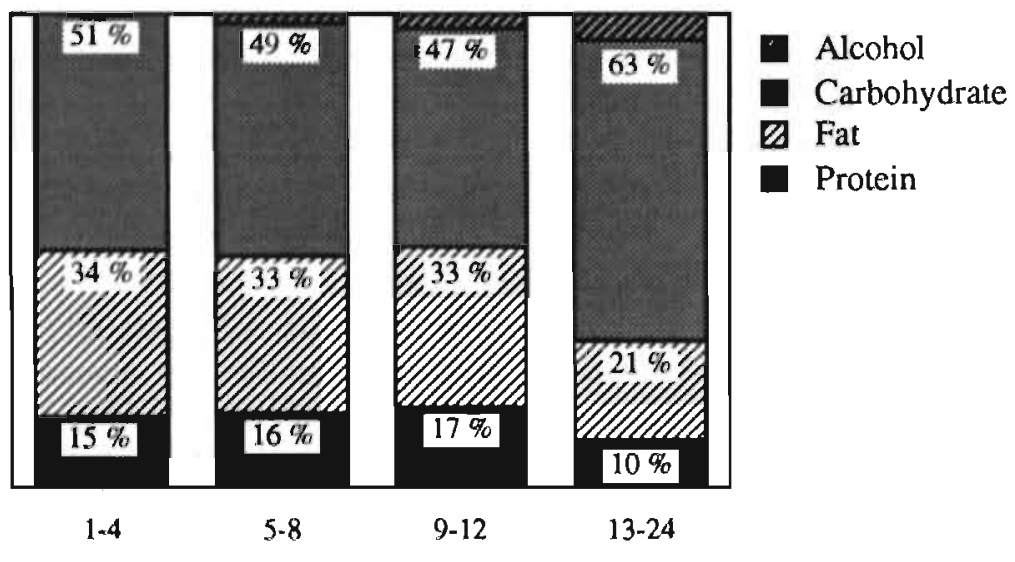

Hours after rising

Control subjects

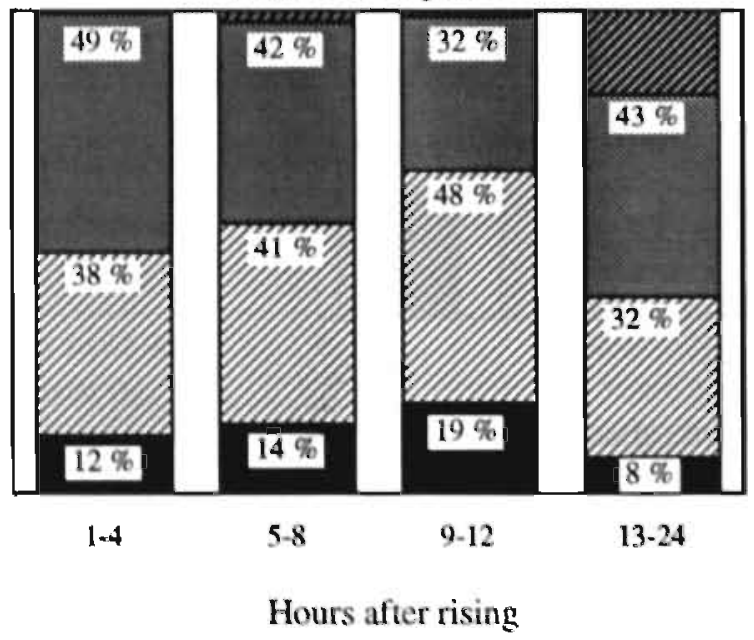

Fig. 5.2 Contribution of protein. fat, carbohydrate and alcohol (\% of total energy intake): over 4 intervals for patients with liver disease and control subjects. 


\section{Discussion}

One of the causes of undernutrition in patients with late stage cirrhosis or other types of liver disease is an insufficient food intake. This is especially common in patients with ascites, probably due to the abdominal tension and early feeling of satiety during eating (2). We investigated the habitual energy and macronutrient intake and the pattern of food intake in patients with liver disease. None of the patients had received a dietary advice that would have influenced the habitual eating behaviour, except for subject 17 (sodium-restricted diet) and 20 (proteinrestricted diet). Total EI per $\mathrm{kg}$ body mass was significantly decreased in patients with liver disease (Table 5.2). Because both body mass and body mass index of the patients were within the normal range, we conclude that patients with liver disease have a reduced energy intake. In patients with liver cirrhosis, incorporation of a late evening meal into the daily energy intake pattern was found to improve the efficiency of nitrogen metabolism, presumably by a delay of the onset of gluconeogenesis from amino acids at night (6). Referring to these findings, the habitual pattern of EI over the day in patients with liver disease was studied as well. During the first four hours after rising in the morning, El was significantly elevated in patients compared to controls (Fig. 5.1). Patients with liver disease probably have limited glycogen stores in the liver, resulting in a more rapid development of a catabolic state (10-11). To compensate for this catabolic state after an overnight fast, patients with liver disease would have higher actual energy needs in the morning, and indeed, they eat more.

Total fat intake was significantly decreased in patients with liver disease, whereas total carbohydrate intake was increased (Table 5.2). Nowadays, medical advice to consume a low-fat diet is not customary in liver disease, and patients in this study did not get such an advice. It is however possible that the patients themselves believe that a low-fat, high-carbohydrate diet has some beneficial effects on their disease, but this is only speculative. We did not check whether the patients had such attitude towards low-fat food items.

Analysis of the diumal distribution of macronutrient intake revealed that protein intake was increased in patients with liver disease during the first four hours after rising in the morning (Fig. 5.2). These findings are in accordance with results of Swart et al. (5), suggesting that patients with liver cirrhosis have elevated protein requirements because of an early onset of gluconeogenesis from amino acids after an overnight fast, due to limited glycogen storage in the liver of these patients. Another important finding was the observed increase in carbohydrate intake during the period from 13-24 hours after rising in patients with liver disease $(63 \pm 5 \%$ vs. $43 \pm 1 \%$ for controls; $p<0.05$ ). It is hypothesized that a high carbohydrate intake during the late evening in patients with liver disease would enhance glycogen restorage in the liver, thereby delaying an early onset of gluconeogenesis from amino acids that would occur because glucose cannot be provided in sufficient amounts. 
In conclusion, patienis with liver disease have a lower $24 \mathrm{~h} \mathrm{EI/kg}$ body mass, a reduced fat intake and a higher carbohydrate intake than healthy subjects. In the morning EI and the contribution of protein to EI is increased in the patient group. During the late evening carbohydrate intake is increased in patients with liver disease when compared to control subjects. These findings are probably functional in order to minimize episodes of catabolism.

\section{References}

1 O'Keefe SJ, El-Zayadi AR, Carraher TE, Davis M and Williams R (1980): Malnuorition and immuno-incompetence in patients with liver disease. Lancet 20: 615-617

2 Johnson RD and Williams R (1985): Nutritional support in alcoholic liver disease. Acta Med Scand, Suppl. 703: 209-218

3 McIntyre $N$ (1987): Undernutrition and malnutrition in cirrhosis. In: Cirrhosis of liver: Methods and fields of research, eds $N$ Tygstrup and F Orlandi, pp. 225-234. Elsevier Science Publishers B.V. (Biomedical Division)

4 Mills PR, Shenkin A, Anthony RS et al. (1983): Assessment of nutritional status and in vivo immune responses in alcoholic liver disease. Am J Clin Nutr 38: 849-859

5 Swart GR, Van den Berg JWO, Wattimena JLD, Rietveld T, Van Vuure JK and Frenkel M (1988): Elevated protein requirements in cirhosis of the liver investigated by whole body protein turnover studies. Clin Sci 75: 101-107

6 Swan GR, Zillikens MC, Van Vuure JK and Van den Berg IWO (1989): Effect of a late evening meal on nitrogen balance in patients with cirrhosis of the liver. Br Med J 299: 1202-1203

7 Becel voedingsprogranma: Een professioneel programma voor de personal computer (versie NL03a) (1988). Rotterdam: Nederlandse Unilever Bedrijven B.V.

8 Ministerie van Welzijn, Volksgezondheid en Cultuur en het ministerie van Landbouw en Visserij (1988): Wat eet Nederland: Resultaten van de voedselconsumptiepeiling 1987 1988

9 Committee on dietary allowances, Fond and Nutrition Board (1980): Recommended dietary allowances. 9th edn., National Academy of Sciences, Washington DC

10 Owen OE, Reichle FA, Mozzoli MA, Kreulen T, Patel MS, Elfentein IB, Golsorkhi M. Chang KHJ, Rac NS, Sue HS and Boden G (1981): Hepatic, gut, and renal substrate flux rates in patiens with hepatic cirhosis. I Clin Invest 68: 240-252

11 Owen OE, Trapp VE, Reichard GA, Mozzoli MA, Moctezuma J, Paul P, Skutches CL and. Boden Gi (1983): Nature and quantity of fuels consumed in patients with alcoholic cirrhosis. J Clin Invest 72: 1821-1832 


\title{
Chapter 6
}

\section{Energy expenditure and substrate metabolism in patients with cirrhosis of the liver: Effects of the pattern of food intake}

W.P.H.G. Verboeket-van de Venne, K.R. Westerterp, B. van Hoek and G.R. Swart

Departments of Human Biology, University of Limburg, Maastricht, Gastroenterology/Hepatology. University Hospital Maastricht and Interna! Medicine II, University Hospital Rotterdam, The Netherlands

submitted for publication

\begin{abstract}
Patients with liver cirhosis are frequently undernourished. In healthy subjects, the pattern of food intake is one of the variables that can influence energy balance and substrate metabolism. We determined the short-term ( 2 d) effect of the pattern of food intake in patients with liver cirrhosis as compared to controls. In a respiration chamber 8 patients with cirrhosis of the liver and 23 controls were fed to estimated energy balance in 2 meals daily ('gorging pattern') and 4-7 meals daily ('nibbling pattern').

$24 \mathrm{~h}$ Energy expenditure expressed as a multiple of the sleeping metabolic rate (SMR) was decreased in patients with cirrhosis $(1.31 \pm 0.03$ vs. $1.44 \pm 0.02$ for controls: $\mathrm{p}<0.01$ ), due to an increased SMR per $\mathrm{kg}$ fat-free mass in patients with cirrhosis. In both patients with cirrhosis and controls, the respiratory quotient (RQ) was significantly lower during the morning preprandial period on the gorging pattern $(9.00 \mathrm{~h}-12.00 \mathrm{~h})$, reflecting a higher oxidation ratio of fat to carbohydrate compatible to a more catabolic state.

Especially for patients with cirrhosis of the liver, a nibbling pattern of food intake including a good breakfast and a late evening meal would be preferable, in order to have shorter episodes of catabolism during the day.
\end{abstract}




\section{Introduction}

Assessment of energy expenditure and substrate metabolism in patients with cirrhosis of the liver is important to elucidatc the combination of processes leading to malnutrition in patients with cirrhosis. Information on energy expenditure measurements in patients with cirrhusis has been inconsistent. Some studies reported an increased resting metabolic rate (RMR) in cirrhotic patients (1-4), while others described a normal (5-6) or decreased RMR $(1,7)$. Part of this variation can be due to the diversity of methods applied for measuring and calculating energy expenditure. Owen et al. (5) reported that after an overnight fast the energy requirements of patients with alcoholic cirrhosis were normal, but the nature of fuels oxidized was more similar to that in healthy controls after 2-3 days of total starvation, i.e. a relatively high contribution of fat to energy metabolism.

The pattern of food intake is often cited as one of the variables that can influence energy balance and substrate metabolism. When the daily energy intake is consumed in a small number of large meals ('gorging pattem') relatively more energy has to be stored compared to a feeding pattern with a large number of small meals ('nibbling pattern'). A gorging pattern has been shown to enhance lipogenesis (8-9), to increase body weight (10), to increase blood serum cholesterol level (11-12) and to reduce glucose tolerance (12-14). In a previous study, in which we investigated the short term (2 d) effect of feeding frequency on nutrient utilization in healthy young subjects, we observed a stronger diurnal periodicity of lipogenesis and lipolysis on a gorging pattern than on a nibbling pattern of food intake (15). In patients with cirrhosis of the liver, a late evening meal seemed to improve the efficiency of nitrogen metabolism (16).

The present study was conducted to assess $24 \mathrm{~h}$ energy expenditure and sleeping metabolic rate of patients with liver circhosis, comparing the results with healthy adult controls. A second aim was to determine whether there is an effect of the pattern of food intake on the oxidation rate of protein, fat and carbohydrate in cirrhotic patients. The results of substrate metabolism were partially compared with a similar study on healthy young adults.

\section{Subjects and methods}

\section{Subjects}

Eight patients with a biopsy-proven cirrhosis of the liver were studied. All were in a stable clinical condition at the time of the study. Their median age was 53 (range 39-62) years, their median body mass index was 23.7 (range 20.6-27.7) $\mathrm{kg} / \mathrm{m}^{2}$. Further details are shown in Table 6.1. The median age of the healthy adult controls (10 M) was 41 (range 25-61) years and their median body mass index was 24.7 (range $20.7-30.4) \mathrm{kg} / \mathrm{m}^{2}$ (17). The healthy young adults (2 M, $11 \mathrm{~F}$ ) had a median age of 20 (range 18-23) years and a median body mass index of 20.6 
(range 18.4-26.1) kg/m² (15). The research protocol was reviewed and approved by the local Ethical Committee. The procedures to be used in the study were carefully explained to the subjects before they gave their written consent to participate.

Table 6.1 Characteristics of the patients.

Abbreviations: Alc, alcoholic cirrhosis; BMI, body mass index; Crypt, cryptogenic cirrhosis: PSC, primary sclerosing cholangitis; AICAH, autoimmune chronic active hepatitis with cirrhosis; PBC, primary biliary cirrhosis.

\begin{tabular}{cccccc}
\hline $\begin{array}{c}\text { Case } \\
\text { no. }\end{array}$ & Sex & $\begin{array}{c}\text { Age } \\
(\mathrm{yr})\end{array}$ & $\begin{array}{c}\text { BMI } \\
\left(\mathrm{kg} / \mathrm{m}^{2}\right)\end{array}$ & Diagnosis. & $\begin{array}{c}\text { Child-Pugh } \\
\text { classification }\end{array}$ \\
\hline 1 & M & 46 & 20.6 & Alc & B \\
2 & M & 49 & 26.8 & Alc & $\wedge$ \\
3 & M & 39 & 23.1 & PSC & A \\
4 & M & 49 & 24.4 & PSC & B \\
5 & F & 56 & 27.7 & PSC & B \\
6 & F & 61 & 23.2 & AlCAII & A \\
7 & F & 62 & 24.2 & PBC & B \\
8 & F & 58 & 22.0 & Crypt & B \\
\hline
\end{tabular}

\section{Experimental design}

The experiment consisted of two periods of two consecutive days. During one episode of 2 days patients consumed two meals ('gorging pattern') and during the other episode of 2 days they had four meals ('nibbling pattern'). The order of administration of the gorging and nibbling pattern was randomized. Subject 4 was studied only during the nibbling pattern, subject 8 only during the gorging pattern. The interval between the two experimental periods was at least 5 days. On the first day of each period the patients came to the University of Limburg in Maastricht to stay in a respiration chamber for \pm 44 hours. Oxygen consumption, carbon dioxide production, and hence respiratory quotient (RQ) and energy expenditure (EE) were the main measurements (see below). Urine samples were collected to deternnine nitrogen excretion and hence calculate the non-protein respiratory quotient (NPRQ) and substrate oxidation. Patients were fed to an estimated energy balance assuming $24 \mathrm{~h}$ EE to be $1.38 \times$ basal metabolic rate (BMR). BMR of the patients was calculated according to the equations of Harris \& Benedict (18), based on sex, age, height and weight of the patients. 


\section{Eating patterns}

The two eating patterns were characterized by a minimal or maximal spruading of the energy intake (EI) throughout the day. The gorging pattern consisted of two large meals: a lunch at $12.00 \mathrm{~h}$ containing 50 per cent of the daily EI and a dinner at $18.00 \mathrm{~h}$ containing the remaining 50 per cent. The nibbling pattern consisted of four smaller meals: a breakfast at $7.30 \mathrm{~h}(20$ energy $\%)$, a lunch at $12.00 \mathrm{~h}(30$ energy \%), a dinner at $18.00 \mathrm{~h}(30$ energy \%) and an evening snack at $22.30 \mathrm{~h} \mathrm{(20}$ energy \%). The patients were instructed to consume all food items and to return any left overs. The total daily EI was the same for the two feeding patterns with the same menu and macronutrient composition. The food provided 12 energy per cent protein, 38 energy per cent fat and 50 energy per cent carbohydrate. The value of the food quotient (FQ) as defined by Flatt (19) was 0.86.

\section{Procedures}

Body mass and body composition

Patients weighed theirselves (without clothing) in the morning of day 2 and 3 upon rising, after voiding and before any food/drink consumption, on a digital balance (Seca delta, model 707) accurate to $0.1 \mathrm{~kg}$. Body composition was measured by deuterium dilution on the first evening of the stay in the respiration chamber. Before going to bed at night on day 1 between $22.30 \mathrm{~h}$ and $23.00 \mathrm{~h}$, a ${ }^{2} \mathrm{H}_{2} \mathrm{O}$ dilution was drunk after emptying the bladder (baseline urine sample). The dosage calculation was based on body mass (BM) in order to create a ${ }^{2} \mathrm{H}$ excess of 100 ppm. A second urine sample was collected by the patients on day 2 in the moming after the first voiding between $8.00 \mathrm{~h}$ and $10.00 \mathrm{~h}$. Isotope abundances in the urine samples were measured with an isotope ratio mass spectrometer (VG Isogas, Aqua Sira). Total body water (TBW) was calculated as the measured deuterium dilution space divided by 1.04 (20). Fat-free mass (FFM) was calculated as TBW/0.73; fat mass (FM) was calculated as BM minus FFM.

\section{Urinary nitrogen excretion}

Urine was collected in six portions: from $18.00 \mathrm{~h}-23.00 \mathrm{~h}$ on day 1 , from $23.00 \mathrm{~h}$ on day 1 to $7.00 \mathrm{~h}$ on day 2 , from $7.00 \mathrm{~h}-12.00 \mathrm{~h}$ on day 2 , from $12.00 \mathrm{~h}-18.00 \mathrm{~h}$ on day 2 , from $18.00 \mathrm{~h}-23.00 \mathrm{~h}$ on day 2 and from $23.00 \mathrm{~h}$ on day 2 to $7.00 \mathrm{~h}$ on day 3. Samples were collected in containers; with $2 \mathrm{ml} \mathrm{H}_{2} \mathrm{SO}_{4}$ to prevent nitrogen loss through evaporation; volume and nitrogen concentration were measured subsequently, the latter using a Heraeus analyser (type CHN-O-Rapid).

\section{Respiration chamber measurements}

Oxygen consumption and carbon dioxide production were measured in a respiration chamber (21). This chamber measures $14 \mathrm{~m}^{3}$ and is furnished with a bed, chair, table. TV, radio, telephone, wash-bowl and toilet facilities. The chamber is ventilated with fresh air at $50 \mathrm{~V} / \mathrm{min}$. The ventilation rate was measured with a dry gasmeter (Schlumberger, type G6). The concentration of oxygen and 
carbon dioxide was measured using a paramagnetic $\mathrm{O}_{2}$ analyser (Servomex, type OA 184) and an infrared $\mathrm{CO}_{2}$ analyser (Hartman \& Braun, type URAS 3G). Ingoing air was analysed once every $15 \mathrm{~min}$ and outgoing air once every $5 \mathrm{~min}$. The gas sample to be measured was selected by a computer (21) which also stored and processed the data. Respiratory quotient (RQ) and energy expenditure (EE) were calculated from $\mathrm{O}_{2}$ consumption and $\mathrm{CO}_{2}$ production (22). Subjects went to bed at $23.00 \mathrm{~h}$, and rose at $7.00 \mathrm{~h}$. During daytime subjects were allowed to move freely, to sit, lie down, telephone, listen to the radio and watch television, only sleeping and strenuous exercise were not allowed.

\section{Analysis of data}

$24 \mathrm{~h} \mathrm{EE}$ and $\mathrm{RQ}$ were calculated from 7.00h to 7.00h. Energy balance was determined by subtracting $24 \mathrm{~h}$ EE from EI. The sleeping metabolic rate (SMR) was measured from $3.00 \mathrm{~h}$ to $6.00 \mathrm{~h}$, when subjects were asleep. To describe the effect of feeding frequency on substrate oxidation, RQ was calculated over $3 \mathrm{~h}$ intervals throughout the day. Urinary nitrogen excretion was determined for the same intervals, taking into account the different collecting periods. Protein, fat and carbohydrate oxidation were calculated according to Jéquier et al. (23). The effects of feeding frequency on the diurnal pattern of RQ, NPRQ and substrate oxidation were analysed by repeated measures analysis of variance (ANOVA) and Scheffé F-tests. Differences between gorging and nibbling pattern were tested using unpaired t-tesis. In the text, tables and figures data are presented as the mean and standard error of the mean (SE).

\section{Results}

\section{Energy balance}

In patients with cirrhosis of the liver the energy balance was negative on both the gorging and the nibbling pattern. For the gorging pattern EI-EE was $-589 \pm 498$ $\mathrm{kJ} / \mathrm{d}$, for the nibbling pattern $-391 \pm 467 \mathrm{~kJ} / \mathrm{d}$. There was no significant effect of feeding frequency on the level of energy balance.

\section{Body mass and body composition}

During the stay in the respiration chamber BM of the cirrhotic patients decreased $0.2 \pm 0.1 \mathrm{~kg}$ on the gorging pattern (df 6, paired t-value: $1.55, \mathrm{p}>0.1$ ) and $0.3 \pm$ $0.1 \mathrm{~kg}$ on the nibbling pattern ( $\mathrm{df} 6$, paired t-value: $4.20, p<0.01$ ). There was no effect of feeding frequency on loss of BM. FFM was significantly lower in women $(49.1 \pm 2.4 \mathrm{~kg}$ ) compared to men $(60.5 \pm 1.2 \mathrm{~kg}$ ) (df 6 , unpaired $\mathrm{t}$-value: 4.22, p $<0.01$ ). FM and percentage body fat ( $\%$ fat) were not significantly different between women (FM: $17.3 \pm 3.6 \mathrm{~kg}$; \% fat: $25.6 \pm 4.1$ ) and men (FM: $13.6 \pm 2.9$ $\mathrm{kg}$; \% fat: $17.9 \pm 3.1)$. 


\section{Energy expenditure}

$24 \mathrm{~h}$ EE in the cirrhotic patients was not significantly different between the gorging $(9191 \pm 605 \mathrm{~kJ} / \mathrm{d})$ and the nibbling pattern $(9146 \pm 580 \mathrm{~kJ} / \mathrm{d})$. There was no effect of the pattern of food intake on SMR, when SMR was expressed in absolute values (gorging pattern: $6817 \pm 460 \mathrm{~kJ} / \mathrm{d}$; nibbling pattern: $7136 \pm 433 \mathrm{~kJ} / \mathrm{d}$ ) or when SMR was expressed as a percentage of $24 \mathrm{~h}$ EE (gorging pattern: $74.2 \pm 1.2$ $\%$; nibbling pattern: $78.2 \pm 2.0 \%$ ). Comparison of energy metabolism between patients with liver cirrhosis and healthy adult controls revealed that $24 \mathrm{~h} \mathrm{EE}$ and SMR (both in absolute values) were not significantly different (Table 6.2). However, when expressing $24 \mathrm{~h} \mathrm{EE}$ as a multiple of SMR, reflecting the level of physical activity in the respiration chamber, $24 \mathrm{~h}$ EE/SMR was significantly decreased for patients with liver cirrhosis (df 16, unpaired t-value: $3.79, p<0.01$ ). SMR per $\mathrm{kg} \mathrm{BM}$ or FFM was significantly increased in patients compared to healthy adult controls (SMR/BM: df 16, unpaired t-value: $2.24, p<0.05$; SMR/FFM: df 16 , unpaired t-value: $3.23, \mathrm{p}<0.01)$. BM and FFM were not significantly different between patients (BM: $70.4 \pm 3.0 \mathrm{~kg}$; FFM: $54.8 \pm 2.5 \mathrm{~kg}$ ) and adult controls (BM: $76.8 \pm 3.9 \mathrm{~kg}$; FFM: $58.2 \pm 1.3 \mathrm{~kg}$ ).

Table 6.2 Energy metabolism in patients with liver cirrhosis $(n=8)$ and healthy adult subjects $(\mathrm{n}=10)$. Data are expressed as mean $\pm \mathrm{SE}$.

Abbreviations: 24 h EE, 24 h energy expenditure; SMR, sieeping metabolic rate; SMR/BM, sleeping metabolic rate per $\mathrm{kg}$ body mass; SMR/FFM, sleeping metabolic rate per $\mathrm{kg}$ fat-free mass:

\begin{tabular}{|c|c|c|}
\hline & Liver cirrhosis & Healthy adults \\
\hline $2+\mathrm{hEE}(\mathrm{kJ} / \mathrm{d})$ & $9105 \pm 519$ & $9365 \pm 210$ \\
\hline $\operatorname{SMR}(\mathrm{kJ} / \mathrm{d})$ & $6971 \pm 418$ & $6528 \pm 147$ \\
\hline $24 \mathrm{~h} \mathrm{EE/SMR}$ & $1.31 \pm 0.03^{* *}$ & $1.44 \pm 0.02$ \\
\hline SMR/BM $\left(\mathrm{kJ}^{\mathrm{k}} \cdot \mathrm{kg}^{-1} \cdot \mathrm{d}^{-1}\right)$ & $99.2 \pm 4.9^{*}$ & $86.4 \pm 3.3$ \\
\hline SMR/FTM $\left(\mathrm{kJ}^{\mathrm{kg}} \mathrm{kg}^{-1} \cdot \mathrm{d}^{-1}\right)$ & $127.1 \pm 4.5^{* *}$ & $112.3 \pm 2.0$ \\
\hline
\end{tabular}

Statistical significance vs. healthy adults: * p<0.05, ** p<0.01.

\section{$R Q$ and NPRQ}

In patients with cirrhosis of the liver $24 \mathrm{~h} R Q$ was not significantly different between the gorging $(0.84 \pm 0.01)$ and the nibbling pattern $(0.84 \pm 0.01)$. For both the gorging and nibbling pattern, RQ was lower than the FQ $(=0.86)$, indicating mobilization of energy from body fat stores. Figure 6.1 A presents the diurnal pattern of $\mathrm{RQ}$ for patients with liver cirrhosis from the night preceding the 
second experimental day to the early morning of the third day. There was a considerable fluctuation in RQ when eating according to the gorging pattern. From $9.00 \mathrm{~h}-12.00 \mathrm{~h}$ on the gorging pattern RQ was significantly lower than on the nibbling pattern (with breakfast at $7.30 \mathrm{~h}$ ), reflecting a higher oxidation ratio of fat to carbohydrate during this period of the day.
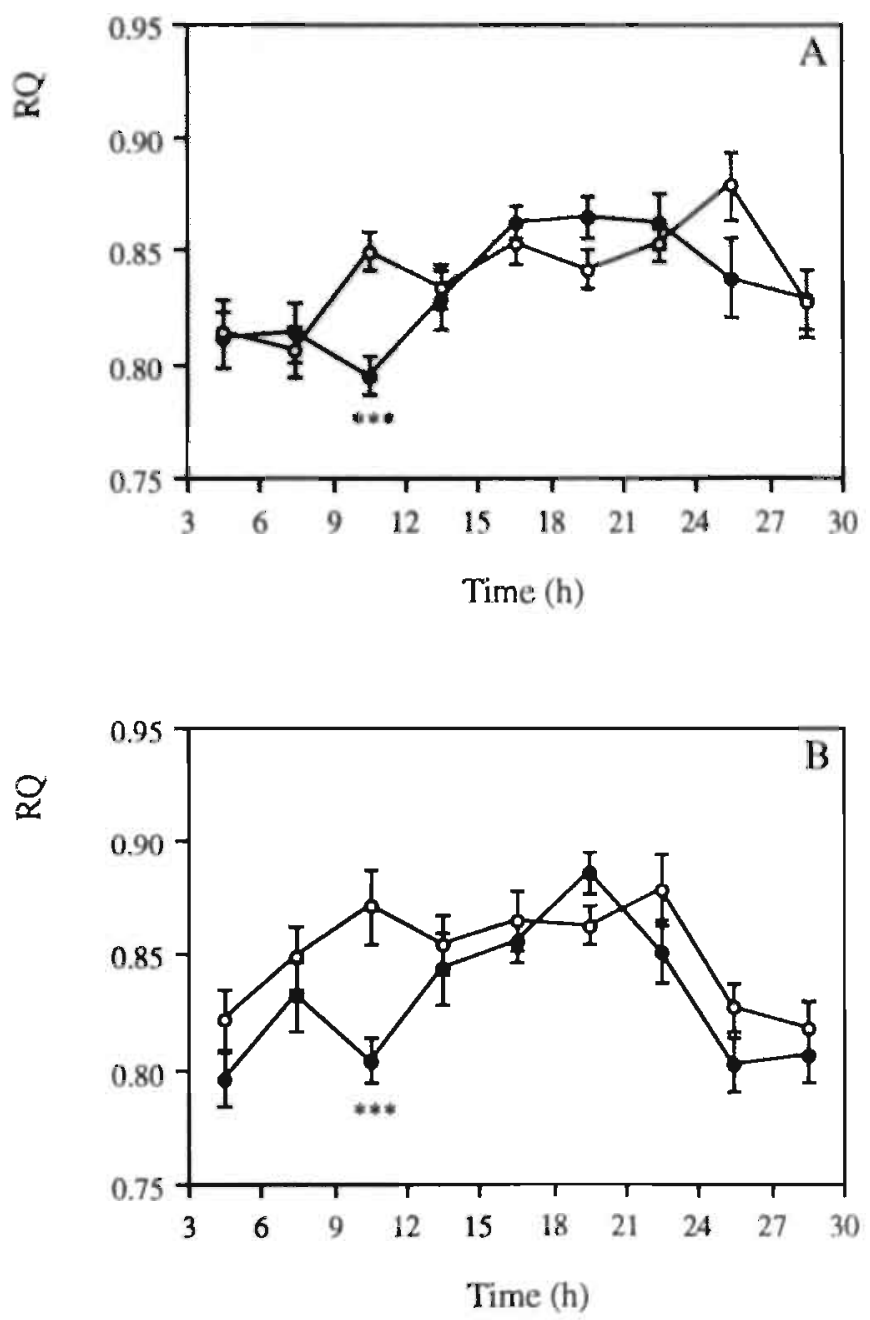

Fig, 6.1 Fluctuation of the respiratory quotient (RQ) over $3 \mathrm{~h}$ intervals, from $3.00 \mathrm{~h}-6.00 \mathrm{~h}$ on day 2 (3-6) to $3.00 \mathrm{~h}-6.00 \mathrm{~h}$ on day $3 .(27-30)$, for both gorging (closed circles) and nibbling (open circles) pattern. Pan A: patients with cirrhosis of the liver $(n=7)$; part $B$; healthy control subjects ( $\mathrm{n}=13)$. Statistical significance gorging vs, nibbling pattern: *** $\mathrm{p}<0.001$. 
Figure 6.1B presents the influence of feeding frequency on the diumal pattem of $R Q$ for healthy young adults. The fluctuation in $R Q$ for cirrhotic patients resembles the pattern for control subjects over most of the $24 \mathrm{~h}$ cycle. However, in patients with liver cirrhosis we failed to observe a spontaneous tendency to an increased $\mathrm{RQ}$ at the time of rising in the moming (i.e. interval 6.00h-9.00h) as described for the controls. Furthermore, we found that the RQ during the night is very similar on both feeding patterns for cirrhotic patients, despite the fact that the last meal of the nibbling pattern is 4.5 hours later than the last meal of the gorging pattern. The effect of feeding frequency on the diumal fluctuation in NPRQ in cirrhotic patients is presented in Figure 6.2.

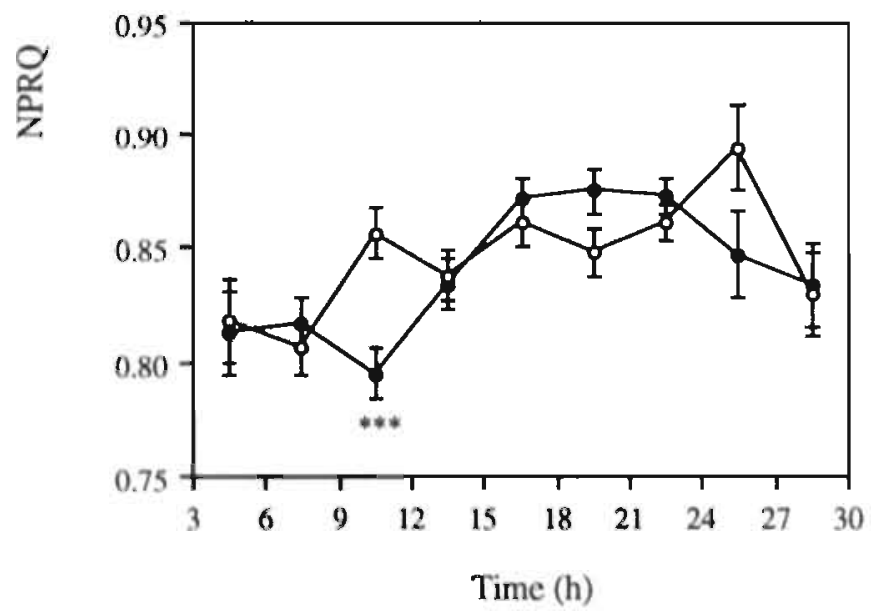

Fig. 6.2 Filuctuation of the non-protein respiratory quotient (NPRQ) over $3 \mathrm{~h}$ intervals, from $3.00 \mathrm{~h}-6.00 \mathrm{~h}$ on day 2 (3.6) to $3.00 \mathrm{~h}-6.00 \mathrm{~h}$ on day 3 (27-30), for patients with liver cirrhosis on the gorging (closed circles) and nibbiing (open circles) pattern $(n=7)$. Statistical significance gorging vs. nibbling pattern: *** $\quad \mathrm{p}<0.001$.

\section{Substrate metabolism}

Table 6.3 presents $24 \mathrm{~h}$ intake, oxidation and balance of protein, fat and carbohydrate. There were no significant differences between the gorging and nibbling pattern with respect to oxidation or balance of one of the substrates. Carbohydrate balance was significantly different from zero (df 6 , paired t-value: 4.77, $\mathrm{p}<0.01$ ) for subjects on the gorging pattern. The diurnal variation in substrate oxidation in cirrhotic patients is presented in Figure 6.3. Oxidation of protein, fat and carbohydrate is calculated over $6 \mathrm{~h}$ intervals and expressed as a 
percentage of total EE during the interval. From $6.00 \mathrm{~h}-12.00 \mathrm{~h}$ the contribution of carbohydrate to total EE was significantly lower on the gorging pattern $(31 \pm 3 \%$ vs. $40 \pm 3 \%$ on the nibbling pattern; df 12 , unpaired t-value: $2.19, p<0.05$ ). During the other time intervals no significant effect of the pattern of food intake on substrate oxidation was observed.

On the nibbling pattern the contribution of protein, fat and carbohydrate to total EE was fairly constant throughout the day. From $6.00 \mathrm{~h}-12.00 \mathrm{~h}$ we observed a significantly higher fat oxidation compared to nocturnal values $(50 \pm 2 \%$ vs. 39 $\pm 4 \%$; F-value: $5.28, \mathrm{p}<0.01$ ), despite the fact that subjects consumed a breakfast at $7.30 \mathrm{~h}$. On the gorging pattern however, there was a marked fluctuation in the nature of substrate being oxidized. Here, during the preprandial period (i.e. from. $6.00 \mathrm{~h}-12.00 \mathrm{~h})$ energy was mostly' derived from fac oxidation $(58 \pm 4 \%)$, and throughout the day less fat and more carbohydrate was being oxidized $(6.00 \mathrm{~h}$ $12.00 \mathrm{~h}$ vs. $12.00 \mathrm{~h}-18.00 \mathrm{~h}$ : F-value: 5.86 , p $<0.01 ; 6.00 \mathrm{~h}-12.00 \mathrm{~h}$ vs. $18.00 \mathrm{~h}-$ 24.00h: F-value: $13.27, \mathrm{p}<0.001)$. During the night the contribution of protein to total EE is becoming more important in the gorging pattern $(24.00 \mathrm{~h}-6.00 \mathrm{~h}$ vs. 6.00h-12.00h: F-value: 3.83 , p<0.05; 24.00h-6.00h vs. 12.00h-18.00h: F-value: $5.19, \mathrm{p}<0.01$ ); oxidation of fat and carbohydrate is increasing and decreasing: respectively, to reach preprandial values. Comparison of substrate oxidation values between patients with cirrhosis and healthy controls was not justified, because the patients with cirrhosis consumed relatively less protiein and more carbohydrate than the controls.

Table 6.3 Mean intake, oxidation and balance (=intake-oxidation) of protein, fat and cartolyydrate over $24 \mathrm{~h}$ on the gorging and nibbling pattern. Data are expressed in g/d.

\begin{tabular}{lrr}
\hline & Gorging pattern & Nibbling pattern \\
\hline Protein intake & $59.8 \pm 3.5$ & $61.1 \pm 3.2$ \\
Protein oxidation & $58.9 \pm 5.2$ & $60.4 \pm 5.5$ \\
Protein balance & $+0.9 \pm 2.8$ & $+0.7 \pm 2.9$ \\
& & \\
Fat intake & $81.6 \pm 4.7$ & $83.1 \pm 4.3$ \\
Fat oxidation & $107.0 \pm 13.0$ & $-18.3 \pm 10.8$ \\
Fat balance & $25.4 \pm 13.2$ & \\
& & $246.1 \pm 11.7$ \\
Carbohydrate intake & $242.1 \pm 12.8$ & $228.6 \pm 14.0$ \\
Carbohydrate oxidation & $219.9 \pm 12.8$ & $+17.5 \pm 16.7$ \\
Carbohydrate balance & $+22.2 \pm 4.6^{* *}$ & \\
\hline
\end{tabular}

$*$ Significantly different from zero $(p<0.01)$. 
Chapter 6
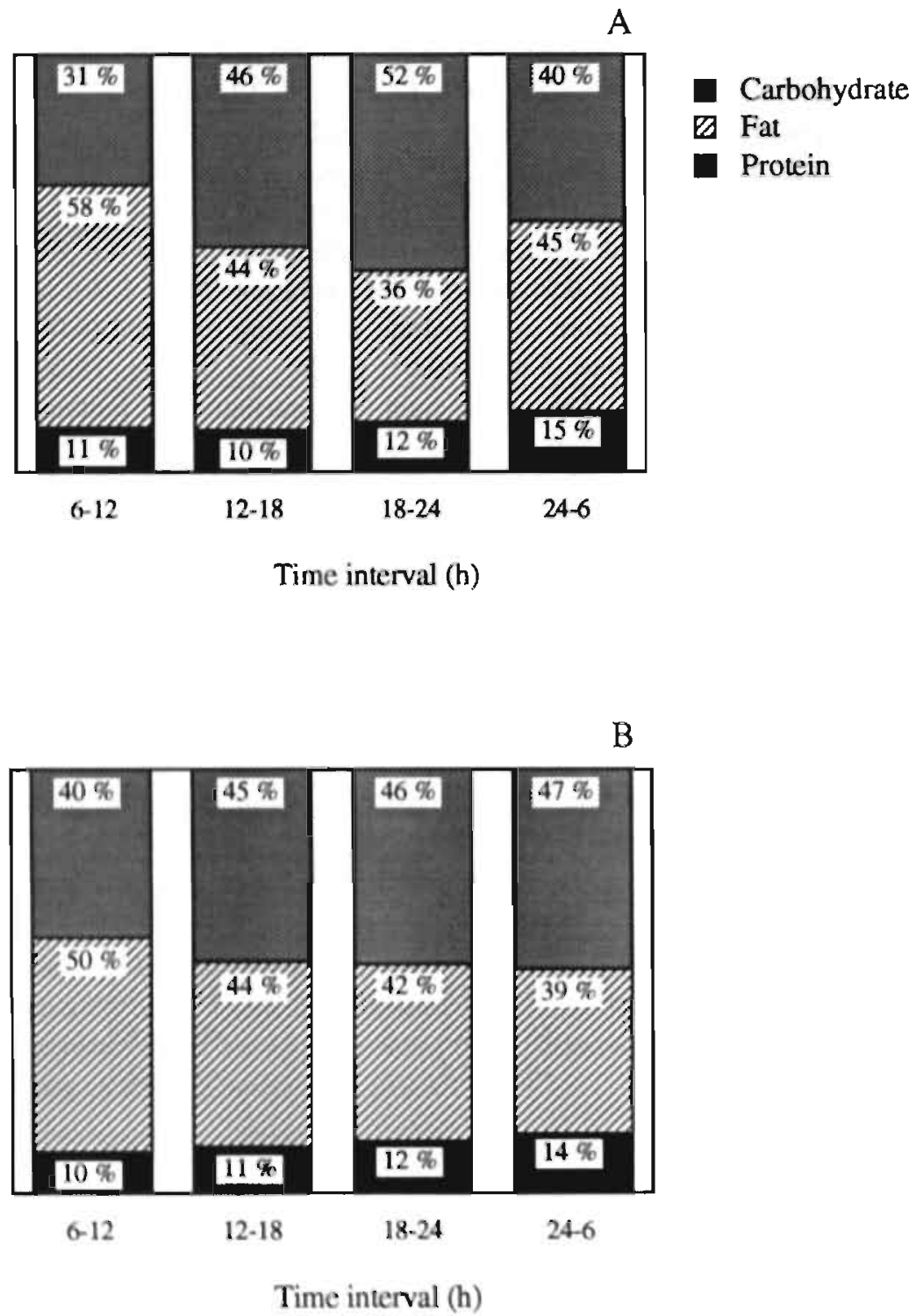

Fig. 6.3 Contribution of protein, fat and carbohydrate oxidation (\% of energy expenditure) over $6 \mathrm{~b}$ intervals for patients with liver cirrhosis on a gorging (A) and nibbling (B) pattern $(\mathrm{n}=7)$. 


\section{Discussion}

One of the aims of this study was to investigate whether energy metabolism in patients with liver cirrhosis is different from healthy controls. Conflicting data are available concerning resting energy expenditure in patients with cirrhosis. Focusing on measurements of the RMR in patients with cirrhosis as compared to healthy controls, no difference in RMR was observed by several investigators when RMR was expressed in absolute values, as a function of total body surface area or per $\mathrm{kg} \mathrm{BM} \mathrm{(2-7).} \mathrm{Relating} \mathrm{RMR} \mathrm{to} \mathrm{urinary} \mathrm{creatinine} \mathrm{excretion} \mathrm{as} \mathrm{an}$ estimate of lean body mass, RMR was increased in cirrhotic patients compared to controls (2-4). RMR per kg FFM was found to be not different between cirrhotic patients and controls in one study where FFM was assessed by skinfold thickness (7); others found RMR/kg FFM to be significantly higher in patients with cirrhosis when assessing FFM by bioelectrical impedance (4).

In the present study we observed a significantly increased SMR per $\mathrm{kg} \mathrm{BM}$ or FFM in patients with cirrhosis (Table 6.2). Because $24 \mathrm{~h}$ EE was similar in patients and controls, this implicates that energy expenditure during the active hours of the day was decreased. This could either be due to a diminished level of physical activity of the patients or it could be due to lowering of the energy costs of processing food, i.e. the diet induced thermogenesis. Recently, Campillo et al (24) described a delayed and blunted increment of $E E$ after a meal in patients with cirrhosis.

Concerning the influence of the patuern of food intake on substrate metabolism, a gorging pattem of intake is associated with a greater fluctuation of the RQ for both, patients with cirrhosis and controls. During the period of rising in the morning, $R Q$ in cirrhotic patients is similar to nocturnal $R Q$ values, in contrast to the control subjects where $R Q$ tended to increase after rising. This tendency towards an increased $R Q$ observed from 6.00h-9.0\% in controls is explained by an increase in carbohydrate utilization due to muscle glycogen oxidation during the arousal process (25). In cirrhotic patients, the time needed to develop the catabolic state of starvation is much shorter than in healthy controls, due to diminished glycogen stores of the liver $(5,26)$. Even after a late evening meal containing 20 per cent of the total EI and an overnight fast of 9 hours, as in the nibbling pattern, glycogen stores are depleted to an extent that a rise in RQ during the arousal process is not observed. Another important finding in cirrhotic patients was the fact that nocturnal RQ values and RQ values at rising were similar on both feeding. patterns, although the first response to a late evening meal was a rise in RQ (24.00h-3.00h) reflecting a temporary higher oxidation ratio of carbohydrate to fat. Because of the reduced glycogen stores in the liver of cirrhotic patients, energy must be derived from other substrate sources (i.e. protein or fat) when fasting is proceeding. Swart et al. (27) studying protein turnover in patients with cirrhosis, suggested an early onset of gluconeogenesis from amino acids at night, resulting in extra amino acid loss and hence a depletion of tissue protein stores. Our data 


\section{Chapter 6}

confirm Owen's findings that after an overnight fast of $10-12 \mathrm{~h}$, energy is mostly derived from fat (5).

Concerning $24 \mathrm{~h}$ oxidation of protein, fat and carbohydrate, no significant effects of the pattern of food intake were observed. On the gorging pattern carbohydrate oxidation was significantly lower than carbohydrate intake, resulting in a positive carbohydrate balance (Table 6.3). We hypothesize that patients with liver cirrhosis have some difficulty in the handling of two large meals, each containing $50 \%$ of the total EI. Probably not all of the carbohydrate ingested was oxidized and because of the limited glycogen storage in the liver, there remains a certain amount of carbohydrate that is not used nor stored. Therefore, to meet energetic requirements fat oxidation is increased in patients with cirrhosis, resulting in a negative fat balance.

Dividing the day in 6 hour intervals to investigate the diurnal variation in substrate oxidation, revealed a marked fluctuation in the nature and amount of substrate oxidized on the gorging pattem (Fig. 6.3A). Nocturnal protein oxidation $(24.00 \mathrm{~h}-6.00 \mathrm{~h})$ was significantly increased when compared to the morning episode $(6.00 \mathrm{~h}-12.00 \mathrm{~h} ; \mathrm{p}<0.05)$ and the afternoon $(12.00 \mathrm{~h}-18.00 \mathrm{~h} ; \mathrm{p}<0.01)$. In the nibbling pattern there was no significant change in protein oxidation throughout the day. These findings support the hypothesis of Swart et al. (27) that, due to the small and inadequate glycogen stores in the liver of cirrhotic patients, gluconeogenesis from amino acids will take place during overnight fasting. A nibbling pattern of food intake including a late evening meal therefore reduces nocturnal amino acid breakdown and hence improves nitrogen balance (16).

During the period from $6.00 \mathrm{~h}-12.00 \mathrm{~h}$, the contribution of fat oxidation to total EE in cirrhotic patients was $58 \%$ in the gorging pattern and as high as $50 \%$ in the nibbling pattern where the patients consumed a breakfast of $20 \%$ of daily EI at $7.30 \mathrm{~h}$. This would implicate that even after a short-term fast of 9 hours fat is used as an alternative fuel for glucose, which cannot be provided in sufficient amounts due to the depleted glycogen stores in the liver. These results are in accordance with the conclusions of other studies on substrate metabolism in cirrhotic patients, revealing that the period to reach a catabolic state (in which most of the energy is derived from fat) is much shorter in patients with cirrhosis of the liver $(3,5,28)$.

Therefore, our data suggest that patients with liver cirrhosis, should eat according to a nibbling pattern. A late evening meal and especially a good breakfast shorten the episodes of catabolism occurring during the night and in the morning, improving energy and substrate balances in patients with liver cirrhosis. 


\section{References}

1 Bosari S, Marradi C, Chiara O, Bevilacqua G and Nespoli A (1984): Energy expenditure in cirrhotic patients. In: Advances in hepatic encephalopathy and urea cycle diseases, eds $G$ Kleinberger, P Ferenci, P Riederer and H Thaler, pp. 674-681. Basel: Karger

2 Shanbhogue RLK, Bistrian BR, Jenkins RL, Jones, C, Benotti P and Blackburn GL. (1987): Resting energy expenditure in patients with end-stage liver disease and in nomal population. J Parenter Enteral Nutr 11: 305-308

3 Schneeweiss B, Graninget W, Ferenci P, Eichinger S, Grimm G, Schneider B, Laggner AN, Lenz K and Kleinberger G (1990): Energy metabolism in patients with acute and chronic liver disease. Hepatology 11: 387-393

4 Müller MJ, Fenk A, Lautz HU, Selberg O, Canzler H, Balks HJ, Von zur Mühlen A, Schmidt E and Schmidt F (1991): Energy expenditure and substrate metabolism in ethanol-induced liver cirhosis. Am J Physiol 260: E338-E344

5 Owen OE, Trapp VE, Reichard GA, Mozzoli MA, Moctezuma J, Paul P, Skutches Ci. and Boden G (1983): Nature and quantity of fuels consumed in patients with alcoholic cirrhosis. $\mathrm{J}$ Clin Invest 72 ; $1821-1832$

6 Jhangiani SS, Agarwal N, Holmes R, Cayten CG and Pitchumoni CS (1986): Energy expenditure in chronic alcoholics with and without liver disease. Am J Clin Nutr 44: 323 329

7 Merli M, Riggio O, Romiti A, Ariosto F, Mango L, Pinto G, Saviolo M and Capocacchia L (1990): Basal energy production rate and substrate use in stable cirrhotic patients. Hepatology 12: 106-112

8 Fábry P, Fodor J, Hejl Z, Braun T and Zvolínková K (1964): The írequency of meals: Its relationship to overweight, hypercholesterolaemia, and decreased glucose tolerance. Lancet 2: 614-615

9. Temstra J, Hessel LW, Seepers J and Van Gent CM (1978): The influence of meal frequency on diumal lipid, glucose and cortisol tevels in nermal subjecis. Eur J Clin Invest 8: $61-065$

10 Dallosso HM, Murgatroyd PR and James WPT (1982): Feeding frequency and energy balance in adult males. Hum Nutr : Clin Nutr 36C: 25-39

11 Irwin MI and Feeley RM (1967): Frequency and size of meals and serum lipids, nitrogen and mineral retention, fat digestibility, and urinary thiamine and riboflavin in young women. Am J Clin Nutr 20: 816-824

12. Young CM, Hutter LF, Scanlan SS, Rand CE, Lutwak L and Simko V (1972): Metabolic effects of́ meal frequency on nomal young meni. J Am. Diet Assoc 61: 391-398

13 Debry G, Rohr R, Azouaou R, Vassilitch I and Mottaz G (1973): Ponderal losses in obese subjects submitted to restricted diets differing by nibbling and by lipid and carbohydrate. In: Energy balance in man, ed M Apfelbaum, pp. 305-310. Paris: Masson

14. Fábry P (1973): Food intake pattern and energy balance. In: Energy balance in man, ed M Appelbaum, pp. 297-303. Paris: Masson 
15 Verboeket-van de Venne WPHG and Westerterp KR (1991): Influence of the feeding frequency on nutrient utilization in man: Consequences for energy metabolism. Eur J Clin Nutr 45: 161-169

16 Swart GR, Zillikens MC, Van Vuure JK and Van den Berg JWO (1989): Effect of a late evening meal on nitrogen balance in patients with cirrhosis of the liver. Br Med J 299: 1202-1203

17 Verboeket-van de Venne WPHG, Westerterp KR and Kester ADM. Effect of the pattem of food intake on human energy metabolism (Chapter 3 this thesis)

18 Harris JA and Benedict FG (1919): A biometric study of basal metabolism in man. Camegic Institution of Washington, 190

19 Flatt JP (1987): Dietary fat, carbohydrate balance, and weight maintenance: Effects of exercise. Am J Clin Nutr 45: 296-306

20 Schoeller DA and Jones PJH (1987): Measurement of total body water by isotopic dilution: A unified approach to calibrations. In: In vivo body composition studies, eds $\mathrm{KJ}$ Ellis, S Yasumura and WD Morgan, pp. 131-136. London: Institute of Physical Sciences in Medicine

21 Schoffelen PFM, Saris WHM, Westerterp KR and Ten Hoor F (1984): Evaluation of an automatic indirect calorimeter for measurement of energy balance in man. In: Human energy metabolism: Physical activity and energy expenditure measurements in epidemiological research based upon direct and indirect calorimetry, Euro Nut Report 5, ed AJH Van Es, pp. 51-54. Wageningerr: The Netherlands Nutrition Foundation

22 Weir JB de V (1949): New methods for calculating metabolic nate with special reference to predict protein metabolism. J Physiol 109: 1-9

23 Jéquier $E_{n}$ Acheson $\mathrm{K}$ and Schutz $\mathrm{Y}$ (1987): Assessment of energy expenditure and fuel utilization in man. Ann Rev Nutr 7: 187-208

24 Campillo B, Bories P-N, Devanlay M, Sommer F, Wirquin E and Fouet P (1992): The thermogenic and metabolic effects of food in liver cirhosis: Consequences on the storage of nutrients and the hormonal counterregulatory response. Metabolism 41: 476-482

25 Lean MEJ and James WPT (1988): Metabolic effects of isoenergetic nutrient exchange over 24 hours in relation to obesity in women. Int J Obes 12: 15-27

26 Owen OE, Reichle FA, Mozzoli MA, Kreulen T, Patel MS, Elfenbein JB, Golsorkhi M. Chang KHJ, Rao NS. Sue HS and Boden G (1981): Hepatic, gut, and renal substrate flux rates in patients with hepatic cirhosis. J Clin Invest $68: 240-252$

27 Swart GR, Van đen Berg JWO, Wattimena JLD, Rietveld T, Van Vuure JK and Frenkel M (1988): Elevated protein requirements in cirrhosis of the liver investigated by whole body protein turnover studies. Clin Sci 75: 101-107

28 Marchesini G, Bianchi GP, Zoli M and Checchia GA (1987): Glucose homeostasis in cirntosis. In: Cirrhosis of the liver: Methods and fields of research, eds N Tygstrup and F Orlandi, pp. 165-176. Elsevier Science Publishers B.V. (Biomedical Division) 


\title{
Chapter 7
}

\section{Substrate utilization in man: Effects of dietary fat and carbohydrate}

\author{
W.P.H.G. Verboeket-van de Venne, K.R. Westerterp and F. ten Hoor
}

Department of Human Biology, University of Limburg, P.O. Box 616, 6200 MD Maastricht, The Netherlands

accepted in Metabolism

\section{Abstract}

There is evidence that man has a limited ability to oxidize fat compared to the capacity to oxidize carbohydrate and protein. The short term ( $3 \mathrm{~d}$ ) effects of a lowfat, mixed, and high-fat diet on human substrate balance were studied using a respiration chamber. Subjects were 14 young female students classified as restrained or unrestrained eaters. Subjects were in energy balance, i.e. the mean difference between energy intake and energy expenditure was $63 \pm 84 \mathrm{~kJ} / \mathrm{d}$. The fat content of the food significantly influenced $24 \mathrm{~h}$ respiratory quotient (RQ) and non-protein respiratory quotient (NPRQ) on all three diets. For both low-fat and mixed diet, $24 \mathrm{~h} \mathrm{RQ}$ was significantly lower than the food quotient (FQ), while $\mathrm{RQ}$ on the high-fat diet was not different from $F Q$, indicating that substrate oxidation is closer to substrate intake at diets higher in fat content. Oxidation of fat and carbohydrate significantly increased with, respectively, an increasing fat and carbohydrate content of the diet, for both restrained and unrestrained eating subjects. Restrained eating subjects showed a reduced fat oxidation compared to unrestrained eaters in response to a high-fat diet, resulting in a positive fat balance for restrained eating subjects. On a low-fat diet fat balance was negative for both groups of subjects, indicating mobilization of energy from endogenous body fat stores. In conclusion, restrained eating subjects have more difficulty in the handling of a high-fat diet, explaining their higher susceptibility to become obese. 


\section{Introduction}

Maintaining a stable body weight requires that over time, energy intake equals energy expenditure and also that intakes of protein, fat and carbohydrate equal the oxidation of each substrate (1-2). In conditions of energy or substrate imbalance, changes occur in the body stores and hence body weight and body composition. A high dietary fat intake is often associated with an increasing prevalence of obesity (3-5). There are several mechanisms for this association. Firstly, a high-fat diet leads to an increase of energy intake (5-7), or a lowering of energy expenditure (89). Secondly, the body fails to adjust fat oxidation in response to excess fat intake (1-2).

Another aspect that has to be considered in the processes leading to obesity is a metabolic difference between individuals in the handling of dietary fat. Studies in post-obese subjects have suggested that reduced fat oxidation may be related to subsequent body weight gain (9-10). Thomas et al. (11) reported that lean subjects have a greater ability to increase fat oxidation in response to a high-fat diet than do obese subjects. This could result in a smaller increase of body fat in lean as compared to obese subjects, when both consume a high-fat diet.

A primary purpose of the present study was to investigate the effect of an isoenergetic exchange of fat and carbohydrate on substrate metabolism, i.e. oxidation and overall balance of protein, fat and carbohydrate. A second aim was to determine metabolic responses to dietary fat and carbohydrate of subjects being more or less susceptible to become obese. By means of the scores on psychometric questionnaires, a distinction was made in the relevant subject characteristics between a restrained or unrestrained attitude towards eating.

\section{Subjects and methods}

\section{Subjects}

Fourteen healthy young female subjects participated in the study. Their physical characteristics are presented in Table 7.1. The procedures to be used in the study were carefully explained to each subject before she gave her consent to participate.

\section{Attitude towards eating}

Characterization of restrained and unrestrained eating subjects was done by means of the scores on psychometric questionnaires. Two types of psychometric questionnaires were used: the Herman-Polivy (H-P) restraint scale (12) which is designed to identify dieters and is mainly weight-concerned (13), and the Three Factor Eating Questionnaire (TFEQ) of Stunkard and Messick (14) which is designed to measure successful dieting and is mainly food-concerned (13). The TFEQ was used to discriminate between 'cognitive restraint' and unrestraint, concerning the scores on the cognitive restraint factor $F_{1}$. In our subject 
population, the median of the H.P scores was 15 and of the $F_{1}$ scores $9(13,15$ 16). Subjects were classified as restrained eaters when the H-P' score $>15$ or $\bar{F}_{1}$ score $>9$; unrestrained eating subjects had a H-P score $\leq 15$ and $F_{1}$ score $\leq 9$. From the seven subjects in the present study classified as restrained eaters, one subject was restrained by being food-concerned, four subjects by being weightconcerned, and two subjects by being food- and weight-concerned.

Table 7.1 Physical characteristics of the subjects and order of treatment (LF: low-fat diet: M: mixed diet; HF: high-fat diet).

\begin{tabular}{cccccc}
\hline Subject & $\begin{array}{c}\text { Age } \\
(\mathrm{yr})\end{array}$ & $\begin{array}{c}\text { Height } \\
(\mathrm{m})\end{array}$ & $\begin{array}{c}\text { Weight } \\
(\mathrm{kg})\end{array}$ & $\begin{array}{c}\text { Attude towards } \\
\text { eating }\end{array}$ & $\begin{array}{c}\text { Order of } \\
\text { reatment }\end{array}$ \\
\hline 1 & 20 & 1.75 & 65.5 & Restrained & LF-HF-M \\
2. & 20 & 1.73 & 71.1 & Restrained & LF-MF-M \\
3 & 21 & 1.71 & 64.5 & Restrained & LF-HF-M \\
4 & 21 & 1.60 & 59.5 & Restrained & HF-LF-M \\
5 & 21 & 1.73 & 67.2 & Restrained & HF-LF-M \\
6 & 21 & 1.75 & 67.7 & Restrained & LF-HF-M \\
7 & 19 & 1.61 & 71.3 & Restrained & LF-HF \\
& & & & Unrestrained & LF-HF-M \\
8 & 20 & 1.71 & 80.1 & Unrestrained & HF-LF-M \\
9 & 22 & 1.71 & 68.4 & Unrestrained & HF-LF-M \\
10 & 19 & 1.71 & 69.7 & Unrestrained & LF-HF-M \\
11 & 19 & 1.70 & 57.7 & Unrestrained & LF-HF-M \\
12 & 24 & 1.76 & 62.6 & Unrestrained & HF-LF-M \\
13 & 20 & 1.63 & 61.9 & Unrestrained & HF-LF \\
14 & 20 & 1.69 & 65.7 & & \\
\hline
\end{tabular}

\section{Experimental design}

Subjects were fed to an estimated energy balance consuming a Jow-fat and a highfat diet over 3-day intervals. The order of administration of low-fat and high-fat diet was randomized. Twelve subjects additionally consumed a mixed diet. The interval between two experimental periods was at least 4 days. The first two days on each dietary regimen food was provided and consumed at home, the last 36 hours of each period were spent in a respiration chamber. In this chamber oxygen consumption, carbon dioxide production, and hence respiratory quotient (RQ) and energy expenditure (EE), were the main measurements (see below). Urine samples were collected to determine nitrogen excretion and hence calculate substrate oxidation. Energy intake for the maintenance of energy balance was based on the 
calculated basal metabolic rate (17) of the subjects multiplied by 1.76 on days 1 and 2 (18); energy intake on day 3 while being in the respiration chamber equalled $1.29 \times$ BMR (19).

\section{Diets}

The diets were taken as 4 meals daily: a breakfast at $8.00 \mathrm{~h}$ containing 20 per cent of the daily energy intake, a lunch at $13.00 \mathrm{~h}$ ( 25 energy \%), a dinner at $18.00 \mathrm{~h}(45$ energy $\%)$ and an evening snack at $20.30 \mathrm{~h}(10$ energy $\%)$. The daily energy intake was the same for the three diets $(\approx 8.0 \mathrm{MJ} / \mathrm{d})$. The low-fat $(\mathrm{LF})$ diet provided 15 energy \% protein, 10 energy \% fat and 75 energy \% carbohydrate; the mixed (M) diet 15 energy \% protein, 30 energy \% fat and 55 energy \% carbohydrate; and the high-fat (HF) diet 15 energy \% protein, 50 energy \% fat and 35 energy \% carbohydrate. Metabolizable energy intake and macronutrient composition of the diets were calculated using the Dutch food composition table (20). This table gives figures for the protein, fat and carbohydrate content of each food as determined by chemical analysis primarily; the energy value of the food is calculated by multiplying these figures by the Atwater factors. Since the heat of combustion of the different proteins, fats and carbohydrates can vary, calculated metabolizable energy intake may differ from true metabolizable energy intake. However, dietary fibre content was 18.0, 27.6 and $19.4 \mathrm{~g} / \mathrm{d}$ respectively, for the LF-, M- and HFdiet, implicating that digestibility of the three diets was fairly comparable. The food quotient (FQ) as defined by Flatl (2I) was $0.936,0.878$ and 0.820 respectively, for the LF-, $\mathrm{M}$ - and $\mathrm{HF}$-diet.

\section{Procedures}

Body mass

Subjects weighed theirselves (without clothing) in the morning of day 1, 3 and 4 upon rising, after voiding and before any food/drink consumption, on a digital balance (Seca delta, model 707) accurate to $0.1 \mathrm{~kg}$.

Respiration chamber measurements

Oxygen consumption and carbon dioxide production were measured in a respiration chamber (22). This chamber measures $14 \mathrm{~m}^{3}$ and is furnished with a bed, chair, table, TV, radio, telephone, wash-bowl and toilet. facilities. The chamber is ventilated with fresh air at $50 \mathrm{l} / \mathrm{min}$. The ventilation rate was measured with a dry gasmeter (Schlumberger, type G6). The concentration of oxygen and carbon dioxide was measured using a paramagnetic $\mathrm{O}_{2}$ analyser (Servomex, type OA 184) and an infrared $\mathrm{CO}_{2}$ analyser (Hartman \& Braun, type URAS 3G). Ingoing air was analysed once every $15 \mathrm{~min}$ and outgoing air once every $5 \mathrm{mint}$. The gas sample to be measured was selected by a computer which also stored and processed the data. Respiratory quotient (RQ) and energy expenditure (EE) (23) were calculated from $\mathrm{O}_{2}$ consumption and $\mathrm{CO}_{2}$ production. The physical activity of the subjects was monitored by means of a radar system, based on the Doppler 
principle. During daytime subjects were allowed to move freely, to sit, lie down, study, telephone, listen to the radio and watch television, only sleeping and strenuous exercise were not allowed.

\section{Urinary nitrogen excretion}

$24 \mathrm{~h}$ Urine was collected on day 3 of each dietary period, while subjects were staying in the respiration chamber. Samples were collected in containers with $8 \mathrm{ml}$ $\mathrm{H}_{2} \mathrm{SO}_{4}$ to prevent nitrogen loss through evaporation; volume and nitrogen concentration were measured subsequently, the latter using a Heraeus analyser (type CHN-O-Rapid).

\section{Substrate oxidation}

Overall substrate oxidation was calculated by measuring oxygen consumption, carbon dioxide production and urinary nitiogen excretion (24). The amount of protein oxidized was estimated from the urinary nitrogen excretion, since most urinary nitrogen ( $>80 \%$ ) is in the form of urea, $\mathrm{i} \mathrm{g}$ urinary nitrogen arising from. approximately $6.25 \mathrm{~g}$ protein. Thus, oxidation of protein, fat and carbohydrate was calculated by the following equations:

Protein oxidation $(\mathrm{g} / \mathrm{d})=\mathrm{N} \times 6.25$

Fat oxidation $(\mathrm{g} / \mathrm{d})=\left(1.689 \times \mathrm{VO}_{2}\right)-\left(1.689 \times \mathrm{VCO}_{2}\right)-(0.324 \times$ prot. $)$

Carbohydrate oxidation $(\mathrm{g} / \mathrm{d})=\left(4.113 \times \mathrm{VCO}_{2}\right)-\left(2.907 \times \mathrm{VO}_{2}\right)-(0.375 \times$ prot. $)$

where $\mathrm{N}$ is the total nitrogen excreted in urine $(\mathrm{g} / \mathrm{d})$

$\mathrm{VO}_{2}$ is the oxygen consumption (liter/d)

$\mathrm{VCO}_{2}$ is the carbon dioxide production (liter/d)

prot. is the protein oxidation $(\mathrm{g} / \mathrm{d})$

Analysis of data

$24 \mathrm{~h} \mathrm{RQ}$ and EE were calculated from $7.30 \mathrm{~h}$ to $7.30 \mathrm{~h}$. Urinary nitrogen excretion was determined for the same interval, to allow calculation of the non-protein respiratory quotient (NPRQ). The effects of diet composition on RQ. NPRQ: substrate oxidation and substrate balance (intake minus oxidation) were analysed by repeated measures analysis of variance (ANOVA) and Schefié F-tests or paired t-tests. Using a two-factor ANOVA (unbalanced model) with the grouping factors 'attitude towards eating' (restrained or unrestrained) and 'second treatment' (low. fat or high-fat diet), we revealed that there was no significant effect of one of these factors on the $24 \mathrm{~h} \mathrm{RQ}$ of the third treatment which was always the mixed diet ('attitude towards eating' $x$ 'second treatment' interaction: of !, F-value: 0.38 , $p>0.1$ ). Correlation analysis was done with the: Pearson correlation coefficient. Changes between the groups of restrained and unrestrained eating subjects were tested using unpaired t-tests. In the text, tables and figures data are presented as the mean and standard error of the mean (SE). 


\section{Chapter 7}

\section{Results}

\section{Energy balance}

Garrow (25) stated that an adult is in energy balance when the difference between energy intake (EI) and energy expenditure (EE) is less than $600 \mathrm{~kJ}$ per day. Energy balance was determined by subtracting EE from EI. EI-EE was near zero on all three diets, averaging $+63 \pm 84 \mathrm{~kJ} / \mathrm{d}$ (range -1588 to $+863 \mathrm{~kJ} / \mathrm{d}$ ).

\section{Body mass measurements}

Body mass showed a slight increase $(0.2 \pm 0.1 \mathrm{~kg})$ over the two days in free living conditions on all three diets. During the subsequent day in the respiration chamber body weight decreased $(0.5 \pm 0.1 \mathrm{~kg})$. There were no significant differences in changes of body mass due to the composition of the diet. Over the 3-day intervals body mass changes were not significantly different from zero.

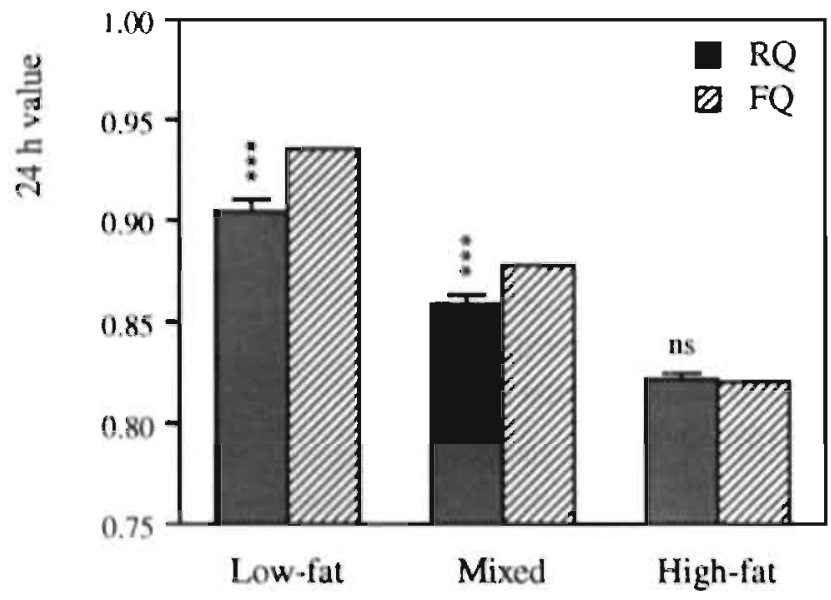

Fig. 7.1 Mean respiratory quotient (RQ) and food quotient (FQ) over $24 \mathrm{~h}$ under different feeding conditions ( $\mathrm{n}=12$ ). Statistical significance between $\mathrm{RQ}$ and FQ: $\mathrm{ns}$ no significance, **** $\mathrm{p}<0.001$.

\section{Respiratory and non-protein respiratory quotient}

There was a highly significant effect of diet composition on RQ (repeated measures ANOVA, df 2, F-value: 144.41, p<0.001). RQ was significantly lower than FQ at a LF-diet (df 11, paired t-value: 5.95, p<0.001) and M-diet (df 11, paired t-value: $4.50, p<0.001$ ), while RQ was not different from FQ at a HF-diet 
(df 11 , paired t-value: $0.76, p>0.1$ ) (Fig. 7.1). The respiratory data for restrained and unrestrained eating subjects are presented in Table 7.2. RQ and NPRQ were significantly lower for unrestrained eating subjects on the high-fat diet. No statistically significant differences in RQ and NPRQ between restrained and unrestrained eating subjects were observed on the low-fat and mixed diet.

Table 7.2 Average daily $(24 \mathrm{~h})$ respiratory quotient (RQ), non-protein respiratory quotient (NPRQ) and food quotient (FQ) for restrained $(n=7)$ and unrestrained eating subjects $(n=7)$ on the three diets.

\begin{tabular}{|c|c|c|c|c|c|c|}
\hline & \multicolumn{6}{|c|}{ RESTRAINED EATING SUBJECTS } \\
\hline & \multicolumn{2}{|c|}{ Low-fat } & \multicolumn{2}{|c|}{ Mixed $^{*}$} & \multicolumn{2}{|c|}{ High-fat } \\
\hline & Mean & SE & Mean & SE & Mean & SE \\
\hline 24 h RQ & 0.908 & 0.003 & 0.860 & 0.008 & 0.829 I & 0.004 \\
\hline 24 h NPRQ & 0.929 & 0.003 & 0.872 & 0.010 & $0.835 \AA$ & 0.005 \\
\hline \multirow[t]{4}{*}{24 h FQ } & 0.936 & 0.000 & 0.879 & 0.000 & 0.820 & 0.000 \\
\hline & \multicolumn{6}{|c|}{ UNRESTRAINED EATING SUBJECTS } \\
\hline & \multicolumn{2}{|c|}{ Low-1̂t } & \multicolumn{2}{|c|}{ Mixed $^{*}$} & \multicolumn{2}{|c|}{ High-1aI } \\
\hline & Mean & SE & Mean & SE & Mean & SE \\
\hline $24 \mathrm{~h} \mathrm{RQ}$ & 0.898 & 0.009 & 0.857 & 0.005 & 0.816 & 0,004 \\
\hline 24 h NPRQ & 0.913 & 0.011 & 0.868 & 0.006 & $0.818^{8}$ & 0.004 \\
\hline $24 \mathrm{~h} \mathrm{FQ}$ & 0.936 & 0.000 & 0.878 & 0.000 & 0.820 & 0.000 \\
\hline
\end{tabular}

* $\mathrm{n}=6$

I $24 \mathrm{~h} \mathrm{RQ}$; restrained vs. unrestrained eaters: df 12, unpaired t-value: 2.60 , $\mathrm{p}<0.05$

\& $24 \mathrm{~h} \mathrm{NPRQ;}$ restrained vs. unrestrained eaters: of 12 , unpaired t-value: $2.69, p<0.05$

\section{Substrate intake, oxidation and balance}

Mean intake, oxidation and balance (i.e. intake-oxidation) of protein, fat and carbohydrate on the LF-, M- and HF-diet are presented in Fig. 7.2. There was no significant effect of diet composition on protein oxidation. Protein balance was near zero for both M-diet (-0.5 $\pm 2.1 \mathrm{~g} / \mathrm{d})$ and HF-diet $(-0.8 \pm 1.9 \mathrm{~g} / \mathrm{d})$, and was significantly different from protein balance at a LF-diet $(+7.2 \pm 2.7 \mathrm{~g} / \mathrm{d}$; repeated measures ANOVA, df 2, F-value: 5.19, p<0.05). Fat oxidation increased significantly with an increasing dietary fat content (repeated measures ANOVA, df 2, Fvalue: $92.30, \mathrm{p}<0.001)$. The difference between fat intake and oxidation was smallest on the HF-diet $(+3.9 \pm 4.4 \mathrm{~g} / \mathrm{d}$ vs. $-26.2 \pm 4.5 \mathrm{~g} / \mathrm{d}$ on the LF-diet and = $14.0 \pm 4.6 \mathrm{~g} / \mathrm{d}$ on the M-diet; repeated measures ANOVA, df 2, F-value: 24.72 , 
Chapter 7
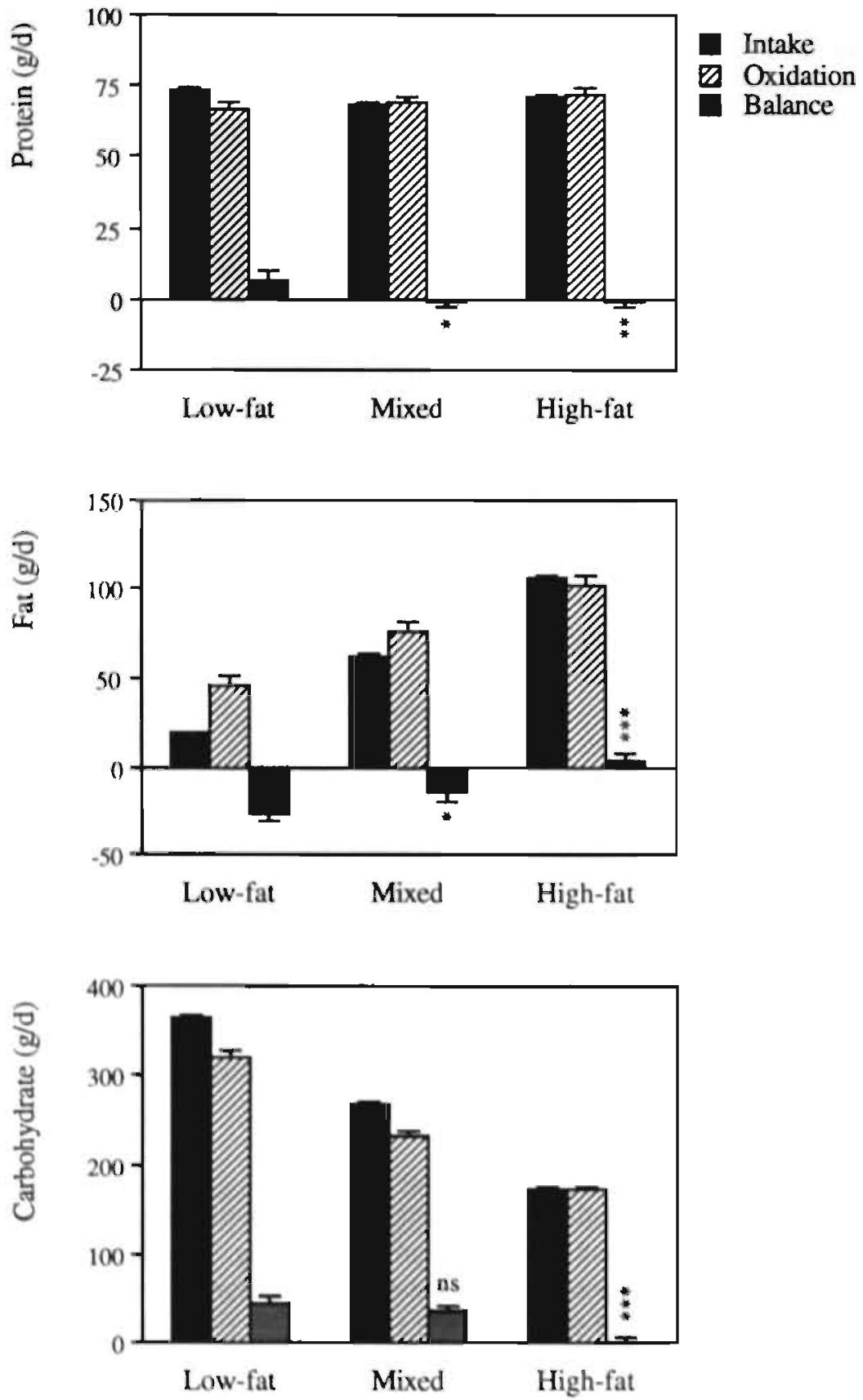

Fig. 7.2 Mean intake, oxidation and balance of protein, fat and carbohydrate over $24 \mathrm{~h}$ under different feeding conditions $(\mathrm{n}=12)$. Statistical significance comparing substrate balance on the $\mathrm{M}$ and HF-diet to the LF-diet: ns no significance, " $p<0.05, * 0<<0.01, * * 0<0.001$. 
$\mathrm{p}<0.001$ ). Oxidation of carbohydrate decreased significantly with an increasing dietary fat content (repeated measures ANOVA, df 2, F-value: 190.39, p<0.001). Carbohydrate balance was positive on all three diets, and highest on the LF-diet $(+44.3 \pm 9.0 \mathrm{~g} / \mathrm{d}$ vs. $+0.2 \pm 4.2 \mathrm{~g} / \mathrm{d}$ on the HF-diet and $+35.7 \pm 6.1 \mathrm{~g} / \mathrm{d}$ on the Ml-diet; repeated measures ANOVA, df 2, F-value: 18.15, p<0.001).

Table 7.3 Protein intake, oxidation and balance (intake-oxidation) for restrained $(\mathrm{n}=7)$ and unrestrained eating subjects $(\mathrm{n}=7)$ on the three diets. Data are expressed in $\mathrm{g} / \mathrm{d}$.

\begin{tabular}{|c|c|c|c|c|c|c|}
\hline & \multicolumn{6}{|c|}{ RESTRAIVED EATING SUBJECTS } \\
\hline & \multicolumn{2}{|c|}{ Low-fat } & \multicolumn{2}{|c|}{ Mixed ${ }^{*}$} & \multicolumn{2}{|c|}{ High-fat } \\
\hline & Mean & SE & Mean & SE. & Mean & SE \\
\hline Protein intake & 73.2 & 0.0 & 67.9 & 0.0 & 70.9 & 0.0 \\
\hline Protein oxidation & $71.1^{9}$ & 1.7 & 70.8 & 1.6 & 74.2 & 1.6 \\
\hline Protein balance & $2.1^{8}$ & 1.7 & $-2,9$ & 1.6 & -3.3 & 1.6 \\
\hline
\end{tabular}

\begin{tabular}{|c|c|c|c|c|c|c|}
\hline & \multicolumn{6}{|c|}{ UNRESTRAINED EATING SUBJECTS } \\
\hline & \multicolumn{2}{|c|}{ Low-fat } & \multicolumn{2}{|c|}{ Mixed $^{*}$} & \multicolumn{2}{|c|}{ High-fat } \\
\hline & Mean & SE & Mean & SE & Mean & SE \\
\hline Protein intake & 74.3 & 1.1 & 69.4 & 1.5 & 71.8 & 0.9 \\
\hline Protein oxidation & 61.79 & 3.9 & 67.6 & 4.0 & 69.6 & 4.2 \\
\hline Protein balance & $12.6^{8}$ & 3.5 & 1.8 & 3.9 & 2.2 & 3.6 \\
\hline
\end{tabular}

- $\quad n=6$

I Protein oxidation; restrained vs. unrestrained eaters: df 12, unpaired i-value: $2.20, \mathrm{p}<0.05$

$\S \quad$ Protein balance; restrained vs. unrestrained eaters: df 12 , unpaired t-value: $2.68, p<0.05$

Protein oxidation was significantly lower for unrestrained eating subjects on the LF-diel, resulting in a more positive protein balance compared to restrained eating subjects (Table 7.3). Unrestrained eating subjects had a significantly increased rate of fat oxidation while on the HF-diet (Table 7.4). Therefore, with an equivalent fat intake, fat balance was positive for restrained eating subjects and negative for unrestrained eating subjects $(\mathrm{p}=0.052)$. There were no significant differences between restrained and unrestrained eating subjects, with respect to oxidation and overall balance of carbohydrate, nor on the LF- nor on the M- or HF-diet (Table $7.5)$. 


\section{Chapter 7}

Table 7.4 Fat intake, oxidation and balance (intake-oxidation) for restrained $(\mathrm{n}=7)$ and unrestrained eating subjects $(n=7)$ on the three diets. Data are expressed in $\mathrm{g} / \mathrm{d}$.

\begin{tabular}{|c|c|c|c|c|c|c|}
\hline & & ESTF & ED EA & ING : & JECTS & \\
\hline & Lo & & $\mathrm{Mi}$ & & Higl & \\
\hline & Mean & SE & Mean & SE & Mean & SE \\
\hline Fat intake & 20.8 & 0.0 & 62.6 & 0.0 & 106.0 & 0.0 \\
\hline Fat oxidation & 41.7 & 2.8 & 73.2 & 6.8 & $94.7^{\mathbf{I}}$ & 5.5 \\
\hline Fat balance & -20.9 & 2.8 & -10.6 & 6.8 & $11.3^{\S}$ & 5.5 \\
\hline & & RES & NED E & TINC & BJECTS & \\
\hline & Lor & & $\mathrm{Mi}$ & & Higl & \\
\hline & Mein & SE & Mean & SE & Mean & SE \\
\hline Fat intake & 21.2 & 0.4 & 64.1 & 1.5 & 108.0 & 2.0 \\
\hline Fat oxidation & 54.1 & 7.1 & 81.4 & 5.9 & $111.2^{9}$ & 3.1 \\
\hline Fat balance & -32.9 & 7.0 & -17.3 & 6.5 & $-3.2 \S$ & 3.9 \\
\hline
\end{tabular}

* $n=6$

1 Fat oxidation; restrained vs, unrestrained eaters: df 12, unpaired t-value: 2.64, p<0.05

\$. Fat balance; restrained vs. unrestrained eaters: df 12, unpaired t-value: $2.16, p>0.05$ 
Table 7.5 Carbohydrate intake, oxidation and balance (intake-oxidation) for restrained $(\mathrm{n}=7)$ and unrestrained eating subjects $(n=7)$ on the three diets. Data are expressed in $g / d$.

\begin{tabular}{|c|c|c|c|c|c|c|}
\hline & \multicolumn{6}{|c|}{ RESTRAINED EATING SUBJECTS } \\
\hline & \multicolumn{2}{|c|}{ Low-fat } & \multicolumn{2}{|c|}{ Mixed ${ }^{*}$} & \multicolumn{2}{|c|}{ High-fat } \\
\hline & Mean & SE & Mean & SE & Mean & SE \\
\hline Carbohydrate intake & 360.7 & 0.0 & 266.0 & 0.0 & 170.6 & 0.0 \\
\hline Carbohydrate oxidation & 318.7 & 6.9 & 227.4 & 11.3 & 176.7 & 3.1 \\
\hline \multirow[t]{4}{*}{ Carbohydrate baliance } & 42.0 & 6.9 & 38.6 & 11.3 & -6.1 & 3.1 \\
\hline & \multicolumn{6}{|c|}{ UNRESTRAINED EATING SUBJECTS } \\
\hline & \multicolumn{2}{|c|}{ Low-fat } & \multicolumn{2}{|c|}{ Mixed $^{*}$} & \multicolumn{2}{|c|}{ High-fat } \\
\hline & Mean & SE & Mean & SE & Mean & SE \\
\hline Carbohydrate intake & 366.4 & 5.7 & 271.7 & 5.7 & 174,1 & 3.5 \\
\hline Carbohydrate oxidation & 310.1 & 15.1 & 238.8 & 4.9 & 166.3 & 6.0 \\
\hline Carbohydrate balance & 56.3 & 16.5 & 32.9 & 5.6 & 7.8 & 6.2 \\
\hline
\end{tabular}

* $\quad \mathrm{n}=6$

The effect of dietary fat and carbohydrate on substrate balance for restrained and unrestrained eating subjects is summarized in Table 7.6. For unrestrained eating subjects protein balance was significantly more positive on the LF-diet (compared to the HF-diet), whereas diet composition had no effect on protein balance in restrained eating subjects. Fat balance was significantly more negative and carbohydrate balance more positive on the $\mathrm{LF}$-diei, for both restrained and unrestrained eating subjects.

Energy balance was positively correlated with fat balance (Pearson's $r=0.68$, $p<0.001$ ) (Fig. 7.3). There was no relationship between energy balance and protein or carbohydrate balance (data not shown). 
Table 7.6 Substrate balance (intake-oxidation) for restrained $(n=7)$ and unrestrained eating subjects $(\mathbf{n}=7)$ on the low-fat and high-fat diet. Data are expressed in $\mathrm{g} / \mathrm{d}$.

\begin{tabular}{|c|c|c|c|c|}
\hline & \multicolumn{4}{|c|}{ RESTRAINED EATING SUBJECTS } \\
\hline & \multicolumn{2}{|c|}{ Low-fat } & \multicolumn{2}{|c|}{ High-fat } \\
\hline & Mean & SE & Mean & SE \\
\hline Protein balance & 2.1 & 1.7 & -3.3 & 1.6 \\
\hline Fat balance & -20.99 & 2.8 & 11.39 & 5.5 \\
\hline \multirow[t]{4}{*}{ Carbohydrate balance } & $42.0^{8}$ & 6.9 & $-6.1 \S$ & 3.1 \\
\hline & \multicolumn{4}{|c|}{ UNRESTRAINED EATING SUBJECTS } \\
\hline & \multicolumn{2}{|c|}{ Low-fat } & \multicolumn{2}{|c|}{ High-fat } \\
\hline & Mean & SE & Mean & SE \\
\hline Protein balance & $12.6^{*}$ & 3.5 & $2.2^{*}$ & 3.6 \\
\hline Fat balance & $-32.9^{\sharp}$ & 7.0 & $-3.2^{\#}$ & 3.9 \\
\hline Carbohydrate balance & $56.3 \ddagger$ & 16.5 & $7.8 \ddagger$ & 6.2 \\
\hline
\end{tabular}

I Restrained eating subjects; fat balance: of 6, paired 1-value: $6.51, \mathrm{p}<0.001$

8 Restrained eating subjects; carbohydrate balance: df 6, paired t-value: $6.70, \mathrm{p}<0.001$

- Unrestrained eating subjects; protein balance: df 6, paired t-value: 3.59, $\mathrm{p}<0.05$

\# Unrestrained eating subjects; fat balance: df 6 , paired l-value: $3.72, p<0.01$

\$ Unrestrained eating subjects; carbohydrate balance: df 6, paired 1-value: $3.80, p<0.01$

\section{Discussion}

In the present study we investigated the relationship between substrate intake and substrate oxidation under different feeding conditions, by comparing the $24 \mathrm{~h} \mathrm{RQ}$ reflecting the fuel mixture oxidized, with the mean $\mathrm{FQ}$ based on the nutrient composition of the diet. In conditions of energy or substrate imbalance, a normal weight subject stores or mobilizes, in the long term, nearly all energy in the form of body fat. Therefore. a RQ $>$ FQ indicates conversion of carbohydrate or protein to body fat and a $\mathrm{RQ}<\mathrm{FQ}$ mobilization of energy from body fat stores. In this study, we observed a highly significant effect of diet composition on $\mathrm{RQ}$, with the lowest value on the HF-diet and the highest on the LF-diet (Fig. 7.1). The difference between RQ and FQ was smallest on the HF-diet (RQ-FQ $=+0.003 \pm$ 0.003 vs. $-0.031 \pm 0.005$ on the LF-diet; repeated measures ANOVA, df $2, F$ value: $24.86, \mathrm{p}<0.001$ ), reflecting a closer regulation of substrate oxidation to substrate intake. Other studies investigating the relationship between dietary fat and carbohydrate and substrate utilization also report a greater deficit between RQ and FQ when a low-fat (high-carbohydrate) diet is consumed $(8-9,26-27)$. 


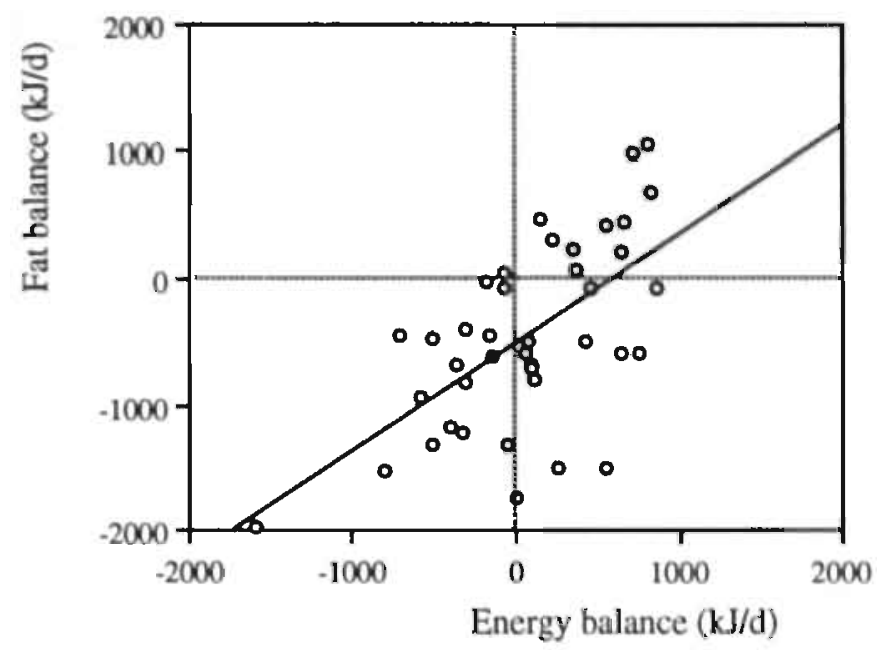

Fig. 7.3 Fat balance plotied as a function of energy balance with the calculated linear regression line. Data of 12 subjects on the LF-, M- and HF-diet are presented.

There are two possible reasons for this finding. First, the experinnental HF-diet as used in the present study is closer to the subject's habitual diet. Note that a dietary fat content of 40 energy \% is more or less 'normal' in Western societies! Furthermore, the overall energy balance can influence whether the body stores excess fuels in the form of body fat, or mobilizes energy from body iat. In the present study we observed a difference of less than $600 \mathrm{~kJ} / \mathrm{d}$ beiween EI and EE, indicating that subjects were in energy balance during the third day of the study. Energy balance was not significantly different on the three diets (EI-EE(LF): $-42 \pm$ $155 \mathrm{~kJ} / \mathrm{d}$; EI-EE(M): $+72 \pm 155 \mathrm{~kJ} / \mathrm{d} ; \mathrm{EI}-\mathrm{EE}(\mathrm{HF}):+162 \pm 131 \mathrm{~kJ} / \mathrm{d})$.

When the relevant subject characteristics with respect to a restrained or unrestrained attitude towards eating were taken into account, RQ and NPRQ were significantly decreased in unrestrained eating subjects on a HF-diet (compared to restrained eating subjects). This suggests a relative higher ratio of fat to carbohydrate oxidation for unrestrained eaters, at least on a HF-diet. Zurlo et al, (28) associated a low ratio of fat to carbohydrate oxidation with a higher risk of subsequent body weight gain, independent of a low energy expenditure.

The results on intake, oxidation and overall balance of protein, fat and carbohydrate (Fig. 7.2) also revealed that substrate oxidation is closer to substrate intake on a HF-diet, indicated by the size of the substrate balances. Alternatively, a LF-diet results in a stronger negative fat balance, reflecting a greater fat oxidation than intake. This suggests that subjects mobilize energy from their body fat reserves more easily on a LF- than HF-diet, implicating a LF-diet as a useful tool' 
in the treatment of obesity. Carbohydrate balances were positive on all three diets. The lower RQ and NPRQ in unrestrained eating subjects on a HF-diet, as described above, could be explained by a significant increase of fat oxidation combined with the tendency to a decrease in carbohydrate oxidation compared to restrained eating subjects (Tables 7.3-7.5). These findings are in agreement with the results of Hill et al. (29), stating that obesity-susceptible individuals have a limited ability to rapidly adjust fat oxidation in response to a high-fat intake. Subjects who have less problems in maintaining their body weight, as the unrestrained eating subject in the present study, probably have a greater ability to adjust oxidation to excess fat intake. Conceming the regulation of protein balance, we observed a lower oxidation of protein and hence a more positive protein balance in unrestrained eating subjects on a LF-diet. We have no explanation for this unexpected finding and further studies will be necessary to elucidate these results.

Considering the effect of dietary fat and carbohydrate on substrate balances within the groups of restrained and unrestrained eating subjects, both fat and carbohydrate balance were more closely regulated while on a HF-diet compared to a LF-diet (Table 7.6). Fat balance is (more) negative on a LF-diet compared to a HF-diet, reflecting more mobilization of endogenous fat stores. Therefore, a LFdiet has favorable effects in both treatment and prevention of obesity. The effect of diet composition on fat balance is especially beneficial for obese-susceptible or latent obese subjects (the restrained eating subjects in the present study), because fat balance was negative on a LF-diet and positive on a HF-diet.

Correlation analysis between energy balance and substrate balances, revealed that only fat balance showed a significant relationship with total energy balance. Abbott et al. (30) described very similar results for both men and women. They stated that fat, rather than protein or carbohydrate, is mobilized or stored in response to day-to-day fluctuations in energy balance.

\section{References}

1 Flatt JP (1987): The difference in the storage capacities for carbohydrate and for fat, and its implications in the regulation of body weight. Ann NY Acad Sci 499: 104.123

Flatt JP (1988): Importance of nutrient balance in body weight regulation. Diabetes Metab Rev 6: $571-581$

Dreon DM, Frey-Hewill B, Ellsworth N, Williams PT, Terry RB and Wood PD (1988):

Dietary fat : carbohydrate ratio and obesity in middle-aged men. Am J Clin Nutr 47: 995 1000

4 Romieu I, Willett WC. Stampfer MJ, Colditz GA, Sampson L, Rosner B, Hennekens CH and Speizer FE (1988): Energy intake and other determinants of relative weight. Am J Clin Nutr 47: 406-412 
Tremblay A, Plourde G, Despres JP and Bouchard C (1989): Impact of dietary fat content and fat oxidation on energy intake in humans. Am J Clin Nutr 49: 799-805

6 Duncan KH, Bacon JA and Weinsier RL. (1983): The effects of high and low energy density diets on satiety, energy intake and eating time of obese and nonobese subjects. Am J Clin Nuts 37: 763-767

7 Lissner L, Levitsky DA, Strupp BJ, Kalkwarf HJ and Roe DA (1987): Dietary fat and the regulation of energy intake in human subjects. Am J Clin Nutr 46: 886-892

Hurni M. Burnand B, Pittet P and Jéquier E (1982): Metabolic effects of a mixed and a high-carbohydrate low-fat diet in man, measured over $24 \mathrm{~h}$ in a respiration chamber. Br J Nutr 47: $33-43$

9 Lean MEJ and James WPT (1988): Metabolic effects of isoenergetic nutrient exchange over 24 hours in relation to obesity in women. Int $\mathrm{J}$ Obes 12: 15-27

10 Froidevaux F, Schutz Y, Christin L and Jéquier E (1988): Twenty-four-hour energy expenditure after weight loss in obese subjects (abstr.). Experientia Basel 44: $31 \mathrm{a}$

11 Thomas CD, Peters JC, Reed GW, Abumrad NN, Sun M and Hill JO (1992): Nutrient balance and energy expenditure during ad libitum feeding of high-fat and high-carbohydrate diets in humans. Am J Clin Nutr 55: 934-942

12 Herman CP and Polivy I (1980): Restrained eating. In: Obesity, ed A Stunkard, pp. 208. 224. Philadelphia: WB Saunders

13 Westerterp-Plantenga MS, Wouters L and Ten Hoor F (1991): Restrained eating, obesity and cumulative food intake curves during four-course meals. Appetite 16: 149-158

14 Stunkard $\mathrm{N}$ and Messick $\mathrm{S}$ (1985): The three factor eating questionnaire to measure dietary restraint, disinhibition and hunger. Psych Res 29: 71-83

15 Westerterp-Plantenga MS, Wouters L and Ten Hoor F (1990): Deceleration in cumulative food intake curves, changes in body temperature, and diet-induced thermogenesis. Physiol Behav 48: $831-836$

16 Westerterp-Plantenga MS, Westerterp KR, Nicolson NA, Mordant A, Schoffelen PIM and Ten Hoor F (1990): The shape of the cumulative food intake curve in humans, during basic and manipulated meals. Physiol Behav 47: 569-576

17 Harris JA and Benedict FG (1919): A biometric study of basal metabolism in man. Camegie Institution of Washington 190

18 Verboeket-van de Venne WPHG, Westerterp KR and Kester ADM. Effect of the pattern of food intake on human energy metabolism (Chapter 3 this thesis)

19 Verboeket-van de Venne WPHG and Westerterp KR (1991): Influence of the feeding frequency on nutrient utilization in man: Consequences for energy metabolism. Eur J Clin Nutr 45: 161-169.

20 Kommissie UCV. Uitgebreide voedingsmiddelen tabel (1985). Den Haag: Voorlichtingsbureau voor de voeding.

21 Flatt JP (1987): Dietary fat, carbohydrate balance, and weight maintenance: Effects of exercise. Am J Clin Nutr 45: 296-306 


\section{Chapter 7}

22. Schoffelen PFM, Saris WHM, Westerterp KR and Ten Hoor F (1984): Evaluation of an automatic indirect calorimeter for measurement of energy balance in man. In: Human energy metabolism: Physical activity and energy expenditure measurements in epidemiological research based upon direct and indirect calorimetry, Euro Nut Report 5, ed AJH Van Es, pp. 51-54. Wageningen: The Netherlands Nutrition Foundation

23 Weir JB de V (1949): New methods for calculating metabolic rate with special reference to predict protein metabolism. J Physiol 109: 1-9

24 Jéquier E, Acheson K and Schutz Y (1987): Assessment of energy expenditure and fuel utilization in man. Ann Rev Nutr 7: 187-208

25 Garrow JS (1974): Energy balance and obesity in man. Amsterdam: North Holland Publishing Company

26 Abbott WGH, Howard BV, Ruotolo G and Ravussin E (1990): Energy expenditure in humans: Effects of dietary fat and carbohydrate. Am J Physiol 258: E347-E351

27 Hill JO, Peters JC, Reed GW, Schlundt DG, Sharp T and Greene HL (1991): Nutrient balance in hurnans: effects of diet composition. Am J Clin Nutr 54: 10-17

28 Zurlo F, Lillioja S, Esposito-Del Puente A, Nyomba BL, Raz I, Saad MF, Swinburn BA, Knowler WC. Bogardus C and Ravussin E (1990): Low ratio of fat to carbohydrate oxidation as predictor of weight gain: study of 24-h RQ. Am J Physiol 259: E650-E657

29 Hill JO (1991): Dietary fat and body weight regulation (abstr.). Int J Obes 15 (Suppl 3): MS 12

30 Abbol WGH, Howard BV, Christin L, Freymond D, Lillioja S, Boyce VL, Anderson TE, Bogardus C and Ravussin E (1988): Short-term energy balance: relationship with protein, carbohydrate, and fat balances. Am J Physiol 255: E332-E337 


\title{
Chapter 8
}

\section{Effects of dietary fat and carbohydrate exchange on human energy metabolism}

\author{
W.P.H.G. Verboeket-van de Venne and K.R. Westerterp \\ Department of Human Biology, University of Limburg, P.O. Box 616, 6200 MD \\ Maastricht, The Netherlands
}

submitted for publication

\begin{abstract}
The short term ( 3 d) effects of a low-fat, mixed, and high-fat diet on $24 \mathrm{~h}$ EE, SMR, DIT and energy expenditure for physical activity (ACT) were siudied using a respiration chamber. Subjects were 16 female students classified as restrained or unrestrained eaters. $24 \mathrm{~h} \mathrm{EE}$ and its compartments were not significantly different between the restrained and unrestrained eating subjects. Within the group of restrained eating subjects, $24 \mathrm{~h}$ EE was decreased ( $p=0.016)$ during the mixed and high-fat diet, compared to the low-fat diet. Diet composition had no effect on $24 \mathrm{~h}$ $\mathrm{EE}$ in the unrestrained eating subjects. Summarizing the results, no significant differences were obtained with respect to $24 \mathrm{~h} \mathrm{EE}$, SMR, DIT or ACT between restrained and unrestrained eating subjects. Concerning the effect of diet composition within each group of subjects, $24 \mathrm{~h} \mathrm{EE}$ was significantly decreased for restrained eating subjects on a mixed diet and tended to be decreased on a highfat diet.
\end{abstract}

\section{Introduction}

High-fat diets have been associated with obesity in humans (1-3). Because obesity results from a positive energy balance, i.e. energy intake exceeding energy expenditure, two possible mechanisms are involved. Firstly, a high-fat intake could result in an increase of energy intake (3-5). The second possibility is that high-fat diets lower energy expenditure, which in turn has been shown to be a risk 


\section{Chapter 8}

factor for weight gain (6). Studies examining the effect of isoenergetic exchange of fat and carbohydrate reported no change in $24 \mathrm{~h}$ energy expenditure ( $24 \mathrm{~h} \mathrm{EE}$ ) due to the composition of the diet (7-8), or a decreased $24 \mathrm{~h}$ EE in post-obese subjects on a high-fat diet (9).

Considering the influence of diet composition on the separate compartments of energy metabolism, results are not consistent. Sleeping metabolic rate (SMR) was significantly decreased on a high-fat diet compared to a low-fat diet for normal weight subjects (7), or was not affected at all (8-9). There was no significant effect of diet composition on the resting metabolic rate (RMR) (7-8,10). According to Flatt (11), dietary fat storage is at a cost of 3 per cent of ingested energy, whereas the cost of storing dietary carbohydrate as fat requires the expenditure of 23 per cent of ingested energy. Furthermore, variations in the thermogenic response were reported with respect to the composition of the diet. A lower thermogenic response to fat than to carbohydrates was described for both normal weight and obese subjects (12) and post-obese subjects (9). Thus, the contribution of the diet induced thermogenesis (DIT) to energy metabolism is expected to be lower on a high-fat diet. However, Abbott et al. (8) reported no differences in DIT due to diet composition for both diabetic and non-diabetic subjects. Energy expenditure due to the physical activity of the subject $(\mathrm{ACT})$ was not affected by the diet composition cither (8).

Another aspect that has to be considered in the processes leading to obesity is the between-subject variation in the response to dietary fat. Nair et al. (13) found no differences in the magnitude of the thermic response to isoenergetic protein, carbohydrate or fat meals between groups of lean and obese subjects. Other studies however, support the view that there is a defect in thermogenesis in response to fat in obese subjects (14-15). Less is known about the metabolic response to food stimuli of latent obese subjects. By means of the scores of psychometric questionnaires a distinction can be made in the relevant subject characteristics between a restrained or unrestrained attitude towards eating. Laessle et al. and Tuschl et al. (16-17) reported less energy consumption and higher preferences for low-calorie foods in restrained eating subjects compared to unrestrained eaters, despite having a higher body mass index (BMI). Furthermore, energy expenditure was lower in restrained eating subjects, reflecting diminished caloric requirements.

In the present study, we investigated the effects of dietary fat and carbohydrate exchange on human energy metabolism and its compartments sleeping metabolic rate (SMR), diet induced therrnogenesis (DIT) and energy expenditure for physical activity (ACT). Furthermore, the relevant subject characteristics were taken into account, in order to explain possible consequences of diet composition for developing obesity. 


\section{Subjects and methods}

\section{Subjects}

Sixteen healthy female students were selected for this investigation. Their physical characteristics are presented in Table 8.1. The procedures to be used in the study were carefully explained to each subject before she gave her consent to participate.

Table 8.1 Physical characteristics and scores on the psychometric questionnaires of the subjects and order of treatment (LF: low-fat diet; M: mixed diet; HF: high-fat diet).

\begin{tabular}{|c|c|c|c|c|c|}
\hline \multirow[t]{2}{*}{ Subject } & \multirow[t]{2}{*}{$\begin{array}{l}\text { Age } \\
(\mathrm{yr})\end{array}$} & \multirow[t]{2}{*}{$\begin{array}{c}\text { BMI } \\
\left(\mathrm{kg} / \mathrm{m}^{2}\right)\end{array}$} & \multicolumn{2}{|c|}{$\begin{array}{l}\text { Scores on the psycho- } \\
\text { metric questionnaires }\end{array}$} & \multirow[t]{2}{*}{$\begin{array}{l}\text { Order of } \\
\text { treatment }\end{array}$} \\
\hline & & & $F_{1}$ & H.P & \\
\hline 1 & 20 & 21.4 & 11 & 13 & LF-HF-M \\
\hline 2 & 20 & 23.8 & 7 & 18 & LF-HF-M \\
\hline 3 & 21 & 22.1 & 11 & 17 & LE-HF-M \\
\hline 4 & 21 & 22.1 & 15 & 19 & L.F-HF-M \\
\hline 5 & 21 & 23.2 & 7 & 17 & $H F-I F-M$ \\
\hline 6 & 21 & 22.5 & 6 & 17 & HF-LF-M \\
\hline 7 & 19 & 27.5 & 4 & 20 & LF-iF \\
\hline 8 & 21 & 22.1 & 9 & 19 & $\mathrm{HF}-\mathrm{LF}$ \\
\hline 9 & 20 & 27.4 & 3 & 6 & $\mathrm{LF}-\mathrm{HF}-\mathrm{M}$ \\
\hline 10 & 22 & 23.4 & 1 & 12 & $\mathrm{HF}-\mathrm{L}-\mathrm{F}-\mathrm{M}$ \\
\hline 11 & 19 & 23.8 & 4 & 11 & HF-LF-M \\
\hline 12 & 19 & 20.0 & 0 & 10 & LF-HF-M \\
\hline 13 & 24 & 20.2 & 0 & 7 & L.F-HF-M \\
\hline 14 & 20 & 23.3 & 4 & 6 & $\mathrm{HF}-\mathrm{LF}-\mathrm{M}$ \\
\hline 15 & 19 & 19.4 & 5 & 7 & HF-LF \\
\hline 16 & 20 & 23.0 & 6 & 13 & HF-LF \\
\hline
\end{tabular}

\section{Attitude towards eating}

Restrained and unrestrained eating subjects were selected by means of the scores on psychometric questionnaires. Two types of psychometric questionnaires were used: the Herman-Polivy (H-P) restraint scale (18) which is designed to identify dieters and is mainly weight-concerned (19), and the Three Factor Eating Questionnaire (TFEQ) of Stunkard et al. (20) which is designed to measure successful dieting and is mainly food-concerned (19). Using the Herman-Polivy restraint scale, we can discriminate between being restrained or unrestrained 


\section{Chapter 8}

eaters. Considering studies of Westerterp-Plantenga et al. (19.21-22), the median of the Herman-Polivy scores in the subject population we use at the Department of Human Biology, University of Limburg, Maastricht was 15 . Thus, subjects with a score $>15$ were classified as restrained eaters and subjects with a score $\leq 15$ were classified as unrestrained eaters. The TFEQ of Stunkard et al. (20) was used to discriminate between 'cognitive restraint' and unrestraint, concerning the scores on the cognitive restraint factor $F_{1}$. The median of the scores on $F_{1}$ in our population of subjects was 9 (19,21-22), implying that subjects with a $F_{1}$ score $>9$ were classified as cognitive restraint, and a score $\leq 9$ as unrestraint. Overall, subjects were classified as restrained eaters when the $\mathrm{H}-\mathrm{P}$ score $>15$ or $\mathrm{F}_{1}$ score $>9$; unrestrained eating subjects had a $\mathrm{H}-\mathrm{P}$ score $\leq 15$ and $\mathrm{F}_{1}$ score $\leq 9$. From the eight subjects in the present study classified as restrained eaters, one subject was restraint by being food-concerned, five subjects by being weight-concerned, and two subjects by being food- and weight-concerned.

\section{Experimental design}

Subjects were fed to energy balance consuming a low-fat diet and a high-fat diet over 3-day intervals. The order of administration of low-fat and high-fat diet was randomized. Twelve subjects additionally consumed a mixed diet. The interval between two experimental periods was at least 4 days. The first two days on each dietary regimen the provided food was consumed at home, followed by the last. day of each period while the subjects stayed in a respiration chamber for \pm 36 hours. In this chamber oxygen consumption, carbon dioxide production, and hence energy expenditure, were the main measurements (see below). Energy intake for the maintenance of energy balance was based on the calculated BMR (23) of the subjects multiplied by 1.76 on days 1 and 2 (24); energy intake on day 3 while being in the respiration chamber equalled $1.29 \times$ BMR (25).

\section{Diets}

All three diets were taken as 4 meals daily: a breakfast at $8.00 \mathrm{~h}$ containing 20 per cent of the daily energy intake, a lunch at $13.00 \mathrm{~h}$ (25 energy \%), a dinner at $18.00 \mathrm{~h}$ (45 energy \%) and an evening snack at $20.30 \mathrm{~h}$ (10 energy \%). The daily energy intake was the same for the three diets with a different macronutrient composition $(=8.0 \mathrm{MJ} / \mathrm{d})$. The low-fat $(\mathrm{LF})$ diet provided $73.2 \mathrm{~g} / \mathrm{d}$ protein $(=15$ energy $\%), 20.8 \mathrm{~g} / \mathrm{d}$ fat $(\approx 10$ energy $\%), 360.7 \mathrm{~g} / \mathrm{d}$ carbohydrate $(\approx 75$ energy $\%)$ and $18.0 \mathrm{~g} / \mathrm{d}$ dietary fibre; the mixed $(\mathrm{M})$ diet $67.9 \mathrm{~g} / \mathrm{d}$ protein $(=15$ energy $\%)$, $62.6 \mathrm{~g} / \mathrm{d}$ fat $(=30$ energy \%), $266.0 \mathrm{~g} / \mathrm{d}$ carbohydrate $(=55$ energy \%) and 27.6 $\mathrm{g} / \mathrm{d}$ dietary fibre; and the high-fat (HF) diet $70.9 \mathrm{~g} / \mathrm{d}$ protein $(\approx 15$ energy $\%)$, $106.0 \mathrm{~g} / \mathrm{d}$ fat $(=50$ energy \%), $170.6 \mathrm{~g} / \mathrm{d}$ carbohydrate $(=35$ energy \%) and 19.4 $\mathrm{g} / \mathrm{d}$ dietary fibre. Metabolizable energy intake and macronutrient composition of the diets were calculated using the Dutch food composition table (26). The value of the food quotient (FQ) as defined by Flatt (27) was $0.94,0.88$ and 0.82 respectively, for the LF-, $\mathrm{M}$ - and HF-diet. 
Determination of $24 \mathrm{hEE}, \mathrm{SMR}_{n}$ DIT and $A C T$

Energy expenditure ( 24 h EE) was measured on the third day of each dietary regimen using a respiration chamber. This measurement allowed to assess SMR and DIT separately (see below) and calculate ACT (energy expenditure due to physical activity in the respiration chamber) as $24 \mathrm{~h} \mathrm{EE}$ minus SMR minus DIT. Energy expenditure was calculated according to Weir (28) from $\mathrm{O}_{2}$ consumption and $\mathrm{CO}_{2}$ production. The respiration chamber measures $14 \mathrm{~m}^{3}$ and is furnished with a bed, chair, table, TV, radio, telephone, wash-bowl and toilet facilities (29). The chamber is ventilated with fresh air at $50 \mathrm{l} / \mathrm{min}$. The ventilation rate was measured with a dry gasmeter (Schlumberger, type G6). The concentration of oxygen and carbon dioxide was measured using a paramagnetic $\mathrm{O}_{2}$ analyser (Servomex, type OA 184) and an infrared $\mathrm{CO}_{2}$ analyser (Hartman \& Braun, type URAS 3G). Ingoing air was analysed once every $15 \mathrm{~min}$. and outgoing air once every $5 \mathrm{~min}$. The gas sample to be measured was selected by a computer which also stored and processed the data. The physical activity of the subjects was monitored by means of a radar system, based on the Doppler principle. In daytime subjects were allowed to move freely, to sit, lie down, study, teiephone, listen to the radio and watch television, only sleeping and strenuous exercise were not allowed.

$24 \mathrm{~h}$ EE was calculated from $7.30 \mathrm{~h}$ to $7.30 \mathrm{~h}$. SMR was measured from $3.00 \mathrm{~h}$ to $6.00 \mathrm{~h}$, when subjects were asleep. The method used for determination of DIT was previously described by Schutz et al. (30) and is based on simultaneous measurements of both physical activity and energy expenditure of the subjects. The individual relationship between the physical activity and energy expenditure both averaged over $30 \mathrm{~min}$. periods was plotted. Only the intervals after the firsi meal until bedtime were used, i.e. from $8.00 \mathrm{~h}$ to $23.00 \mathrm{~h}$. The intercept of the regression line at zero activity represents the energy expenditure in the inactive state ( $E_{0}$ activity) consisting of two components: SMR and DIT. By subtracting SMR from $E_{0}$ activity we obtained DIT, thus including the energy cost of arousal (31). ACT was assessed by $24 \mathrm{~h}$ EE minus SMR minus DIT. Thus, the separate compartments of energy metabolism are obtained by the following equations:

$\mathrm{SMR}=$ measured from $3.00 \mathrm{~h}$ to $6.00 \mathrm{~h}$

$\mathrm{DIT}=\mathrm{EE}_{\mathrm{O}}$ activity $-\mathrm{SMR}$

$A C T=24$ h EE - SMR - DTT

Body weight

Subjects weighed theirselves (without clothing) in the morning of day 1, 3 and 4 upon rising, after voiding and before any food/drink consumption, on a digital balance (Seca delta, model 707 ) accurate to $0.1 \mathrm{~kg}$. 


\section{Chapter 8}

\section{Analysis of data}

The effects of diet composition on $24 \mathrm{~h}$ EE, SMR, DIT and ACT were analysed by repeated measures analysis of variance (ANOVA) and Scheffé F-tests or paired ttests. Using a two-factor ANOVA (unbalanced model) with the grouping factors 'attitude towards eating' (restrained or unrestrained) and 'second treatment' (lowfat or high-fat diet), we revealed that there was no significant effect of one of these factors on $24 \mathrm{~h}$ EE of the third treatment which was always the mixed diet ('attitude towards eating' $x$ 'second treatment' interaction: $\mathrm{df} 1, \mathrm{~F}$-value: 0.18 , $\mathrm{p}=0.682$ ). Changes between the groups of restrained and unrestrained eating subjects were tested using unpaired t-tests. Correlation between physical activity and energy expenditure was analysed using the Pearson correlation coefficient. In the text, tables and figures data are presented as the mean and standard error of the mean (SE).

\section{Results}

\section{Energy metabolism}

Over the 3-day intervals, provided energy intake (EI) was based on the calculated BMR of individual subjects. They were instructed to consume all food itens and returned any left overs. Mean EI of the twelve subjects who consumed all three diets is presented in Table 8.2. $24 \mathrm{~h}$ EE was not significantly different between subjects on the LF-, M-, or HF-diet, although there was a trend (repeated measures ANOVA, df 2, F-value: 3.40, $\mathrm{p}=0.052$ ) towards an decreased $24 \mathrm{~h}$ EE at a M- and HF-diet. Comparing the results of LF- and M-diet, 24 h EE was significantly decreased on the M-diet (df 11, paired t-value: $2.58, p=0.026$ ). Energy balance, i.e. EI minus $24 \mathrm{~h}$ EE, was slightly negative on all three diets. According to Garrow (32), adult subjects are in energy balance when the difference between EĨ and $\mathrm{EE} \leq 600 \mathrm{~kJ} / \mathrm{d}$.

\section{SMR. DIT and ACT}

SMR, DIT and ACT for subjects on all three diets are presented in Table 8.3. The method used for determination of DIT was based on simultaneous measurements of both physical activity of the subjects and energy expenditure. Within individuals, physical activity and energy expenditure were related significantly, except for subject 3 on the LF- and HF-diet. Therefore, Table 8.3 represents data of $1 \mathrm{i}$ subjects ( 5 restrained, 6 unrestrained eating subjects).

SMR, DIT and ACT were not significantly affected by the diet composition, not expressed in $\mathrm{kJ} / \mathrm{min}$ nor expressed as a percentage of $24 \mathrm{~h} \mathrm{EE}$. The contribution of DIT to energy metabolism was highest on the LF-diet and lowest on the HF-diet, but differences were not statistically significant. 
Table 8.2 Mean energy intake (EI), energy expenditure (24h hE) and energy balance (EI-24 h EE) for the twelve subjects on all three diets. Data of El and $24 \mathrm{~h} \mathrm{EE}$ are expressed in MJ/d; data of energy balance in $\mathrm{MJ} / \mathrm{d}$ and as a percentage of $24 \mathrm{~h} \mathrm{EE}$.

\begin{tabular}{|c|c|c|c|c|c|c|}
\hline & \multicolumn{2}{|c|}{ Law-fat } & \multicolumn{2}{|c|}{ Mixed } & \multicolumn{2}{|c|}{ High-fat } \\
\hline & Mean & SE & Mean & SE & Mean & SE \\
\hline E & 8.1 & 0.1 & 8.0 & 0.1 & 8.1 & 0.1 \\
\hline $24 \mathrm{~h} \mathrm{EE}$ & 8.7 §ฐป & 0.2 & $8.4^{8}$ & 0.1 & 8.5 I & 0.2 \\
\hline $\mathrm{EI}-24 \mathrm{~h} \mathrm{EE}$ & -0.6 & 0.2 & -0.4 & 0.2 & -0.4 & 0.2 \\
\hline EJ-24 h EE (\%) & -6.1 & 1.8 & -4.5 & 1.8 & -4.4 & 1.7 \\
\hline
\end{tabular}

$824 \mathrm{~h} \mathrm{EE}$ low-fat vs. mixed diet; df 11 , paired t-value: $2.58, \mathrm{p}=0.026$

I $24 \mathrm{~h} \mathrm{EE}$ low-fat vs. high-fat diet; df 11 , paired t-value: $1.67, \mathrm{p}=0.123$ (NS)

Table 8.3 Mean sleeping metabolic rate (SMR), diet induced thermogenesis (DTT) and energy expenditure due to physical activity (ACT) in the respiration chamber for eleven subjects on all three diets. Data are expressed in $\mathrm{kJ} / \mathrm{min}$ and as a percentage of $24 \mathrm{~h} \mathrm{EE}$.

\begin{tabular}{|c|c|c|c|c|c|c|}
\hline & \multicolumn{2}{|c|}{ Low-fat } & \multicolumn{2}{|c|}{ Mixed } & \multicolumn{2}{|c|}{ High-fat } \\
\hline & Mean & SE & Mean & SE & Mean & SE \\
\hline $\operatorname{SMR}(\mathrm{kJ} / \mathrm{min})$ & 4.29 & 0.10 & 4.26 & 0.10 & 4.18 & 0.09 \\
\hline DIT (kJ/min) & $0,90^{8}$ & 0.11 & 0.75 & 0.15 & $0.53 \AA$ & 0.19 \\
\hline $\mathrm{ACT}(\mathrm{kJ} / \mathrm{min})$ & 0.85 & 0.14 & 0.85 & 0.14 & 1.17 & 0.23 \\
\hline $\operatorname{SMR}(\%)$ & 71.2 & 0.9 & 72.8 & 1.3 & 71.3 & 1.4 \\
\hline DIT (\%) & $14.9^{9}$ & 1.9 & 12.7 & 2.5 & $9.2 \%$ & 3.1 \\
\hline $\operatorname{ACT}(\%)$ & 13.9 & 2.2 & 14.5 & 2.4 & 19.6 & 3.5 \\
\hline
\end{tabular}

$\$$ DrT ( $\mathrm{kJ} / \mathrm{min}$ ) low-fat vs. high-fat diet; df 10 , paired t-value: $1.82, \mathrm{p}=0.098$ (NS)

I $\operatorname{DrT}(\%)$ low-fat vs, high-fat diet; df 10 , paired $t$-value: $1.73, \mathrm{p}=0.115$ (NS) 


\section{Restrained or unrestrained attitude towards eating}

Table 8.4 presents mean $24 \mathrm{~h}$ EE, SMR, DIT and ACT for the restrained and unrestrained eating subjects on the three diets. Mean $24 \mathrm{~h}$ EE was not significantly different between the restrained and unrestrained eating subjects, not on the LFnor on the M- or HF-diet. There were also no significant differences for SMR, DIT and ACT between restrained and unrestrained eating subjects.

Within the group of restrained eaters, $24 \mathrm{~h} \mathrm{EE}$ was significantly lower (repeated measures ANOVA, df 2, F-value: 6.45 , $\mathrm{p}=0.016$ ) on the M- and HFdiet, compared to the LF-diet (Table 8.5). Comparing the results of one diet versus another, $24 \mathrm{~h} \mathrm{EE}$ on the M-diet was significantly lower (df 5, paired t-value: 4.78 , $p=0.005$ ), and on the HF-diet tended to be lower (df 5, paired t-value: 2.50 , $p=0.055$ ) than on the LF-diet. Within the group of unrestrained eating subjects, diet composition had no significant effect on $24 \mathrm{~h}$ EE (repeated measures ANOVA, df 2, F-value: $0.38, p=0.694$ ).

Table 8.4 Mean $24 \mathrm{~h} \mathrm{EE,} \mathrm{SMR,} \mathrm{DIT} \mathrm{and} \mathrm{ACT} \mathrm{for} \mathrm{restrained}(\mathrm{n}=8)$ and unrestrained eating subjects $(n=8)$ on the three diets. Data of $24 \mathrm{~h}$ EE are expressed in MJ/d; data of SMR, DIT and $\mathrm{ACT}$ as a percentage of $24 \mathrm{~h} \mathrm{EE}$.

\begin{tabular}{|c|c|c|c|c|c|c|}
\hline & \multicolumn{6}{|c|}{ RESTRAINED EATING SUBJECTS } \\
\hline & \multicolumn{2}{|c|}{ Low-fat } & \multicolumn{2}{|c|}{ Mixed $^{\S}$} & \multicolumn{2}{|c|}{ High-fat } \\
\hline & Mean & SE & Mean & SE & Mean & SE: \\
\hline 24 h EE (MJ/d) & 8.7 & 0.2 & 8.2 & 0.2 & 8.4 & 0.3 \\
\hline $\operatorname{SMR}(\%)$ & 71.3 & 0.7 & 75.0 & 1.4 & 72.3 & 1.4 \\
\hline DIT $(\%)^{\mathbf{I}}$ & 13.7 & 2.5 & 11.6 & 4.2 & 8.1 & 4.9 \\
\hline \multirow[t]{4}{*}{$\operatorname{ACT}(\%) !$} & 15.3 & 3.0 & 13.3 & 4.3 & 19.8 & 5.2 \\
\hline & \multicolumn{6}{|c|}{ UNRESTRAINED EATING SUBJECTS } \\
\hline & \multicolumn{2}{|c|}{ Low-fat } & \multicolumn{2}{|c|}{ Mixed $^{\S}$} & \multicolumn{2}{|c|}{ High-fat } \\
\hline & Mean & SE & Mean & SE & Mean & SE \\
\hline $24 \mathrm{~h} \mathrm{EE} \mathrm{(MJ/d)}$ & 8.6 & 0.3 & 8.7 & 0.1 & 8.5 & 0.2 \\
\hline $\operatorname{SMR}(\%)$ & 71.4 & 1.2 & 70.8 & 1.4 & 69.8 & 1.7 \\
\hline $\operatorname{DrT}(\%)$ & 16.3 & 1.8 & 15.7 & 2.9 & 11.4 & 1.2 \\
\hline $\operatorname{ACT}(\%)$ & 12.2 & 2.2 & 13.5 & 2.9 & 18.7 & 2.2 \\
\hline$n=6$ & & & & & & \\
\hline for low-fa & - & $t: n=7$ & & & & \\
\hline
\end{tabular}


Table 8.5 Mean $24 \mathrm{~h}$ EE for restrained $(\mathrm{n}=6)$ and unrestrained eating subjects ( $\mathrm{n}=6$ ) on all three diets (LF: low-fat diet; M: mixed diet; HF; high-fat diet). Data are expressed in MJ/d.

\begin{tabular}{lcccc}
\hline & \multicolumn{2}{c}{ Restrained eaters } & \multicolumn{2}{c}{ Unrestrained eaters } \\
& Mean & SE & Mean & SE \\
\hline 24 h EE (LF) & $8.6^{89}$ & 0.2 & 8.8 & 0.3 \\
24 h EE (M) & $8.2^{8}$ & 0.2 & 8.7 & 0.1 \\
24 h EE (HF) & $8.2^{\text {I }}$ & 0.3 & 8.7 & 0.1 \\
& & & & \\
\hline
\end{tabular}

8 Restrained eating subjects LF- vs. M-diet; df 5, paired t-value: 4.78, $\mathrm{p}=0.005$

I Restrained eating subjects LF- vs. HF-diet; df 5, paired t-value: $2.50, \mathrm{p}=0.055$ (NNS)

\section{Body weight measurements}

Table 8.6 presents mean changes in body weight during the 3-day experimental period. Resulis of eight subjects on all three diets are presented; data of subjects 1 , 9, 10 and 11 were not complete with respect to body weight measurements. The discrepancy between body weight on days 1 and 3 was representative of free living conditions, whereas the comparison between days 3 and 4 gave information about the situation in an experimentally controlled environment, i.e. the respiration chamber. On all three diets there was a slight increase in body weight during days 1 and 2, when subjects consumed the provided diet at home. During the stay in the respiration chamber body weight decreased with $0.5 \mathrm{~kg}$ on average. Over the 3 day intervals body weight changes were nonsignificantly different from zero. There were no significant differences in changes of body weight due to the composition of the diet.

Table 8.6 Mean changes in body weight during the 3-day experimental period for eight subjects ( 5 restrained eaters, 3 unrestrained eaters) on the three diets. Data are expressed in $\mathrm{kg}$.

\begin{tabular}{lrrrrrrr}
\hline & \multicolumn{2}{c}{ Low-fat } & \multicolumn{2}{c}{ Mixed } & \multicolumn{2}{c}{ High-fat } \\
Observation interval & Mean & SE & Mean & SE & Mean & SE \\
& & & & & & \\
\hline Day 1 and 2 (home) & & & & & & & \\
Day 3 (respiration chamber) $\mathbf{T}$ & -0.29 & 0.18 & +0.26 & 0.12 & +0.21 & 0.17 \\
Day 1 through $3{ }^{\dagger}$ & -0.45 & $0.1 !$ & -0.48 & 0.10 & -0.55 & 0.11 \\
& -0.16 & 0.15 & -0.21 & 0.20 & -0.34 & 0.16
\end{tabular}

8. LF-vs. M- and HF-diet; repeated measures ANOVA, df 2, F-value: $0.11, p=0.897$ (NS)

I LF-vs. $\mathrm{M}$ - and HF-diet; repeated measures ANOVA, of 2, F-value: $0.20, p=0.825$ (NS)

₹ LF-vs. M- and HF-diet; repeated measures ANOVA, df 2, F-value: $0.34, p=0.720$ (NS) 


\section{Discussion}

The results of the present study showed no significant effect of the composition of the diet on $24 \mathrm{~h} \mathrm{EE}$. However, there was a trend $(p=0.052)$ towards an decreased $24 \mathrm{~h} \mathrm{EE}$ on the M- and HF-diet (Table 8.2) and, comparing the results of one diet versus another, $24 \mathrm{~h} \mathrm{EE}$ on the M-diet was significantly lower than on the LF-diet. Hurni et al. (7), studying the effects of an isoenergetic exchange of fat and carbohydrate in lean subjects, reported only a tendency to expend less energy on a M-diet than on a LF-diet. However, differences in diet composition were less extreme than in the present study, reflected by the food quotients (FQ) of the diets (Hurni et al.: LF-diet $F Q=0.94$, M-diet $F Q=0.84$; this study: $L F-d i e t ~ F Q=0.94$, $\mathrm{M}$-diet $\mathrm{FQ}=0.82$ ). Other studies on this topic failed to demonstrate any effect of dietary fat and carbohydrate exchange on $24 \mathrm{~h} \mathrm{EE} \mathrm{(8),} \mathrm{or} \mathrm{reported} \mathrm{a} \mathrm{lower} 24 \mathrm{~h} \mathrm{EE}$ on a HF-diet than on a LF-diet in post-obese subjects (9).

Furthermore, the influence of diet composition on the separate compartments of energy metabolism was studied. Earlier studies indicated a decreased SMR on a HF-diet compared to a LF-diet (7), or no effect at all (8-9). In the present study, no significant effect of diet composition on SMR was observed (Table 8.3). The contribution of DIT to energy metabolism was expected to be lower on a HF-diet (9,12). According to Acheson et al. (33), the explanation for this finding could be the greater obligatory cost of glycogen storage and a facultative increase in thermogenesis due to glucogenic stimulation of the sympathetic nervous system (34). Abbott et al. (8), however, found no change in DIT due to the composition of the diet. In the present study no effect of dietary fat and carbohydrate exchange on DIT was observed either, although the contribution of DIT to energy metabolism was highest on the LF-diet and lowest on the HF-diet (Table 8.3). Possibly because of the high intra-person variability statistical significance was not reached. Considering the energy expenditure for physical activity, no significant effect of diet composition could be observed, not in an earlier study (8) nor in the present study.

A second objective of this study was to examine whether the influence of diet composition was different for different types of subjects, to explain possible consequences of both attitude towards eating and diet composition for developing obesity. There were no significant differences foi $24 \mathrm{~h} \mathrm{EE}, \mathrm{SMR}$. DIT and ACT between the groups of restrained and unrestrained eating subjects, not on the LFdiet nor on the M- or HF-diet (Table 8.4). Within the group of restrained eating subjects, $24 \mathrm{~h}$ EE was significantly lower during the M- and HF-diet, compared to the LF-diet (Table 8.5). Therefore, the decreased $24 \mathrm{~h} \mathrm{EE}$ on the M- and HF-diet as observed for all subjects $(n=12)$ was on account of the group of restrained eating subjects (Tables 8.2,8.5). Tuschl et al. (17) conducted a study on the relationship between average daily metabolic rate and the eating behaviour of female normal weight subjects. Although the group of restrained eating subjects had a higher BMI compared to the unrestrained eating subjects, self-reported 
energy intake and measured energy expenditure were significantly lower. Because body weight did not change during the observation period, this should mean that restrained eating subjects have diminished energetic requirements, which in turn can induce chronic weight concern. On the other hand, restrained eaters report multiple dieting periods with various weight fluctuations, resulting in a decreased energy expenditure. In the present study, BMI did not differ significantly between the groups of restrained and unrestrained eating subjects. Nevertheless, the response of restrained and unrestrained eating subjects to dietary exchange of fat and carbohydrate differed substantially. Considering the results with respect to development and treatment of obesity a LF-diet would be beneficial, especially if subjects have a restrained type of eating behaviour.

In conclusion, dietary exchange of fat and carbohydrate had no significant effect on $24 \mathrm{~h} \mathrm{EE}$, although there was a trend towards a decreased $24 \mathrm{~h} \mathrm{EE}$ at a Mand HF-diet. When the relevant subject characteristics were taken into account, 24 h EE was significantly lower at a M- and HF-diet compared to a LF-diet in restrained eating subjects, reflecting a possible risk factor at $\mathbf{M}$ - and HF-diets in developing obesity. Dietary composition had no significant effect on the compartments of energy metabolism SMR, DIT and ACT.

\section{References}

1 Dreon DM, Frey-Hewitt B, Ellsworth N, Williams PT, Terry RB and Wood PD (1988): Dietary fat: carbohydrate ratio and obesity in middle-aged men. Am J Clin Nutr 47: 995 . 1000

2 Romieu I, Willett WC, Stampfer MJ, Coldizz GA, Sampson L, Rosner B, Hennekens CH and Speizer FE (1988): Energy intake and other determinants of relative weight. Am J Clin Nut 47: 406-412

3 Tremblay A. Plourde G, Despres JP and Bouchard C (1989): Impact of dietary fat content and fat oxidation on energy intake in humans. Am J Clin Nutr 49: 799-805

4 Duncan KH, Bacon JA and Weinsier RL (1983): The effects of high and low energy density diets on satiety, energy intake and eating time of obese and nonobese subjects. Am J Clin Nutr 37: 763-767

5 Lissner L, Levitsky DA, Strupp BJ, Kalkwarf HJ and Roe DA (1987): Dietary fat and the regulation of energy intake in human subjects. Am J Clin Nutr 46: 886-892

6 Ravussin E, Lillioja S, Knowler WC, Christin Ln, Freymond D, Abbott WGH, Boyce V, Howard BV and Bogardus C (1988): Reduced rate of energy expenditure as a risk factor for body-weight gain. New Engl J Med 318: 467-472

7 Hurni M, Burnand. B, Pittet P and Jéquier E (1982): Metabolic effects of a mixed and a high-carbohydrate low-fat diet in man, measured over $24 \mathrm{~b}$ in a respiration chamber. $\mathrm{Br} J$ Nutr 47: $33-43$

8 Abbott WGH, Howard BV, Ruotolo G and Ravussin E (1990): Energy expenditure in humans: Effects of dietary fat and carbohydrate. Am J Physiol 258: E347-E351 
9 Lean MEJ and James WPT (1988): Metabolic effects of isoenergetic nutrient exchange over 24 hours in relation to obesity in wornen. Int J Obes 12: 15-27

10 MeNeill G, Bruce AC, Ralph A and James WPT (1988): Inter-individual differences in fasting nutrient oxidation and the influence of diet composition. Int J Obes 12: $455-463$

11 Flatt JP (1985): Energetics of intermediary metabrolism. In: Substrate and energy metabclism in man, eds JS Garrow and E Halliday, pp. 58-69. London: Libbey

12 Schwartz RS, Ravussin E, Massari M, O'Connell M and Robbins DC (1985): The thersnic effect of carbohydrate versus fat feeding in man. Metabolism 34: 285-293

13 Nair KS, Halliday D and Garrow JS (1983): Thermic response to isoenergetic protein, carbohydrate or fat meals in lean and obese subjects. Clin Sci 65: 307-312

14 Swaminathan R, King RFJ, Holmfield J and Wales JK (1981): Dietary fat induced thermogenesis in obesity. Clin Sci 62: 16P'

15 Zed C and James WPT (1986): Dietary thermogenesis in obesity: fat feeding at different energy intakes. Int J Obes 10: 375-390

16 Laessle RG, Tuschl RJ, Kotthaus BC and Pirke KM (1989): Behavioral and biological correlations of dietary restraint in normal life. Appetite 12: 83-94

17 Tuschl RJ, Platte P, Laessle RG, Stichler W and Pirke KM (1990): Energy expenditure and everyday eating behavion in healthy young women. Am J Clin Nutr 52: 81-86

18 Herman CP and Polivy J (1980): Restrained eating. In: Obesity, ed A Stunkard, pp. 208224. Philadelphia: WB Saunders

19 Westerterp-Plantenga MS, Wouters L and Ten Hoor F (1991): Restrained eating, obesity and cumulative food inake curves during four-course meals. Appecite 16: 149-158

20 Stunkard $\mathrm{N}$ and Messick $S$ (1985): The three factor eating questionnaire to measure dietary restraint, disinhibition and hunger. Psych Res 29: 71-83

21 Westernerp-Plantenga MS, Wouters $\mathrm{L}$ and Ten Hoor F (1990): Deceleration in cumulative lood intake curves, changes in body temperature, and diet-induced thermogenesis. Physiol Behav 48: 831-836

22 Westerterp-Plantenga MS, Westerterp KR, Nicolson NA, Mordant A. Schoffelen PFM and Ten Hoor F (1990): The shape of the curnulative food intake curve in humans, during basic and manipulated meals. Physiol Behav 47: 569-576

23. Harris JA and Benedict FG (1919): $A$ biometric study of basal metabolism in man. Camegie Institution. of Washington 190

24 Verbocket-van de Venne WPHG, Westerterp K.R and Kester ADM. Effect of the pattern of food intake on human energy metabolism (Chapter 3 this thesis)

25 Verboeket-van de Venne WPHG and Westerterp KR (1991): Influence of the feeding. frequency on nutrient utilization in man: Consequences for energy metabolism. Eur J Clin Nutr 45: 161-169

26 Kommissie UCV. Uitgebreide voedingsmiddelen tabel (1985). Den Haag: Voorlichtingsbureau voor de voeding

27 Flatt JP (1987): Dietary fat, carbohydrate balance, and, weight maintenance: Effects of exercise. Am J Clin Nutr 45: 296-306

28 Weir JB de V (1949); New methods for calculating metabolic rate with special reference to predict protein metabolism. J Physiol 109: 1-9 
29 Schoffelen PFM, Saris WHM, Westerterp KR and Ten Hoor F (1984): Evaluation of an automatic indirect calorimeter for measurement of energy balance in man. In: Human energy metabolism: Physical activity and energy expenditure measurements in epidemiological research based upon direct and indirect calorimetry, Euro Nut Report 5, ed AJH Van Es, pp. 51-54. Wageningen: The Netherlands Nutrition Foundation

30 Schutz $Y$, Bessard $T$ and Jéquier E (1984): Diet-induced thermogenesis measured over a whole day in obese and nonobese women. Am J Clin Nutr 40: 542-552

31 Goldberg GR, Prentice A.M, Davies HL and Murgatroyd PR (1988): Overnight and basal metabolic rates in men and women. Eur J Clin Nutr 42: 137-144

32 Gañow JS (1974): Energy balance and obesity in man. Amsterdam: North Holland Publishing Company, 1974

33 Acheson KJ, Schutz Y, Bessard T, Ravussin E and Jequier E (1984): Nutritional influences on lipogenesis and thermogenesis after a carbohydrate meal. Am J Physiol 246: E62-E70

34 Acheson KJ, Ravussin E, Wahren J and Jequier E (1984): Thermic effect of glucose in man: obligatory and facultative thermogenesis. J Clin Invest 74: 1572-1580 



\section{Chapter 9}

\section{General discussion}

Pattern of energy intake and diet composition are often cited as variables that can influence energy' balance and hence body weight. A small number of large meals per day is accompanied by more storage and mobilization of energy than a large number of small meals and thus may influence energy balance. In this thesis effects of the pattern of energy intake on energy metabolism and on substrate oxidation have been described in normal weight healthy subjects (short-term effect: Chapter 2; long-term effect: Chapter 3), in moderately obese women on a slimming diet for 4 weeks (Chapter 4 ) and in patients with cirrhosis of the liver (Chapter 6). To investigate whether a reduced ability to store glycogen in the liver is reflected in the pattern of energy intake, the habitual pattern of energy intake was studied in patients with liver disease (Chapter 5). The effect of diet composition on energy metabolism and substrate oxidation was studied in normal weight subjects with a restrained or unrestrained attitude towards eating (Chapters 7 and 8 ). Thus the association between susceptibility of subjects to become obese and their response to a high fat intake was evaluated.

To interpret the effects of a change in meal frequency or diet composition correctly, it is important that subjects are in energy balance during the observation period. Feeding subjects to energy balance is not easy to accomplish. In the studies described in this thesis, 24 h energy requirements were based on measured SMR (Chapter 2), calculated BMR (1) (Chapters 6-8) or self-reported energy intake using a 7-day food record (Chapter 3). Pooled data on energy expenditure of all healthy subjects $(n=39)$ measured in the respiration chamber revealed that 24 h EE equalled 1.31 $\times$ BMR (Coefficient of Variation: $6.8 \%$ ) and $1.40 \times$ SMR (CV: $6.0 \%)$. For patients with cirrhosis of the liver $(n=8) 24 \mathrm{~h} \mathrm{EE}$ was found to be $1.47 \times$ BMR (CV: $12.4 \%$ ) and $1.31 \times$ SMR (CV: $6.5 \%)$. Measured SMR per $\mathrm{kg}$ fat-free mass was significantly increased in these patients. Daily energy expenditure in free living conditions $(n=10)$ averaged $1.69 \times$ BMR $(C V: 7.2 \%)$ and $1.82 \times$ SMR (CV: $4.6 \%)$.

Goldberg et al. (2) recently reviewed data from studies on energy expenditure measured in physically restricted conditions (3-11) and in free living conditions $(8,12-16)$. For subjects with a sedentary life-style " 24 h energy expenditure in physically restricted conditions averaged $1.35 \mathrm{x}$ measured BMR and in free living conditions $1.67 \times$ measured BMR (men: $1.78 \times$ BMR; women: $1.62 \times$ BMR). Considering the fact that BMR is higher than SMR due to the 
energy costs of arousal, these data are comparable to the results of the studies described in this thesis.

When subjects were fed according to their self-reported energy intake (Chapter 3), daily energy expenditure in free living conditions was underestimated by 16.0 (sd 8.7 ) \%. Livingstone et al. (13) studying the accuracy of weighed dietary records, reported that energy expenditure in free living conditions was underestimated by 18.9 (sd 21.7) \% in adult men with physical characteristics comparable to those of the subjects of Chapter 3. Reasons for this phenomenon included underreporting of energy intake and/or undereating during the observation period, indicated by loss of body weight (17).

It is concluded that daily energy requirements are most accurately predicted when energy requirements are based on measured SMR. In healthy subjects calculated BMR can be used as well for estimation of energy requirements, since there is little difference in the coefficient of variation compared with estimates based on measured SMR. However, in patients with cirrhosis of the liver it is recommended to base energy requirements on measured SMR. Self-reported energy intake underestimates daily energy requirements.

\section{Pattern of energy intake}

\section{Effects on energy metabolism}

In the experiments described in this thesis dietary energy was supplied with a minimal or maximal spreading throughout the day. A gorging pattern of energy intake always consisted of two meals daily that were consumed at $12.00 \mathrm{~h}$ and 18.00h (Chapters 2, 3, 4 and 6). A nibbling pattern consisted of 7 meals daily with the first meal at $7.30 \mathrm{~h}$ and the last meal at $20.30 \mathrm{~h}$ in normal weight healthy subjects (Chapters 2 and 3), 3-5 meals with the first meal at 7.30h and the last meal between $18.00 \mathrm{~h}$ and $21.00 \mathrm{~h}$ in moderately obese women on a slimming diet (Chapter 4 ), or 4 meals with the first meal at $7.30 \mathrm{~h}$ and the last meal at $22,30 \mathrm{~h}$ in patients with liver cirrhosis (Chapter 6). In all studies described above, it was revealed that the pattern of energy intake has no significant effect on 24 h energy expenditure as measured in restricted or in free living conditions. Other studies also failed to observe a significant effect of meal frequency on energy metabolism (18-20).

The components SMR, DIT and ACT were also not affected by the pattern of energy intake. The observed increase in total energy expenditure between $19.00 \mathrm{~h}-$ $7.00 \mathrm{~h}$ when on the gorging pattern (Fig. 3.2) was similar to findings of Dallosso et al. (19). One explanation for this result could be a prolonged DIT during the evening and night, due to the meal at $18.00 \mathrm{~h}$ containing 60 per cent of daily energy intake. Support for this hypothesis is given by Kinabo and Durnin (21), reporting higher DIT values on a meal of high energy content compared with a meal of low energy content. Schutz et al. (22), investigating the metabolic effects of over- 
feeding, observed that thermogenesis was prolonged during the day and even throughout the subsequent night. In the study described in Chapter 3, the effect of meal frequency on DIT was determined from the first meal until bedtime at $23.00 \mathrm{~h}$. If thermogenesis is prolonged throughout the night, which might have been the case on the gorging pattern, we would not have noticed this because of the method used for the assessment of DIT.

\section{Effects on substrate oxidation}

Substrate oxidation was studied by comparing the $\mathrm{RQ}$, reflecting the composition of the fuel mixture oxidized, with the calculated FQ of the diet. Periods of lipogenesis were defined as $\mathrm{RQ}>\mathrm{FQ}$ and periods of lipolysis as $\mathrm{RQ}<\mathrm{FQ}$. By measuring oxygen consumption, carbon dioxide production and urinary nitrogen excretion, oxidation of protein, fat and carbohydrate was determined (23).

In both healthy subjects and patients with cirrhosis of the liver, there was no significant effect of meal frequency on $24 \mathrm{~h} \mathrm{RQ}, 24 \mathrm{~h} \mathrm{NPRQ}$ or $24 \mathrm{~h}$ oxidation of protein, fat or carbohydrate. During the period from $9.00 \mathrm{~h}-12.00 \mathrm{~h}$ (i.e. the preprandial interval), the $\mathrm{RQ}$ was significantly decreased on a gorging pattern compared with a nibbling pattern of intake, reflecting a higher oxidation ratio of fat to carbohydrate (Fig. 6.1).

In healthy subjects there was a marked fluctuation of lipogenesis and lipolysis with a gorging pattern of energy intake. Fat oxidation was significantly increased from $9.00 \mathrm{~h}-12.00 \mathrm{~h}$ on the gorging pattern, whereas oxidation of carbohydrate was decreased during the same period. Furthermore, carbohydrate oxidation was increased from $18.00 \mathrm{~h}-21.00 \mathrm{~h}$ on the gorging pattern, indicating an enhanced lipogenic activity during the interval following the second meal.

Cirrhotic patients on a gorging pattern of energy intake showed a similar fluctuation in $\mathrm{RQ}$ as the healthy subjects, but during the period of waking up and rising in the morning (i.c. $6.00 \mathrm{~h}-9.00 \mathrm{~h}$ ) the RQ remained low in these patients. This was reflected by the high proportion of energy that was derived from fat oxidation from $6.00 \mathrm{~h}-12.00 \mathrm{~h}$, even in cirrhotic patients on a nibbling pattern consuming a breakfast at $7.30 \mathrm{~h}$ (Fig. 6.3), suggesting that patients with cirrhosis of the liver have reduced liver glycogen stores. Swart et al. (24) hypothesized that during an overnight fast, glycogen stores of cirrhotic patients are insufficient to ensure a normal blood glucose level, resulting in an increased gluçoneogenesis from amino acids. This will lead to extra amino acid loss and hence depletion of tissue protein stores. The findings of the study described in Chapter 6, indicating that nocturnal protein oxidation (i.e. $24.00 \mathrm{~h}-6.00 \mathrm{~h}$ ) is increased on a gorging pattern of energy intake, support this hypothesis. A pattern of energy intake including a late evening meal might delay the otherwise early onset of gluconeogenesis in these patients so that extra amino acid loss is diminished, resulting in a more positive (or less negative) nitrogen balance (25). Considering the habitual pattern of energy intake in patients with liver disease (Chapter 5), it is suggested that the inclusion of a breakfast into the daily pattern of food intake 
might have beneficial effects too. It has been reported that the period to reach a catabolic state (in which most of the energy is derived from fat) was much shorter in patients with cirrhosis of the liver as compared with healthy controls (26-28). Thus, even after a late evening meal and an overnight fast of 9 hours (as described in Chapter 6) glucose cannot be provided in sufficient amounts because of depleted glycogen stores in the liver, resulting in an increased use of fat as an altemative fuel. It is concluded that in patients with cirrhosis of the liver the pattern of energy intake is an essential factor for maintenance of energy- and substrate balance. A pattern of food intake with a maximal spreading of meals throughout the day (including an early breakfast and a late evening meal) would minimize episodes of catabolism in these patients.

\section{Effects on body weight and body composition}

In all studies there was no significant effect of the pattern of energy intake on body weight or body composition. In healthy adult men on a gorging and nibbling pattern of energy intake for 7 days each, body weight changes $(-0.6 \mathrm{~kg} / 14 \mathrm{~d})$ wer: not significantly different from zero (Chapter 3). Patients with cirrhosis of the liver showed a significant decrease in body weight $(-0.2 \mathrm{~kg} / \mathrm{d})$ during the stay in the respiration chamber (Chapter 6 ). However, the change in body weight was not. related to the pattern of energy intake. In moderately obese women on a reducing diet with or without a breakfast, body weight significantly decreased after 4 weeks of dieting (Chapter 4). Body weight loss averaged $4.4 \mathrm{~kg} / 28 \mathrm{~d}$ of which $2.5 \mathrm{~kg}$ as fat mass and $1.9 \mathrm{~kg}$ as fat-free mass. Again, the change in body weight and body composition was not affected by the pattern of energy intake.

Information on the influence of meal frequency on body weight and body composition is not consistent. In isoenergetic conditions body weight was found to be increased on a gorging pattem (19). Studies on the effect of meal frequency in hypocaloric conditions reported that weight loss was greater on a nibbling diet (29-30), or that there was no relationship between meal frequency and rate of weight loss (31-32) or rate of fat mass loss (33). Schlundt et al. (34) conducted a study on the role of breakiast in the treatment of obesity, taking into account the habitual breakfast-eating habits of the subjects. After 12 weeks of treatment, baseline breakfast eaters lost more weight on a no-breakfast treatment, whereas baseline breakfast skippers lost more weight on a breakfast treatment, suggesting that subjects who had to make the most substantial changes in eating habits achieved better results with regard to weight loss. Subjects on the breakfast treatment showed a concomitant reduction in dietary fat intake and less impulsive eating of snacks, suggesting that incorporation of a breakfast into a slimming diet is beneficial in the treatment of obesity.

Summarizing, the available data from literature together with our own data do not allow definite conclusions as to the effects of the pattern of energy intake on body weight and body composition. 


\section{Diet composition}

\section{Effects on energy metabolism}

The effects of isoenergetic low-fat (high-carbohydrate) and high-fat (lowcarbohydrate) diets on energy metabolism were studied in normall weight subjects with a restrained or unrestrained attitude towards eating (Chapter 8 ). There were no significant differences in $24 \mathrm{~h}$ EE, SMR, DIT or ACT between these two groups. Within groups, in restrained eating subjects $24 \mathrm{~h}$ EE was significantly increased on a low-fat diet compared with a mixed and high-fat diet. In unrestrained eating subjects there was no effect of these diets on $24 \mathrm{~h} \mathrm{EE}$. Other studies investigating the effects of an isoenergetic exchange of fat and carbohydrate reported no change in $24 \mathrm{~h} \mathrm{EE}$ for normal weight and obese subjects (35-40). In post-obese subjects, who are supposed to be restrained eaters, $24 \mathrm{~h} \mathrm{EE}$ was found to be increased on a low-fat diet when compared with a high-fat diet (37), and also when compared with normal weight controls on a low-fat diet (41). In free living conditions, Tuschl et al. (42) reported that daily energy expenditure was significantly lower in normal weight subjects with a restrained attitude towards eating. Suggestions to explain this phenomenon included a biological predisposition to a low energy expenditure (43), or an adaptation of energy expenditure to repeated cycles of weight loss and weight gain (44).

In conclusion, $24 \mathrm{~h}$ EE was significantly increased in restrained eating subjects on a low-fat diet, compared with a mixed diet and a high-fat diet. Thus, a diet with a low fat content might be beneficial in the prevention of obesity in these subjects.

\section{Effects on substrate oxidation}

In Chapter 7 the short-term effects of dietary fat and carbohydrate on substrate oxidation have been described. On a high-fat diet $24 \mathrm{~h} \mathrm{RQ}$ was similar to $24 \mathrm{~h} \mathrm{FQ}$ indicating substrate balance, whereas on a low-fat and mixed diet RQ was lower than $F Q$ reflecting the oxidation of more fat than ingested and/or less carbohydrate than ingested. These data are supported by similar findings reported in literature (35,37-39). In subjects with a restrained attitude towards eating a high-fat diet resulted in a significantly lower oxidation of fat than in unrestrained eating subjects. A low-fat diet resulted in a negative fat balance in restrained as well as unrestrained eaters. However, the fat balance tended to be less negative in restrained than in unrestrained eaters (Table 7.4). Both observations suggest that restrained eaters have a smaller ability to oxidize fat than unrestrained eaters. Thomas et al. (40) reported that in response to a low-fat diet obese subjects oxidized proportionally less fat and more carbohydrate than lean subjects. There was a positive relationship between fat intake and fat oxidation in lean subjects consuming a high-fat diet, but not in obese subjects. Our data and those from Thomas et al. (40) suggest that in restrained eating subjects and obese subjects fat oxidation may be more difficult than in unrestrained eaters, resulting in an easy 


\section{Chapter 9}

storage and a less easy mobilization of fat, explaining the higher susceptibility of restrained eating subjects to become obese.

\section{Conclusions}

1 Energy requirements in sedentary conditions are best predicted when they are based on measured SMR. In normal weight healthy subjects calculated BMR can be used as well.

2 In patients with cirrhosis of the liver, it is recommended to base energy requirements on measured SMR.

3 Seli-reported energy intake underestimates daily energy requirements.

4 The pattern of energy intake has no significant effect on $24 \mathrm{~h}$ energy expenditure nor on the components SMR, DIT and ACT.

5 In healthy subjects there is a marked fluctuation of lipogenesis and lipolysis with a gorging pattern of energy intake.

6 The habitual pattern of energy intake in patients with liver disease is characterized by a relatively high energy intake $( \pm 30 \%$ of daily energy intake) during the first four hours after rising.

7 In patients with cirrhosis of the liver, episodes of catabolism are minimized on a pattern of energy intake including an early breakfast and a late evening meal.

8 The pattern of energy intake, as observed over intervals up to 4 weeks, has no measurable effects on (changes in) body weight and body composition.

9) For subjects with a restrained attitude towards eating, $24 \mathrm{~h} \mathrm{EE}$ is significantly increased on a low-fat diet compared with a mixed diet and a high-fat diel.

10 In response to a high-fat diet, the increase in fat oxidation is smaller in resirained eating subjects compared with unrestrained eating subjects.

11 Subjects with a restrained attitude towards eating are more susceptible to become obese because they oxidize relatively less fat and more carbohydrate compared with unrestrained eating subjects.

12 Restrained eating subjects are advised to consume a low-fat diet. 


\section{References}

1 Harris JA and Benedict FG (1919): A biometric study of basal metabolism in man. Carnegie Institution of Washington 190

2 Goldberg GR, Black AE, Jebb SA, Cole TJ, Murgatroyd PR, Coward WA and Prentice AM (1991): Critical evaluation of energy intake data using fundamental principles of energy physiology: 1. Derivation of cut-off limits to identify under-recording. Eur J Clin Nutr 45: 569-581

3 Ravussin E, Burnand B, Schutz. Y and Jéquier E (1982): Twenty-four hour energy expenditure and resting metabolic rate in obese, moderately obese, and control subjects. Am J Clin Nutr 35: 566-573

4 Bessard T, Schutz $\mathrm{Y}$ and Jéquier E (1983): Energy expenditure and postprandial thermogenesis in obese women before and after weight loss. Am J Clin Nutr 38: 680-693

5 Dallosso HM and James WPT (1984): Whole-body calorimetry studies in adult men. 1. The effect of fat overfeeding on $24 \mathrm{~h}$ energy expenditure. Br J Nutr 52: 49-64

6 Ravussin E, Schutz Y, Acheson KJ, Dusmet M, Bourquin L and Jéquier E (1985): Shortterm mixed-diet overfeeding in man: No evidence for 'luxuskonsumption'. Am J Physiol 249: E470-E477

7 Garby L.,. Lammert $O$ and Nielsen E (1986): Energy expenditure over 24 hours on low physical activity programmes in human subjects. Hum Nutr: Clin Nutr $40 \mathrm{C}:$ 141-150

8 Prentice AM, Black AE, Coward WA, Davies HL, Goldberg GR, Murgatroyá PR, Ashíord J, Sawyer M and Whitehead RG (1986):High levels of energy expenditure in obese women. Br Med J 292: 983-987

9 Zed C and James WPT (1986): Dietary thermogenesis in obesity: Fat feeding at different energy intakes. Int J Obes 10: 375-390

10 Warwick PM, Edmundsom HM and Thompson ES (1988): Prediction of energy expenditure: Simplified FAONHO/UNU factorial method vs continuous respirometry and habitual energy intake. Am J Clin Nutr 48: 1188-1196

11 McNeill G, McBride A. Smith JS and James WPT (1989): Energy expenditure in large and small eaters. Nutr Res 9: 363-372

12 Bingham SA. Goldberg GR, Coward WA, Prentice AM and Cummings JH (1989): The effect of exercise and improved physical fitness on basal metabolic rate. Br J Nutr 61: 155 163

13 Livingstone MBE, Prentice AM, Strain JJ, Coward WA, Black AE, Barker ME, McKenna PG and Whitehead RG (1990): Accuracy of weighed dietary records in studies of diet and health. Br Med J 300: 708-712

14 Diaz EO, Prentice AM; Goldberg GR, Murgatroyd PR and Coward WA (1991): Metabolic and behavioural responses to altered energy intake in man. 1. Experimental overfeeding. Proc Nutr Soc 50: 110A

15 Goldberg GR, Black AE, Prentice AM and Coward WA. (1991): No evidence of lower energy expenditure in post-obese women. Proc Nutr Soc 50: 109A 
16 Goldberg GR, Davies HL, Prentice AM, Coward WA, Sawyer M, Ashford J, Murgatroyd and Black AE (1991): How is the energy budget balanced in well-nourished lactating women? Proc Nutr Soc 50: 8A

17 Schoeller DA, Bandini LG and Dietz WH (1990): Inaccuracies in self-reported intake identified by comparison with the doubly labelled water method. Can J Physiol Pharmacol 68: $941-949$

18 Swindells YE, Holmes SA and Robinson MF (1968): The metabolic response of young women to changes in the frequency of meals. $\mathrm{Br} \mathrm{J}$ Nutr 22: 667-680

19 Dallosso HM, Murgatroyd PR and James WPT (1982): Feeding frequency and energy balance in adult males. Hum Nutr: Clin Nutr 36C: $25-39$

20 Wolfram G, Kirchgeßner M, Múller HL and Hollomey S (1987): Thermogenese des Menschen bei unterschiedlicher Mahlzeitenhäufigkeit. Ann Nutr Metab 31: 88-97

21 Kinabo JL and Dumin JVGA (1990): Thermic effect of food in man: Effect of meal composition, and energy content. Br J Nutr 64: 37-44

22 Schutz $\mathrm{Y}$, Acheson KJ and Jéquier E (1985): Twenty-four hour energy expenditure and thermogenesis: Response to progressive carbohydrate overfeeding in man. Int J Obes 9: $111-114$

23 Jéquier E, Acheson $\mathrm{K}$ and Schutz $\mathrm{Y}$ (1987): Assessment of energy expenditure and fuel utilization in man. Ann Rev Nutr 7: 187-208

24 Swart GR, Van den Berg IWO. Wattimena ILD, Rietveld T, Van Vuure JK and Frenkel M (1988): Elevated protein requirements in cirrhosis of the liver investigated by whole body protein tumover studies. Clin Sci 75: 101-107

25 Swart GR, Zillikens MC, Van Vuure JK and Van den Berg JWO (1989): Effect of a late evening meal on nitrogen balance in patients with cirrhosis of the liver. Br Med J 299: 1202-1203

26 Owen OE, Trapp VE, Reichard A, Mozzoli MA, Moctezuma J, Paul P, Skutches CL and Boden G (1983): Nature and quantity of fuels consumed in patients with alcoholic cirnosis of the liver. J Clin Invest 72: 1821-1832

27 Marchesini G, Bianchi GP, Zoli M and Checchia GA (1987): Glucose homeostasis in cirrhosis. In: Cirrhosis of the liver: Methods and fields of research, eds $\mathrm{N}$ Tygstrup and $\mathrm{F}$ Orlandi, pp. 165-176. Elsevier Science Publishers B. V. (Biomedical Division)

28 Schneeweiss B, Graninger W, Ferenci P. Eichinger S. Grimm Gi, Schneider B, Laggner AN, Lenz K and Kleinberger G (1990): Energy metabolism in patients with acute and chronic liver disease. İepatology 11: 387-393

29 Debry G. Rohr R. Azouaou R. Vassilitch I and Mottaz G (1973): Ponderal losses in obese subjects submitted to restricted diets differing by nibbling and by lipid and carbohydrate. In: Energy balance in man, ed M Apfelbaum, pp. 305-310. Paris: Masson

30 Kudlicka V, Fábry P, Dobersky P and Kudlicková V (1966). Proc. VIIth Internat. Congress of Nutrition, pp. 264. Hamburg: Pergamon Press.

31 Bortz WM, Wroldsen A, Issekutz B and Rodahl K (1966): Weight loss and frequency of feeding. New Engl J Med 274: 376-379

32 Finkelstein B and Fryer BA (1971): Meal frequency and weight reduction of young women. Am J Clin Nutr 24: $465-468$ 
33 Garrow JS, Durrant M, Blaza S, Wilkins D, Royston P and Sunkin S (1981): The effect of meal frequency and protein concentration on the composition of the weight lost by obese subjects. Br J Nutr 45: 5-15

34 Schlundt DG, Hill JO, Sbrocco T. Pope-Cordle J and Sharp T (1992): The role of breakfast in the treatment of obesity: A randomized clinical trial. Am J Clin Nutr 55: 645651

35 Humi M, Burnand B, Pittet P and Jéquier E (1982): Metabolic effects of a mixed and a high-carbohydrate low-fat diet in man, measured over $24 \mathrm{~h}$ in a respiration chamber. $\mathrm{Br} \mathrm{J}$ Nutr 47: $33-43$

36 Wolfram G, Kirchgeßner M, Müller HL and Hollomey S (1985): Energiebilanzversuche mit fettreicher Diăt beim Menschen. Ann Nutr Metab 29: 23-32

37 Lean MEJ and James WPT (1988): Metabolic effects of isoenergetic nutrient exchange over 24 hours in relation to obesity in women. Int J Obes 12: 15-27

38 Abbott WGH, Howard BV, Ruotolo G and Ravussin E (1990): Energy expenditure in humans: Effects of dietary fat and carbohydrate. Am J Physiol 258: E347-E351

39 Hill JO, Peters JC, Reed GW, Schlundt DG, Sharp T and Greene HL (1991): Nutrient balance in humans: Effects of diet composition. Am J Clin Nutr 54: 10-17

40 Thomas CD, Peters JC, Reed GW, Abumrad NN, Sun M and Hill JO (1992): Nutricnt balance and energy expenditure during ad libitum feeding of high-fat and high-carbohydrate diets in humans. Am J Clin Nutr 55: 934-942

41 Astrup A, Buemann B, Christensen NJ and Madsen J (1992): 24-Hour energy expenditure and sympathetic activity in postobese women consuming a high-carbohydrate diet. Am J Physiol 262: E282-E288

42 Tuschl RJ, Platte P, Laessle RG, Stichler W and Pirke KM (1990): Energy expenditure and everyday eating behavior in healthy young women. Am J Clin Nutr 52:81-86

43 Bouchard C, Tremblay A, Nadeau A et al. (1989): Genetic effect in resting and exercise metabolic rates. Metabolism 38: 364-370

44 Steen SN, Oppliger RA and Brownell KD (1988): Metabolic effects of repeated weight loss and regain in adolescent wrestlers. JAMA 260: 47-50.

45 Westerterp-Plantenga MS, Wouters L and Ten Hoor F (1991): Restrained eating, obesity, and cumulative food intake curves during four-course meals. Appetite 16: 149-158 



\section{Summary}

Energy balance and hence body weight is influenced by nutritional factors including the pattern of energy intake and diet composition. A small number of large meals (gorging pattern) is accompanied by more storage and mobilization of energy than a large number of small meals (nibbling pattern). A diet high in fat is often associated with an increasing prevalence of obesity, the latter possibly due to a decreased energy expenditure or a reduced ability to adjust fat oxidation to fat intake. In this thesis the effects of the pattern of energy intake and of diet composition on energy metabolism and substrate oxidation are investigated.

Chapter 2 describes the short-term effects of meal frequency on the diurnal pattern of substrate oxidation in healthy young adults. There is no significant effect of the pattern of energy intake on $24 \mathrm{~h}$ energy expenditure ( $24 \mathrm{~h} \mathrm{EE}$ ). A gorging pattern of energy intake results in a stronger diurnal periodicity of lipogenesis and lipolysis, compared to a nibbling pattern. On a gorging pattern, carbohydrate oxidation is decreased during the fasting period (from rising in the morning until the first meal), whereas fat oxidation is increased during the same period to cover energy needs. On a nibbling pattern carbohydrate and fat oxidation remain relatively constant during the active hours of the day.

Chapter 3 reports on the influence of the pattern of energy intake on $24 \mathrm{~h}$ energy metabolism (in both free living and experimentally controlled conditions) and on its components basal metabolic rate (BMR), diet induced thermogenesis (DIT) and energy expenditure due to physical activity (ACT). During one week healthy adult subjects are fed to estimated energy balance at two meals per day and during another week at seven meals per day. There is no significant effect of meal frequency on the average daily metabolic rate (ADMR) or $24 \mathrm{~h}$ EE. BMR and ACT are not different between the two patterns either. DIT is significantly elevated on the goiging pattern, but this effect is neutralized as the elevation is over a shorter time interval.

The effects of meal frequency on the rate and composition of weight loss and on energy metabolism are studied in moderately obese women on a slimming diet for 4 weeks (Chapter 4). There is no significant effect of the pattern of energy intake on the rate of weight loss, fat mass loss or fat-free mass loss. Meal frequency has no significant effect on the sleeping metabolic rate (SMR), not after 2. weeks nor after 4 weeks of dieting. The decrease in SMR after 4 weeks is significantly greater in subjects on the nibbling diet. $24 \mathrm{~h} \mathrm{EE}$ and DIT are not significantly different between the two eating patterns.

To investigate whether a reduced ability to store glycogen in the liver is reflected in the pattern of energy intake, the habitual pattern of energy intake is studied in patients with liver disease (Chapter 5). Total energy intake is not different between patients with liver disease and healthy control subjects. When energy intake is expressed per $\mathrm{kg}$ body mass, intake is significantly lower for the 
patient group. Intake of protein and alcohol is similar for both groups, whereas fat intake is reduced and carbohydrate intake is increased in patients with liver disease. Considering the pattern of energy and macronutrient intake, energy intake and protein intake are significantly increased in the patients during the first four hours after rising in the morning. During the late evening the contribution of carbohydrate to energy intake is higher in the patient group than in the control group. These findings are probably functional in order to minimize episodes of catabolism in patients with liver disease.

Chapter 6 reports on the effects of the pattern of energy intake on energy metabolism and substrate oxidation in patients with cirrhosis of the liver. $24 \mathrm{~h} \mathrm{EE}$ expressed as a multiple of SMR is decreased in patients with cirrhosis, due to an increased SMR per $\mathrm{kg}$ fat-free mass. In both groups, patients with cirrhosis and healthy control subjects, the respiratory quotient $(R Q)$ is significantly lower during the morning preprandial period on a gorging pattern $(9.00 \mathrm{~h}-12.00 \mathrm{~h})$, reflecting a higher oxidation ratio of fat to carbohydrate compatible to a more catabolic state. During the period from $6.00 \mathrm{~h}-12.00 \mathrm{~h}$, the contribution of fat oxidation to total energy expenditure in cirrhotic patients is $58 \%$ on the gorging pattern and as high as $50 \%$ on the nibbling patern where the patients consume a breakfast. During the same period, carbohydrate oxidation is significantly decreased on the gorging pattern, compared to the nibbling pattern. Our data suggest that patients with liver cirrhosis should eat according to a nibbling pattem. An early breakfast and a late evening meal shorten the episodes of catabolism occurring during the night and in the morning, improving energy and substrate balances in patients with liver cirrhosis.

Chapters 7 and 8 describe the results of a study on the short-term effects of dietary fat and carbohydrate exchange on substrate oxidation and energy metabolism. To elucidate the metabolic responses to dietary fat and carbohydrate of subjects being more or less susceptible to become obese, the subject characteristics of a restrained or unrestrained attitude towards eating are taken into account. Oxidation of fat and carbohydrate significantly increases with, respectively, an increasing fat and carbohydrate content of the diet, for both restrained and unrestrained eating subjects. Restrained eating subjects show a reduced fat oxidation compared to unrestrained eaters in response to a high-fat diet, resulting in a positive fat balance for restrained eating subjects. On a low-fat diet fat balance is negative for both groups of subjects, indicating mobilization of energy from endogenous body fat stores. In conclusion, restrained eating subjects have more difficulty in the handling of a high-fat diet, which can be a possible explanation for their higher susceptibility to become obese. $24 \mathrm{~h} \mathrm{EE}$ and its components SMR. DIT and ACT are not significantly different between the restrained and unrestrained eating subjects. Within the group of restrained eating subjects, $24 \mathrm{~h} \mathrm{EE}$ is increased on the low-fat diet, compared to the mixed and high-fat diet. Diet composition has no effect on $24 \mathrm{~h} \mathrm{EE}$ in the unrestrained eating subjects. 


\section{Samenvatting}

Het patroon van voedselopname en de samenstelling van de voeding zijn twee factoren die van invloed kunnen zijn op de energiebalans en het lichaamsgewicht. Het nuttigen van enkele grote maaltijden per dag (gorging patroon) gaat gepaard met meer opslag en mobilisatie van energie dan een patroon van voedseiopname dat bestaat uit meerdere kleine maaltijden per dag (nibbling patroon). Het nuttigen van een vetrijke voeding wordt vaak in verband gebracht met een verhoogd risico voor overgewicht, dat laatste mogelijk vanwege een verlaagd energiegebruik of vanwege een verminderde capaciteit om de verbranding van vetten te verhogen als reactie op een hoge vetopname. In dit proefschrift zijn de effecten beschreven van het patroon van voedselopname en de samenstelling van de voeding op het energie- en substraatgebruik.

In hoofdstuk 2 zijn de korte-termijn effecten beschreven van de maaltijdfrekwentie op het dagelijks patroon van substraatverbranding van gezonde jong volwassenen. Er is geen significant effect van het patroon van voedselopname op het 24 uurs energiegebruik. Een gorging patroon van voedselopname resulteert in een sterkere afwisseling van lipogenese (vetsynthese en opslag) en lipolyse (vetverbranding), vergeleken met een nibbling patroon. Tijdens een gorging patroon is de koolhydraatverbranding verlaagd tijdens de periode van vasten (vanaf het opstaan 's morgens tot de eerste maaltijd), terwijl de vetverbranding in diezelfde periode verhoogd is om in de energiebehoefte te voorzien. Tijdens een nibbling patroon blijven koolhydraat- en vetverbranding overdag relatief constant.

Hoofdstuk 3 beschrijft de invloed van het patroon van voedselopname op het 24 uurs energiegebruik (in dagelijkse leefomstandigheden en in een respiratiekamer met overwegend zittende activiteit) en op de onderdelen basaalstofwisseling (BMR), dieet geïnduceerde thermogenese (DIT) en het energiegebruik voor lichamelijke activiteit (ACT). Er is geen significant effect van de maaltijdfrekwentic op het 24 uurs energiegebruik in dagelijkse leefomstandigheden of in een respiratiekamer. BMR en ACT zijn niet verschillend tussen beide maaltijdpatronen. DIT is significant verhoogd tijdens een gorging patroon van voedselopname, maar dit effect verdwijnt wanneer gecorrigeerd wordt voor het tijdsinterval waarover DIT bepaald wordt.

In hoofdstuk 4 zijn de effecten beschreven van de maaltijdfrekwentie op de mate en samenstelling van gewichtsverlies bij vrouwen met overgewicht tijdens een 4 weken durende dieetperiode. Er is geen significant effect van het patroon van voedselopname op de mate van gewichtsverlies of verlies, van vetmassa of vet-vrije massa. De maaltijdfrekwentie heeft evenmin effect op de slaapstofwisseling (SMR), niet na 2 weken noch na 4 weken dieet. De daling in SMR na 4 weken is groter bij die personen die tijdens hun dieet een ontbijt nuttigen. Er is geen verschil in 24 uurs energiegebruik en DIT tussen beide maaltijdpatronen. 
Patiënten met een leveraandoening hebben een verminderde capaciteit om een tijdelijk overschot aan energie op te slaan. Hoofdstuk 5 beschrijft het spontane patroon van voedselopname bij patiënten met een leveraandoening. De totale energieopname is niet significant verschillend tussen patiënten met een leveraandoening en gezonde controle personen. De energieopname per $\mathrm{kg}$ lichaamsgewicht is significant lager voor de patiëntgroep. Opname van eiwit en alcohol is gelijk voor beide groepen, terwijl de vetopname verlaagd en de koolhydraatopname verhoogd is bij patiënten met een leveraandoening. De energie- en eiwitopname zijn significant verhoogd in de patiëntgroep tijdens de eerste vier uur na opstaan. 's Avonds is de bijdrage van koolhydraten aan de energieopname verhoogd in de patiëntgroep, vergeleken met de controle groep. Deze resultaten zijn waarschijnlijk van belang in het vermijden of beperken van periodes van catabolisme bij patiënten met een leveraandoening.

Hoofdstuk 6 beschrijft de invloed van het patroon van voedselopname op het energie- en substraatgebruik bij patiënten met levercirrhose. Het 24 uurs energiegebruik uitgedrukt als veelvoud van SMR is verlaagd bij patiënten met levercirrhose, als gevolg van een verhoogd SMR per kg vet-vrije massa. Zowel bij patiënten met levercirrhose als gezonde controle personen, is het respiratoir quotient (RQ) significant verlaagd tussen $9.00 \mathrm{~h}$ en $12.00 \mathrm{~h}$ tijdens een gorging patroon van voedselopname. Dit betekent dat er relatief meer vetten en relatief minder koolhydraten verbrand worden. Tussen $6.00 \mathrm{~h}$ en $12.00 \mathrm{~h}$ is de bijdrage van vet aan het energiegebruik bij patiënten met levercirrhose $58 \%$ tijdens een gorging patroon van voedselopname, en $50 \%$ tijdens een nibbling patroon terwijl hier een ontbijt genuttigd wordt. In diezelfde periode is de koolhydraatverbranding significant verlaagd tijdens een gorging patroon. Samenvattend kan geconcludeerd worden dat een nibbling patroon van voedselopname aanbeveling verdient voor patiënten met levercirrhose. Door het nuttigen van een ontbijt en een late avondmaltijd worden periodes van catabolisme tijdens de nacht en vroege ochtend vermeden of tenminste beperkt.

In de hoofdstukken 7 en 8 zijn de resultaten beschreven van een onderzoek naar de korte-termijn effecten van isoenergetische uitwisseling van vet en koolhydraat op het energie- en substraatgebruik. Om de metabole respons van een vetarme cq. vetrijke voeding te bestuderen bij personen die meer of minder gevoelig zijn om overgewicht te ontwikkelen, zijn personen geselecteerd met een geremd of ongeremd eetgedrag. Verbranding van vetten en koolhydraten neemt significant toe bij een toename van respectievelijk de hoeveelheid vetten en koolhydraten in de voeding. Personen met een geremd eetgedrag hebben een verlaagde vetverbranding vergeleken met ongeremde eters als reactie op een vetrijke voeding, resulterend in een positieve vetbalans bij geremde eters. Tijdens een vetarme voeding is de vetbalans negatief voor zowel geremde als ongeremde eters. Dit betekent dat energie gemobiliseerd wordt uit de vetreserves van het lichaam. Samenvattend kan gezegd worden dat personen met een geremd eetgedrag meer moeite hebben om een vetrijke voeding te verwerken. Dit kan een 
mogelijke verklaring zijn voor hun grotere gevoeligheid voor het ontwikkelen van overgewicht. Het 24 uurs energiegebruik en de onderdelen SMR, DIT en ACT zijn niet significant verschillend tussen personen met een geremd of ongeremd eetgedrag. Bij geremde eters is het 24 uurs energiegebruik verhoogd tijdens een vetarme voeding, vergeleken met een gemiddelde vette of vetrijke voeding. De samenstelling van de voeding heeft geen effect op het 24 uurs energiegebruik van personen met een ongeremd eetgedrag. 



\begin{tabular}{|c|c|}
\hline $\mathrm{ACT}$ & energy expenditure for physical activity \\
\hline ADMR. & average daily metabolic rate \\
\hline BM & body mass \\
\hline BMI & body mass index \\
\hline BMR & basal metabolic rate \\
\hline $\mathrm{CO}_{2}$ & carbon dioxide \\
\hline d & day \\
\hline df & degrees of freedom \\
\hline DIT & diet induced thermogenesis \\
\hline $\mathrm{EE}$ & energy expenditure \\
\hline $24 \mathrm{~h} \mathrm{EE}$ & 24 hour energy expenditure \\
\hline $\mathrm{EE}_{0}$ activity & energy expenditure in the inactive state \\
\hline El & $\begin{array}{l}\text { energy intake calculated according to the Dutch food } \\
\text { composition table ( }=\text { metabolizable energy) }\end{array}$ \\
\hline F & female \\
\hline FM & fat mass \\
\hline FFM & fat-free mass \\
\hline $\mathrm{FQ}$ & food quotient \\
\hline $\mathrm{h}$ & hour \\
\hline $\mathrm{HF}$-diet & high-fat (low-carbohydrate) diet \\
\hline${ }^{2} \cdot \mathrm{H}_{2} \mathrm{O}$ & deuterium \\
\hline${ }^{2} \mathrm{H}_{2}{ }^{18} \mathrm{O}$ & doubly labeled water \\
\hline $\mathrm{kJ}$ & kilojoule \\
\hline LF-diet & low-jat (high-carbohydrate) diet \\
\hline M & male \\
\hline M-diet & mixed diet \\
\hline M] & megajoule $(1000 \mathrm{~kJ})$ \\
\hline $\mathrm{n}$ & number \\
\hline $\mathrm{N}$ & nitrogen \\
\hline NPRQ & non-protein respiratory quotient \\
\hline $\mathrm{D}_{2}$ & oxygen \\
\hline RMR & resting metabolic rate \\
\hline RQ & respiratory quotient \\
\hline SD & standard deviation \\
\hline $\mathrm{SE}(\mathrm{M})$ & standard error (of the mean). \\
\hline SMR & sleeping metabolic rate \\
\hline TBW & total body water \\
\hline wk & week \\
\hline
\end{tabular}





\section{Nawoord}

Tijdens mijn werkzaamheden de afgelopen vier jaar bij de vakgroep Humane Biologie heb ik met veel mensen samengewerkt. Op deze plaats wil ik iedereen bedanken voor hun bijdrage aan de totstandkoming van dit proefschrift. Een aantal mensen wil ik graag met name noemen.

Allereerst mijn co-promotor Dr. Klaas Westerterp, die mij enthousiast maakte voor dit onderzoek. Zijn vakinhoudelijke ondersteuning en practische ervaring in het onderzoek waren van groot belang.

Mijn promotor Prof. dr. Foppe ten Hoor, die altijd tijd wist vrij te maken om de onderzoeksresultaten, en in een later stadium het proefschrift, te bespreken.

De leden van de beoordelingscommissie, Prof. dr. M.J. Drop. Prof. dr. J.E. Blundell, Prof. dr. R.W. Stockbrügger, Prof. dr. ir. A.J.H. van Es en Prof. dr. ir. R.J.J. Hermus, wil ik bedanken voor de waardevolle suggesties en opmerkingen over mijn proefschrift.

Ook gaat mijn dank uit naar Dr. Margriet Westerterp-Plantenga, die mij wegwijs maakte in de materie van geremd en ongeremd eetgedrag. Onze discussies hebben zeker bijgedragen aan de interpretatie van de onderzoeksresultaten.

Dr. Bart van Hoek en Dr. Roel Swart wil ik bedanken voor de goede samenwerking en nuttige adviezen tijdens en na het onderzoek bij leverpatiënten.

Dr. Arnold Kester ben ik dank verschuldigd voor de statistische ondersteuning.

De proefpersonen en patiënten wil ik bedanken voor hun vrijwillige deelname en medewerking aan de onderzoeken. Ik heb veel bewondering yoor de wijze waarop zij zich aanpasten aan de door mij opgelegde voedingsregimes.

Suzanne Koster, Ingrid Sprenger, Doremieke Donkers en Mignon de Jager, die als stagiaires bij de verschillende projecten betrokken waren.

Loek Wouters, voor het analyseren van de vele urinemonsters. Bovendien kon ik altijd een beroep op hem doen bij technische problemen.

Paul Schoffelen, voor de ondersteuning bij de talrijke respiratiekamermetingen.

Annemie Gijsen, voor het uitvoeren van de stikstofbepalingen. 
Mijn kamergenoten op Beeldsnijdersdreef 101, Ellen van den Heuvel, Ruud Hermus, Margriet Westerterp-Plantenga, Nicole Duysens en Wouter van Marken Lichtenbelt, voor de plezierige werksfeer en nuttige discussies over de verschillende onderzoeken.

Mijn huidige kamergenoten, Daphne Pannemans en Carlijn Bouten, wil ik vooral bedanken voor hun morele ondersteuning ten tijde van de afronding van mijn proefschrift.

Mijn peetoom Harrie Slangen, die altijd een warme belangstelling toonde voor mijn werkzaamheden. Helaas komt mijn promotie enkele maanden te laat voor hem.

Mijn ouders wil ik bedanken voor de wijze waarop zij altijd voor me klaarstonden.

Tot slot gaat mijn dank uit naar René, die mij steeds motiveerde om door te gaan en die mij ook ondersteunde wanneer mijn universitaire werkzaamheden zich uitbreidden tot avonden, weekenden en feestdagen. 


\section{Curriculum vitae}

Wilhelmine P.H.G. Verboeket-van de Venne werd op 9 januari 1966 in Roermond geboren. In 1984 behaalde zij het VWO diploma aan het Bouwens van der Boye College te Helden-Panningen. In datzelfde jaar begon zij haar studie biologie aan de Katholieke Universiteit Nijmegen, om in januari 1989 het doctoraal examen te behalen, met als hoofdvak Dierfysiologie (Drs. J.P.H. Oskam, Drs. R.G.J.M. Hanssen en Prof. dr. S.E. Wendelaar Bonga) en als bijvak Gynaecologie (Dr. H.J.M. Goverde en Prof. dr. R. Rolland), Per 1 januari 1989 trad zij in dienst als assistent in opleiding (A.I.O.) bij de vakgroep Humane Biologie (Dr. K.R. Westerterp en Prof. dr. F. ten Hoor) aan de Rijksuniversiteit Limburg te Maastricht. Het onderzoek dat zij daar gedurende vier jaar verrichtte is beschreven in dit proefschrift. 



\section{Publications}

* Van de Venne WPHG, Westerterp KR and Ten Hoor F (1990) (abstr.): Influence of the feeding frequency on nutrient utilization in man. Voeding 51: 156-157

* Van de Venne WPHG, Westerterp KR and Ten Hoor F (1990) (abstr.): Influence of the feeding frequency on nutrient utilization in man. Int 1 Obes 14 (Suppl. 2): 52

- Verboeket-van de Venne WPHG and Westerterp KR (1991): Influence of the feeding frequency on nutrient utilization in man: Consequences for energy metabolism. Eur J Clin Nutr 45: 161-169

* Verboeket-van de Venne WPHG and Westerterp KR (1991) (abstr.): Substraat- en energiegebruik als functie van het patroon van de energieopname. Voeding 52: 15

* Verboeket-van de Venne WPHG, Westerterp KR and Ten Hoor F (1991) (abstr.): Effect of the pattern of food intake on human energy metabolism. Int J Obes 15 (Suppl. 1): 60

* Verboeket-van de Venne WPHG, Westerterp KR and Kester ADM: Effect of the pattern of food intake on human energy metabolism. Br J Nutr (in press)

* Verboeket-van de Venne WPHG and Westerterp KR: Frequency of feeding, weight reduction and energy metabolism. Int 3 Ohes (in press)

* Verboeket-van de Venne WPHG, Westerterp KR and Ten Hoor F (abstr.): Influence of dietary fat on human substrate balance. Am I Clin Nuts (in press)

* Verboeket-van de Venne WPHG, Westerterp KR and Ten Hoor F: Substrate utilization in man: Effects of dietary fat and carbohydrate (accepted in Metabolism)

* Verboeket-van de Venne WPHG, Westerterp KR and Ten Hoor F (1992) (abstr.): Effect of diell composition on human energy metabolism. In J Obes I6 (Suppl. 1): 13

* Verboeket-van de Venne WPHG and Westerterp KR: Effects of dietary fat and carbohydrate exchange on human energy metabolism (submitted for publication)

* Verboeket-van de Venne WPHG, Westerterp KR, Van Hoek B, Swart GR and Stockbrügger RW (abstr.): Het patroon var de voedselopname en het energie- en substraatgebruik bij leverpatiënten. Voeding (in press)

* Verboeket-van de Venne WPHG, Westerterp KR, Van Hock B. Swart GR and Stockbrügger RW (abstr.): Influence of the pattern of food intake on energy expenditure and substrate metabolism in patients with iiver cirrhosis. Neth J Med (in press)

* Verboeket-van de. Veme WPHG, Westerterp KR, Van Hoek B and Swart GR: Habitual pattern of food intake in patients with liver disease (submitted for publication)

* Verboeket-van de Venne WPHG, Westerterp KR, Van Hoek B and Swart GR: Energy expenditure and substrate metabolism in patients with cirrhosis of the liver: Effects of the pattern of food intake (submitted for publication)

* Westerterp KR, Verboeket-van de Venne WPHG, Meijer GAL and Ten Hoor F (1992): Self-reported intake as a measure for energy intake: A validation against doubly labelled water. In: Obesity in Europe 91, ed Ailhaud G et al., pp. 17-22 

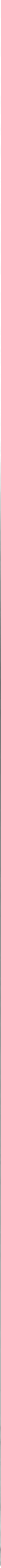